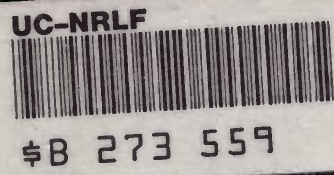









\section{CALIFORNIA \\ SILK GROWER'S MANUAL,}

\section{LOUIS PREVOST,}

PIUNEFU SILK CL LTUHST UE THE PACIFIC COAST.

WITH TWELVE YFARS EXPERIENGE IN RAISING THE MULBERRY, AND SIX YEAR: IN RAISING THE SILKWTORM.

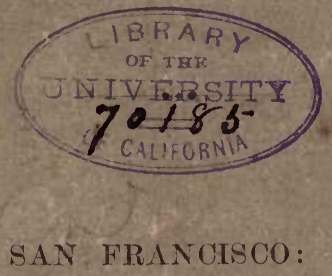

H. H. BANCROFT AND COMPANY.

TOWNE AND BACON, PRINTERя.

$$
186 \% \text {. }
$$




\section{$3^{*}$}

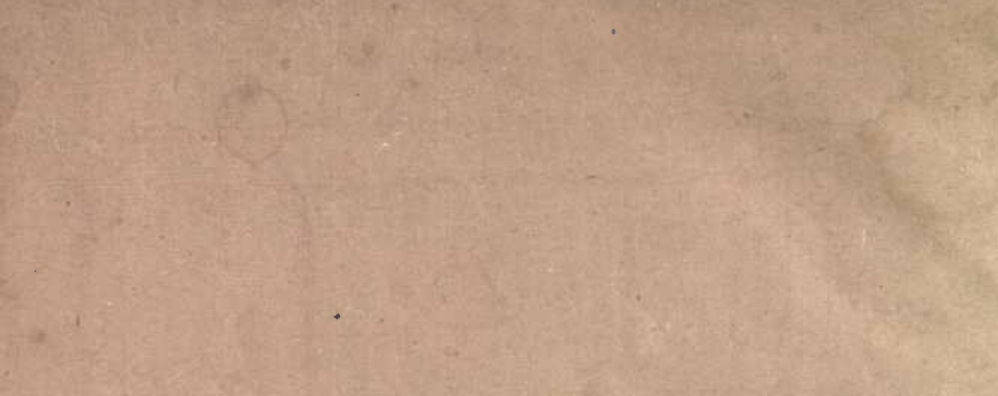

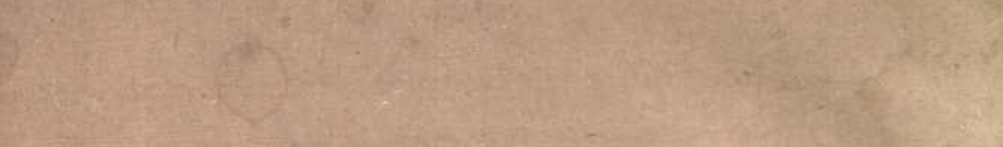




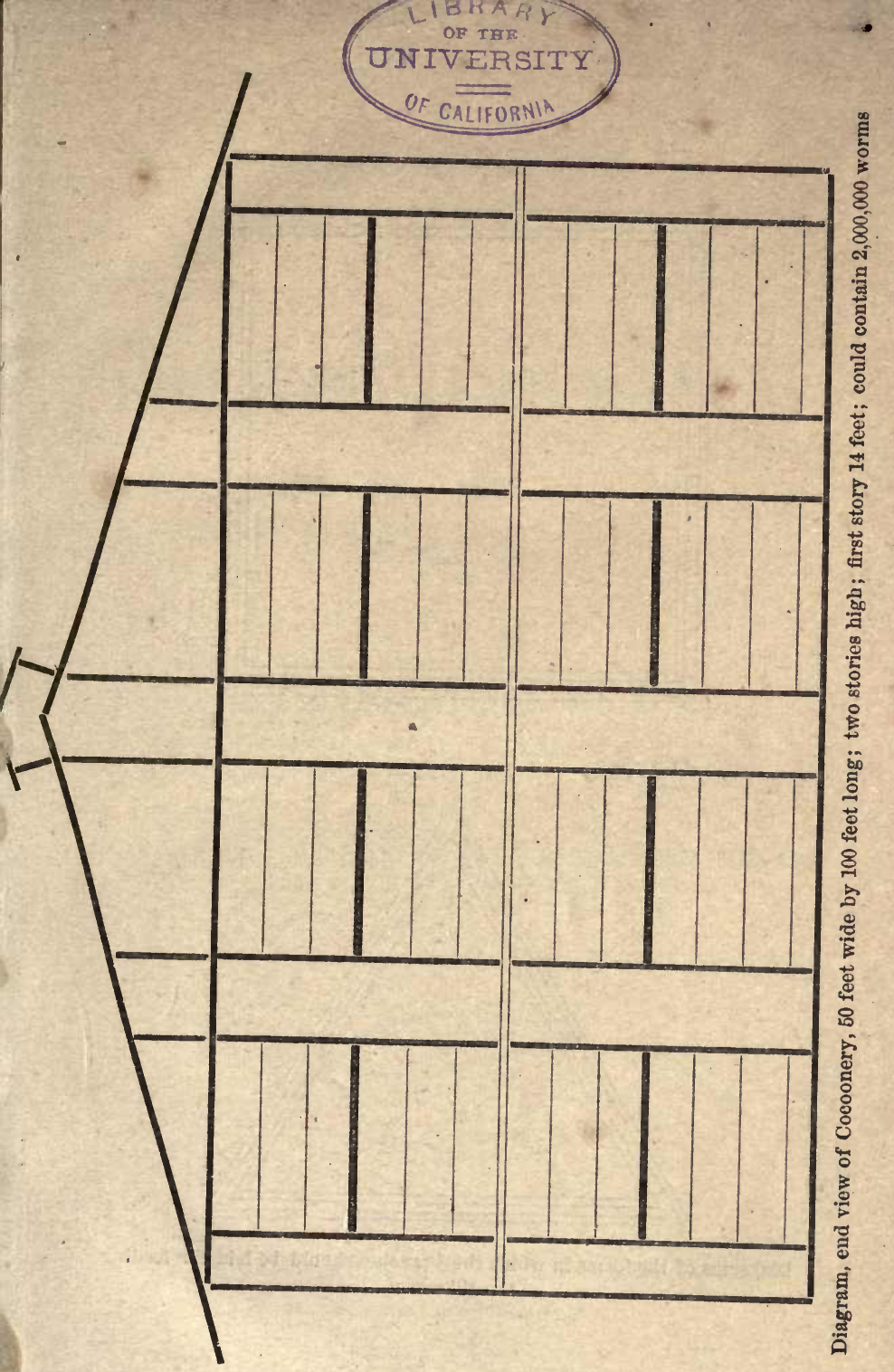



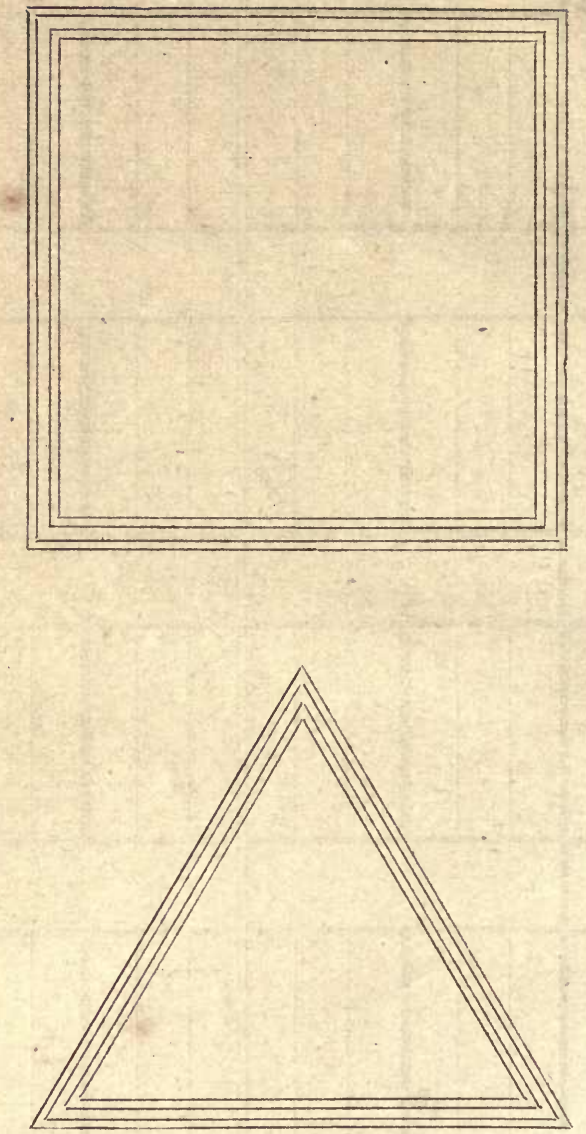

Diagrams of the forms in which the branches should be laid for feeding the silkworm. 


\section{CALIFORNIA}

\section{SILK GROWER'S MANUAL,}

BY

\section{I, OUIS PREVOST,}

PIONEER SILK CULTURIST OF THE PACIFIC COAST.

WITH TWELVE YEARS' EXPERIENCE IN RAISING THE MULBERRY, AND SIX YEARS IN RAISING THE SILKWORM.

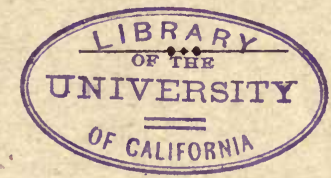

SAN FRANCISCO:

H. H. BANCROFT AND COMPANY.

TOWNE AND BACON, PRINTERS.

1867 . 
Entered according to Act of Congress, in the year of our Lord One Thousand Eight Hundred and Sixty-Six,

BY LOUIS PREVOST,

In the Clerk's Office of the District Court of the District of Califormia. 


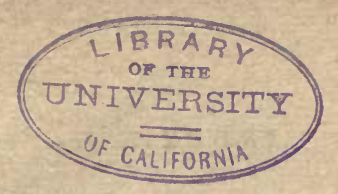

\section{IN D.EX.}

CHAPTER.

PAGE.

Preface............................. 7

Introduction, Letters, etc................. 11

1. Our Climate, its superiority, and its advantages........143

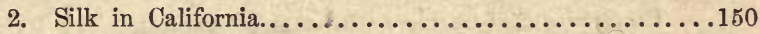

3. History of Silk, its antiquity and commerce.........155

4. History of the Silkworm.................... 161

5. The Mulberry (Morus).........................

Morus Multicaulis, or Chinese................. 169

do. Alba, or White........................

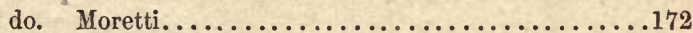

6. The Soil.................................

Preparation of the Soil.....................

7. Mulberry Culture and Propagation................. 178

Mode for Cuttings in California.................181

8. Plantation of the Mulberry for our California Culture...184

9. Mulberry Trees everywhere.................. 188

10. Cocoonery, or Maguanerie........................ 192

Importance of a Cocoonery...................193

A good Cocoonery is needed on every farm..........194 1* 
Plan of a California Cocoonery................. 195

11. Silkworms, the different varieties................. 198

12. Modes of Raising Silk in different countries.........202

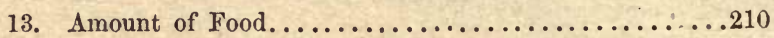

14: Observations on feeding and quality of food.........213

15. Treatment of the Silkworms aceording to our climate....217 The feeding with branches....................218 Hatehing, different ages, care, ete.............220 Formation of the Cocoons...................225

Gathering of the Cocoons...................226

Select your Cocoons for Eggs................228

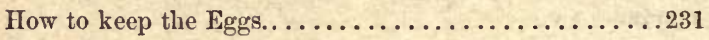

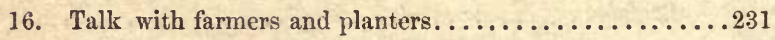

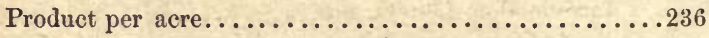

Benevolent Societies, Orphans, etc.............237

Going into that business with a small eapital........240

Persons who have been successful already.........242

Our Pioneer Silk manufacture...............243 


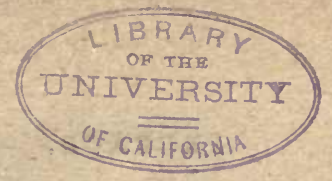

\section{PREFACE.}

Having been frequently solicited, by the friends of the silk cause, to publish the results of my experience and observation on silk-growing in this State, I have concluded to do so; that all may be benefited by it, as most of the works already published on the subject are mere compilations from foreign authors, made up of details not at all applicable to what I shall term our California Silk Culture, for such must be the system by which we shall succeed in raising the raw silk, which is bound to be the greatest staple of our State, and by which we shall induce our farmers to turn their attention to its extensive cultivation, as they need pay no further attention to the frequent croakings of short-sighted persons about the high price of labor. It is too late now for such a ridiculous argument, because I have already demonstrated, but will more fully prove it again in this Manual, by facts only, that our advantages are so numerous and everything is so much in our favor here, that we certainly can raise the silk in California for half the cost of many other silk countries. We have the best soil and the best climate to raise silk, and we will soon have a large population to produce it, because I know, that rich culture, which is superior to the mines, as it is surer, will bring a large emigration here from the States, and all parts of the world. I personally know, through my correspondence, of many who are coming already for that culture ; and the publication of our California Manual will determine many more, as they will find in it all the information that they may desire on that important subject.

We can raise here silk of the very best quality, and I think that I 
can venture to say here, that China and Bengal will before long feel the effects of my efforts, which will result in the production of silk to compete with them. They may produce a low priced article, if they choose, but the quality of silk, in all cases, decides the question of preference.

Fine phrases, generally, do not tell anything, and I do not like them; some may say, because I cannot make them. It may be so; but as my object is to be useful, I think I need offer no apology for the plain and unadorned pages which I offer, as I put here everything which I think necessary to be known, to show California as the best silk-producing country.

Thousands are inquiring: What work on the subject is best; where shall we look for information? As I have said before, all the published works are translations from foreign authors, or compilations, that are not, and cannot, in my opinion, and in that of all the reasoning class, be any way adapted to our fine silk growing State; we have to experiment and find out what is the best way to raise silk, according to the climate where we are. This I have done, and I am offering to-day to our farmers and planters generally, the results of my experience on the subject. The reason why I recommend my California Silk Culture is, because it is the system particularly adapted to our own highly favored climate, to our more serene atmosphere, and perpetual sunshine during summer, and to the peculiar requirements of our people. The genial climate for silk is ours, and also the best soil for the mulberry.

It is immense, the millions that are sent out annually for the importation of that article only. These millions could be retained among us, as California alone can produce silk, not only enough for our general consumption, but also for exportation. With that staple only, we would soon be able to pay our national debt, and our own; we only need to have a Congress that understands the general interests of the nation, by keeping the present high tariff on the article for several years more.

The demand for silk, which is now so great, is continually increasing. Since a short period of years the amount of silk consumed is more than doubled, and is rising in price every year. I see that, in 1840 , the price of raw silks was four dollars per pound, and at the present day, that same raw silk is worth seven dollars per pound, 
and more for the best quality. It is bound to keep increasing, as it is becoming more and more in fashion; and after all, no matter how high it sells, if it is of good quality, silk is the cheapest of all the dresses, everything considered.

Our advantages are many in California, and, indeed, very great. To be duly appreciated, they must be estimated singly and individually; but how much greater and more striking will they then appear, if eonsidered collectively. The decisive impulse is already given, and its mighty influences extending throughout our State; our people are awake; hope dawns auspicious; the day and its brightness will be ours, endued as are our people with fortitude, with energy, and intellectual resources unsurpassed. Is there one American who can doubt it?

I have no desire for pecuniary benefit to myself, to grow out of any knowledge of the silk culture, which it may be in my power to impart to the public. Anything that may be a benefit to that noble cause I will publish, as my earnest desire is to be useful, by aiding the introduction of a culture, which will make our people rich. In opening for them a field (and also to our country) of unceasing wealth, I shall feel amply compensated for the years of practical experience which I have given to silk culture, from the pleasure I shall receive in the knowledge that my humble efforts were to some extent the means of introducing and establishing in our State an industry which will save annually many millions of dollars to our pcople, and make us the largest silk-producing country in the world. 


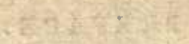

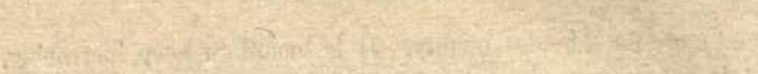

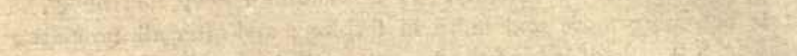

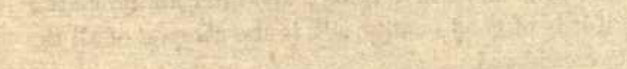

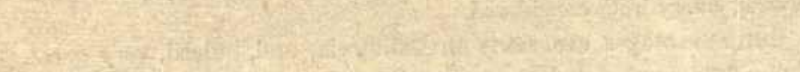
S.7.

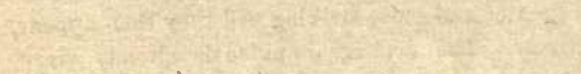

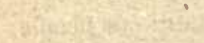

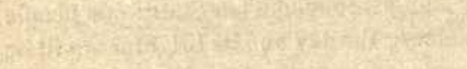

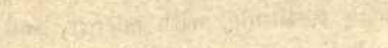

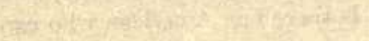

E.

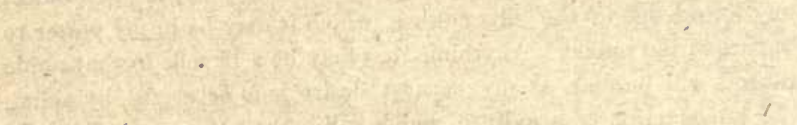

Q

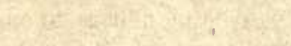

thentas 
we have no rain at the time of feeding, no storms, no shoeks of electricity; nothing to disturb the worms or create any disease. On the contrary, we have everything to prevent it; as you all know, throughout the summer we have a blue sky, with any amount of sunshine, from morning till night; it is just there where our force and superiority is ; because our mulberry trees, growing constantly under the influence of the sun's rays, produce healthy leaves, and consequently, healthy food, making healthy worms. But the leaves must be given fresh to the worms; otherwise, if they are allowed to remain in heaps, and get fermented or heated, the mephitic air that they contain in that state would poison the worms. Therefore, it is very easy to understand that our superiority is on account of our constant sunshine; and as in other countries, their trees are growing nearly without it, in a damp and wet atmosphere, this cause creates the disease there. 


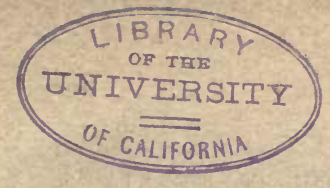

T H E

\section{SILK GROWER'S MANUAL.}

[From the California Farmer, Nov. 26, 1856.]

Extract from the Report of the Visiting Committee, State Agricultural Society.

The Committee first visited the garden and nursery of $L$. Prevost, which is very favorably situated near San Jose, on the river Guadaloupe, and has quite a large number of native oaks and other forest trees scattered over its grounds, giving it a very picturesque appearance. Mr. Prevost has nearly seventy acres inclosed-a great part of which is in a high state of cultivation. The soil is admirably fitted for the purposes of a nursery and garden. Mr. P. has two artesian wells, which enables him to irrigate his grounds, and every part of his extensive garden shows care, industry and skill in its management. The nursery contains one of the most extensive assortments of fruit trees, flowering plants and ornamental shrubbery that can be found in the State. He has in his nursery nearly 14,000 pear trees, of ninety-two different varieties; over 8,000 apple trees, of over one hundred varieties, and nearly 25,000 peaches, apri- 
cots, quinces, plums and cherries, of the choicest kinds. Over 25,000 mulberry trees are growing very finely. The Committee cannot pass the garden of Mr. Prevost without a particular notice of his efforts to introduce into our State the cultivation of the mulberry, and we may safely say he is the pioneer in this new work of silk-raising. The Committee most warmly commend this enterprise, and in noticing his fine plantation of over 25,000 mulberry trees, they feel that at least a just and appreciating notice of his laudable exertions is due to him at the hands of the Visiting Committee. Mr. Prevost assured us that no country in the world was more favorably adapted to the raising of the silkworm than California, from the fact of the absence of electricity, which is peculiarly injurious to the worm; and another favorable feature is the dryness of our atmosphere. From all the facts gathered thus far, wo may look to a new era by the introduction of the mulberry culture, as the certain forerunner of silk culture.

His ornamental trees and shrubbery, such as catalpas, locusts, privets, lilacs, honeysuckles, English walnuts, \&c., are all in a most thrifty condition. The collection of roses amounts to over 17,000 , and contain over eighty varieties. Mr. P. has a small flower garden inclosed with a beautiful willow hedge, and laid out with great taste and beauty. But few have achieved or deserved success in their efforts to promote the cause of Horticulture more than Mr. Prevost. 


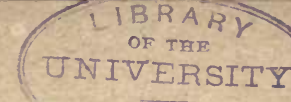

SILK GROWER'S MANUAL.

[From the California Farmer, December 25, 1857.]

Mons. Prevost has a large plantation of the mulberry, of different kinds, for feeding silk worms. There is no tree that grows so rapid, and the large rich leaves make the limbs hang pendant like the weeping willow. It is certainly important that the mulberry should be brought into extensive cultivation, both for its merits as food of the silkworm, for fruit, and as an ornamental tree; for each the tree is valuable.

Neatness, order, and good taste are manifest in these gardens. Mons. P. has made a fine entrance to his grounds over the river, by a new bridge, and it will pay the purchaser of a quantity to visit this garden-it will well repay them; and Mons. P. is truly worthy of patronage, as one skilled and reliable in his business.

[From the California Farmer, Aug. 17, 1860.]

THE TRIUMPH OF THE SILKWORM IN CALIFORNIA.

Nearly seven years since we announced in this journal that this climate was peculiarly adapted to the growing of the mulberry and the successful raising of silkworms, and the manufacture of silk, and asserted that in coming years the women of California would wear garments made of California Silk. Each year since that time we have called public attention to this very $\mathrm{i}_{\text {mportant subject, and we have urged upon our Legis- }}$ 
lature the duty they owed the State, to consider the importance of offering a bounty, independent of the trifles that we had induced the Agricultural Society to award; and within the past year we received from $\mathrm{Mr}$. Hentsch and Mr. McNulty parcels of silkworms' eggs, which we offered to those who desired to try the experlment, but for want of due attention on the part of those who tried, the successful result has not been attained until now; and to L. Prevost, Esq., of San Jose, will be awarded the honor of being the first to show the Chinese silkworms in successful operation.

We are glad to present the following letter from $\mathrm{Mr}$. Prevost, which we regret was not received till too late for our last issue; but now we lay it before our readers, and hope this new field of labor for thousands of our people will be improved, and especially for the fair sex, as this is an easy employment, and will certainly prove in coming years a profitable one.

\section{San Jose, August 7, 1860.}

Editor Farmer: For want of time, I am compelled to write to you a few lines in great haste, to let you know that we have now the California silk. My silkworms began to work last Sunday, and now a large number of fine cocoons can be seen; as I have a great number and of different ages, there will be some at work every day for several weeks; then those interested in that fine culture can come and see them, and ascertain for themselves how easy they are to raise in this 
country. Mr. Hentsch, Mr. Muller, myself, and others acquainted with the silk culture, always thought that the California climate was very favorable to such culture, but this surpasses all our expectations. There s no disease among them; I was afraid for the last period, but the last has been like the others. Now there will be a fine work for our ladies who should be very proud to raise their own silk. There is no more doubt about it; we are in the very best silk-growing country in the world.

Yours truly,

L. Prevost.

SILK AND SILKWORMS.

The triumph of the silkworm in California is now complete. By the very handsome exhibition of cocoons, floss silk, and reeled silk floss, together with the silkworms at work, as shown by L. Prevost, Esq., from San Jose, at the Mechanies' Fair, we think we can confidently say, the triumph is complete.

To Henry Hentsch, Esq., who imported the silkworm eggs, and to Monsieur Prevost, who has with indefatigable zeal raised the mulberry tree, warmed into life the eggs, and set the worm to work upon the leaves, and finally carried on the work until the reeled silk is before our eyes - to these gentlemen great praise and honor are due, and it is not too much to ask of our 
Legislature that a special notice and bounty should be given for the zeal, labor, and care of Monsieur Prevost, in bringing to perfection the first silkworms in California; and we hope that the Legislature will cause a special Gold Medal to be given to Mr. P. Of course our Agricultural Societies can do no less than notice and reward him in the most honorable manner.

\footnotetext{
"Tall oaks from little acorns grow;"

So from these working "worms" we know

Labor for thousands soon will show;

And richest silks of brightest dyes,

Fresh from the looms, shall feast the eyes.

We'll "learn to labor and to wait"

For such grand scenes in this great State.
}

How few persons of the thousands that visit the Pavilion but will pass these seemingly insignificant worms, without dreaming that here is the beginning of an enterprise that shall count in millions annually in coming years in this State!

[From the California Farmer, Sep. 28, 1860.]

\section{SILK CULTURE.}

We are pleased to lay before our readers the following letter from L. Prevost, Esq., the successful silkgrower of California. We here present facts from one fully qualified to speak. Let all now give heed, and another year let a thousand cocooneries be started, and ere long we will show California-made silk. We 
now prophesy, that at the next Fair of 1861, sewingsilk of California-make will be shown.

$$
\text { San Jose, Sept. 21, } 1860 .
$$

Editor Farmer: You requested me to send you a few. lines on the silk culture; but it has been entirely impossible for me to do so sooner, and now $I$ am obliged to do it in a hurry.

I think that the principal object is to show that we produce silk in California to more advantage than any other country, notwithstanding the usual cry here, the price of labor!

We have so many things in California in favor of that culture, that, in my opinion, they far surpass the difference in the price of labor. The principal are as follows.

1st. The climate, which is so favorable that no disease can be observed; while in Europe, where the silk is cultivated, it is calculated the very best year when the losses are only thirty per cent.; but these losses vary from thirty to eighty per cent., according to the quantity of rain that falls, and the storms, with thunder and lightning, during the time of feeding. Here we have none of such things, and consequently no reason to lose a single worm, except by accident. But suppose these accidental losses from four to ten per cent., this is a very great difference with Europe, and this is to be considered.

2d. The rent for land in Europe is very high; in France, I know, they pay for rent only, double the price 
we have to pay here to buy it. Who can prove that they have not to take the price of these high rents from their profits. That item only is enough in itself to compensate the difference in the price of labor.

3d. The mulberry trees thrive so well here, that their luxuriance of growth leaves very far behind them the mulberry trees in Europe; and they give such fine leaves, that there is less work in feeding the worms.

4th. The feeding and care, of the worms in the silkgrowing countries is generally done in Europe, by women and children. Why should we not do it here also ? We are not obliged for that kind of work to employ men at twenty-five or thirty dollars a month, when it can be done with half of the expense and less. The Chinese, who are used to that work, could be employed, if we have nothing better.

5 th. As everything, climate, etc., are so favorable, I do not see the necessity of erecting any of those costly buildings, as they have in Europe, for the worms. Here, any common adobe building, where you can regulate the heat, is sufficient.

6th. As the mulberry grows wild in this country, it it shows that this is the spot designated by the Great Master for the silk culture.

Everything being so favorable, I am under the impression that the California Sill must be of superior quality, and so fine that it will command a price in the market over any other silk, particularly if we cultivate only the best varieties of mulberry-trees, well known to produce the best silk; and that our cocoon 
will also produce more silk. It requires, generally, some three hundred cocoons to a pound; but I should not be surprised to find that we will need here no more than about two hundred and fifty.

Any person that will only take into consideration the above items must be convinced that we can not only furnish the silk here as cheap as in Europe, but cheaper. Truly yours,

L. Prevost.

SILKWORMS.

One of the finest and most important exhibitions, made at San Jose, was the temple for the silkworms, their cocoons, and the silk. Mons. Prevost deserves very great credit for his zeal and energy in carrying on this great work. A very neat arching temple of evergreens and flowers was made, and in these arches were festoons of white and yellow cocoons, forming a gay appearance. In the temple stood three pyramids of the cocoons, as they were made in the group on branches of the shrub on which they were built. In front of the temple were the reels of floss, in their shining threads. The whole thing is now in its infancy, but in coming years will become a type of various manufactories of the rich silks and satins that our women of the Golden State will wear. To Mons. Prevost we shall ever ac- 
cord praise for his energy and desire to promote so good a work.

[From the California Farmer, Nov. 2, 1860.]

\section{THE SILKWORM.}

Success! success! to our friend, L. Prevost, Esq., of San Jose. Before us we have one of those fine stands or clusters of the "silkworm cocoons," which were shown at the late Fairs, and which Mons. P. has kindly presented to us, that we may show at our office the proof of the success of the silkworm.

We hope that the citizens of California will look to this subject ; millions of wealth are in store for us, and an opening for useful and profitable labor for women and children. As the worms can be well attended and fed, and the gathering of cocoons and silk-reeling all done by women and children, let a thousand acres of the mulberry be planted this year as preparatory to this great interest.

As we always desire to give due credit to all originators of useful inventions, and to those who introduce articles of value into our State, we accord to Henry Hentsch, Esq., banker, the credit of importing the eggs from various sources, and Mons. L. Prevost the credit of maturing them, and thus proving the success of the enterprise. 


\section{SILKWORMS AND MULBERRY TREES.}

We are again favored with a very interesting letter from that zealous friend (Mons. Prevost of San Jose) of those important enterprises, the raising of silkworms, the manufacture of silk, and the growing of mulberry trees; although intimately linked together, they are separate enterprises, and should each of them be duly considered by our citizens as worthy the earnest attention of all who are so situated as to give the matter serious thought. That the breeding of silkworms and the manufacture of silk and silk goods will become an important branch of industry in our State in coming years, we have not the least doubt. We believe the amount will be told in millions of dollars annually; and it behooves those who have land suitable to the culture of the mulberry to think of it in season. As is justly said by Mr. Prevost, the Morus Multicaulis will do for the worms in their early stages of growth; then other varieties-Morus Moretti, Morus Alba, and Morus Nigra.

The coming season there will be considerable interest felt in this enterprise, and a more extended attention paid to it. We shall give space in our columns for the information needed for it, and shall record its progress. We feel that our State is largely indebted to Mons. Prevost, and to H. Hentsch, Esq., and all others who have been successful in thus laying the foundation for this truly great work. We would also accord to Mons. Prevost due praise for his zeal in past years, and 
his efforts and free offering of time and money to prepare the way for the manufacture of wine, and also of sugar, from the sugar-beet, to which he refers in his letters, and which we know as true, as we remember well his untiring efforts then in behalf of both enterprises. It is such labors and such men that our Legislature should encourage by a suitable token; and we hope the time is not far distant when such labors will be duly. rewarded.

\section{SAin Jose, November 22, 1860.}

EdTTOR FARMer-Dear Sir : I have always observed in your paper the great interest you take in our home industry, or in other words, the prosperity of our young State, by advocating every new production that would save us from importing. We concur in the same ideas on that point. My thoughts and efforts always have been towards that great cause. Besides other things, I have from the beginning advocated the manufacture of wine. I also spent time and money to help M. Delessert establish the sugar-beet manufacture, that we are bound to have also in California.

For the past six or seven years, in observing the nature of our fine climate, and seeing that the enemies of silkworms were not here, I always said that we were in the best silk country in the world; and consulting with Mr. H. Hentsch, who was exactly of the same opinion, we then imported the seeds of the best varieties of mulberry for the feeding of the worms. I have sown them 
and raised the mulberry. Afterwards, Mr. H. Hentsch imported the silkworms' eggs; but they are of such delicate nature that when they arrived here they were dead; and they met the same fate the following year. But the third time, last year, he received some from France in better order, and I succeeded in hatching them, and the result is now known all over California. I sent samples of fine silk cocoons to nearly every Fair of our State.

Every person acquainted with the silk culture, with whom I conversed on the subject, all agreed that it is the very best country to raise silk; among them was one of my good friends here, Mr. T. J. Muller, who has been engaged in the silk-culture in Switzerland for fifteen years. He had so much confidence in the silkculture in California, that he offered himself to help me in the first trial. This he did; and great praise is also due him for our success; and this success far surpassed our expectations, because I was not certain that the eggs would hatch. I was not prepared, and had not a suitable room for the worms; and to have succeeded against such disadvantages the only explanation I can give for it is that we are in California ; and, in fact, it is so, because elsewhere they would have been all dead, but here we have not been able to discover any disease.

Now that we have the California silk before us, and that we also know that it is so easy to raise it here, (as you have seen in my letter of September 21, published in No. 5 of your paper) it is of no use for me to reiterate these facts. 
Now, I say, we must all do all we can to raise that important article among us; and to accomplish it we must prepare for it. We must first plant the mulberry, but particularly the varieties that are known to give silk of good quality. With the Morus Multicaulis which has been so celebrated since the time of the mulberry fever in the States, some twenty-four years ago, we will never see such foolish speculations, because every one. now knows that the mulberry can be obtained as cheap as any other trees. The mulberry has such a remarkable growth, and is as ornamental as any other trees, having a fine foliage; that for these reasons it ought to be planted everywhere to ornament our streets, avenues, etc. ; and at any time the leaves may become useful, if you choose to raise your own silk. Besides this, plantations will also be made for the purpose of raising silk on a large scale.

I wanted to say about the celebrated Morus Multicaulis, that it is very good, but only for the first feeding, that is to say, for the two or three first periods; while after that, the other should be used, because we must have in view to raise silk of the very best quality.

The coming season I will have my worms in a better room, and will not have half of the trouble I had the first time. I must close this long letter.

$$
\text { Truly yours, L. Prevost. }
$$


THE SILKWORM AND SILK CULTURE.

We are pleased to learn of the increasing interest manifested for this branch of industry, which to our State in its future years, will be one of great magnitude.

The demand for mulberry trees has taken all from the nurseries that were for sale. It has generally been supposed that the Morus Multicaulis is the chief variety for the silkworm; this is not so. The cocoons are much superior (so we are informed by the best authoriities) when the worms are fed upon the Morus Alba, and the Morus Moretti. These, with a small portion of the Multicaulis, will be the food of silk-worms in this State.

As we have often said, we are confident of the success of silk manufactures in California, and ere ten years from this date, the wives, daughters and sisters of the Golden State will be clothed in robes of silk, manufactured in our own State.

We trust, if our Chief Magistrate cannot find time or opportunities to look after the manufacturing interests of our State, that some of our legislators will, and that there may be such legislation for these interests as they demand.

In the present condition of this matter-now while many persons are beginning to look round and see what can be done, while many are planting the seed of the mulberry and the tree also, we ask, would it not be a 
wise act on the part of the Legislature for them to offer a noble bounty for the successful produce of the first five pounds of sewing-silk made in the State.

We feel confident, that if a bounty of $\$ 1,000$, or $\$ 5,000$, or even $\$ 10,000$ should be offered, it would bring back into the State Treasury ten dollars for one, by reason of the improvements and buildings, etc., which would be under way for the purpose. The taxable property in the State would be increased enough to pay the bounty. We hope such an interest as this will not be slighted. We learn, with much regret, that $\mathrm{L}$. Prevost, Esq., the zealous friend and promoter of this valuable industry, has never received any just reward for his untiring efforts to bring this business to a successful issue, and although he has exhibited the silkworms, the cocoons and the reeled silk, in a highly creditable manner, at the District Fair at Marysville, Stockton, San Francisco, and at the State Fair, no reward of a medal, or even a just report has been tendered him or made of this interest, except at the Fair at Stockton, where a diploma was awarded him, to the credit of San Joaquin District, be it said.

We respectfully ask, shall so great an interest as that of silk culture, which will be millions annually, be passed by at our Fairs, while Guinea hens, lop-eared rabbits and white swans, have prizes from five to twenty dollars each; and gold and silver goblets and cups are given for articles that never can advance the interest of the State. We hope our legislators will think of these things. 
SILK PRODUCTION IN CALIFORNIA-FAVORABLE PROSPECTS-A NEW SYSTEM.

We are truly glad to receive the following letter from one who is so earnest in the cause of silk culture. As Mons. Prevost says, the culture of the mulberry, the rearing of silkworms, and the manufacture of silk, will be one of the great branches of our industrial labor in coming years, and we would fain hope that the Committee on Agriculture may see the importance of giving attention to the subject this session of the Legislature, and offering a just bounty to this valuable interest. We hope they will make due inquiry, and not forget that Mons. Prevost has done much to advance this interest, and deserves an honorable mention. The many new productions here named by our correspondent demand a liberal bounty direct from the Legislature (the State) before they can be securely introduced into a large and successful cultivation.

\section{San Jose, Feb. 24, 1862.}

EDITOR FARMER : In your valuable paper, under the head of "New Productions," you ask for information on "hemp, canary seed, hops, flax, Chinese sugar-cane, and West India sugar-cane, dioscorea batatas, true Carolina potato, the cork-bark oak, tea and coffee." I regret to see that you forget to mention the -silk. Knowing your opinion on that culture, I consider it as an involuntary omission. This induced me to write you a few lines, to bring your attention again to that subject, 
which is also very important to our State, as it would save her many millions of dollars for imported silk. Please tell me why should we send all that money away, when we can keep it here, in raising our own silk?

Since my arrival in California, it has always been my opinion that we were in the best country in the world! But the first attempt I made, the season before last, has surpassed all my expectations. The finest and best silk has been exhibited all over the State, and thousands have seen it; but many think that silk cannot be raised in California, to any advantage, on account of the price of labor. That question I consider solved, and I wish to say a few words to prove it.

The first silk ever produced in California was in 1860 . I obtained it, assisted by my friend, Mr. Muller. We have proceeded according to the system adopted in Europe for the silk culture; but this is too much work for California to compete with other countries where the price of labor is not so high. What have we, then, to do, to avoid such an obstacle? To simplify that work and to reduce it to less than half of what it is there. And I have turned all my attention toward that point, knowing that it was the only way to insure the success of silk culture in California. Then, in reflecting on all the advantages of our soil and fine climate, so well adapted for the silk culture, and combining all my observations, and all the remarks I could get on the nature of the worms, I found what I will call The California Silk Culture. It is entirely different from the 
system followed in France or Italy. According to the latter system, it requires volumes to explain and give all the particulars pertaining to the culture. But the California culture is so that I can give all the particulars about it in a small pamphlet of three or four pages, and this new system is so simplified that every one will understand it, and find it no more difficult than any other culture.

I intend to try the California silk culture for one or two seasons more, so as to perfect it, and after that, if properly encouraged, I will publish it for the benefit of the State ; and this branch, only, will be a great addition to our home industry.

Everything seems to be in favor of the silk culture in California. Besides so favorable a climate, the mulberry trees thrive so well here that I have never seen such a growth in any other country. And while the mulberry tree is thus useful for the feeding of silkworms, it is also one of our best ornamental trees.

Yours respectfully,

L. Prevost.

[From the California Farmer, Aug. 22, 1862.]

THE SILKQUESTION SETTLED.

San Jose, August 13, 1862.

Editor Farmer: As I stated in my letter on the silk culture, of the 24th of February last, I have tried 
again my California silk culture, and exceeded beyond my expectations. The worms this season have taught me another lesson themselves, and shown me another point to save labor.

In my last letter on this subject, above mentioned, to insure the success of the silk culture in California, I said that it was necessary "to simplify the work, and reduce it more than half of what is required in $\mathrm{Eu}$ rope." I now say, that according to the California culture, one man (or lady, no matter) can raise and take care of more worms than six or eight could according to the system followed in France and Italy. The climate is so very favorable here, that we have very little to do to raise our own silk. The great objection, the price of labor, does not exist any more. Now it will devolve on our representatives to have this impor: tant branch of industry extended all over our State. I will pledge myself to prove what I have said, and will write a description of that culture in a small pamphlet of very few pages; it is so simple that every one will understand it. And more, if any rich man that has plenty of land would make a large plantation of mulberry trees, I would go and turn all his leaves into silk before any quantity of persons that would like to come and see the California silk culture. I have certificates and letters from Europe, that the California silk has been acknowledged there to be of the first quality.

Now, Mr. Editor, several years ago you predicted the success of silk culture in your paper; but I am sure that you were very far from thinking that it would 
be so easily raised. I am very happy to be able to prove that your opinion was well founded. Persevere, and continue to do all you can to induce the people of California to raise their own material, and keep their money. They can do it, because we can produce everything in this country; there is no other like it.

It is under that impression that I remain,

$$
\text { Yours truly, } \quad \text { L. Prevost. }
$$

[From the California Farmer, Sep. 9, 1864.]

THE SILK WORM ENTERPRISE.

San Jose, August 28, 1864.

Editor California Farmer :

Your favor of yesterday is just received, and according to your wishes I answer it immediately. You ask me for some hundreds of ounces of silkworms' eggs, for a gentleman in Mexico. I am sorry that I can not furnish so many ounces. I only have a few ounces of my last crop-say three or four - to dispose of, as I only had raised a small lot this year, to keep up a supply of fresh eggs. Last year I had several orders for silkworm eggs, and I sold all I could dispose of, keeping only a small lot for myself.

Last year, I had an order from Italy, for one hundred pounds, but it was impossible for me to do anything toward that big order. If I could have had so many it would have been a little fortune for me. Only think of 
such a quantity; at 40,000 eggs per ounce it would only be sixty-four millions of eggs. The reason there is such a demand for eggs for Europe, is because they are diseased there, and they know that in Califormia they are not, the climate being unexceptionably favorable to their culture. For these reasons, the business would be one of the most profitable, to raise silk-worms on a large scale for their eggs only, so as to supply Europe and some other parts of the world, whose interest is to get their eggs from the best sources and free from disease. Now, what would make the business more profitable, is, that taking advantage of our fine climate; and according to California culture, one man can take care of as many silk-worms as six or eight would in Europe, according to the old system, which they are obliged to follow, as the nature of the atmosphere did not allow them to do as we can here. My repeated experiments, every year-or the last several years-convinces me that my system is the best, and the only one to be adopted in California, or any other country, that would possess a similar climate.

I remember that I had promised to write you a series of articles on the "Silk Culture," but for want of time I have not been able to do it yet; but I will write them as soon as my occupations will allow me a little leisure -have patience.

Every time I have been in San Francisco I called at your office, but had not the pleasure to find you. I will try it again, next time-that will not be very long, if I conclude to take some silk and cocoons to the Fair. Respectfully yours,

I. Prevost. 
[From the California Farmer, Oct. 28, 1864.]

\section{SILK CULTURE.}

SILKWORMS, SILK CULTURE, SILKWORM EGGS, ETC.

We are happy to lay before our readers the very interesting and valuable letter of L. Prevost, Esq., of San Jose, the pioneer silkworm grower and silk culturist of our State.

We call special attention of all who feel an interest in the upbuilding of our State, to the facts here presented. Not only have we received one order for 500 ounces of the eggs named, (which, at the price of $\$ 12$ per ounce, would have been $\$ 6,000$ ) but many other orders, and we agree fully with Mr. Prevost that silk culture will be one of the "greatest interests" of our State.

The CaLIFornia Farmer has been an earnest advocate of this branch of home industry from the very first number that was issued, in January, 1854, to the present time.

In another column we publish, from the FARMER, our views of some past dates, and often at that early date these views were looked upon almost with contempt, as being the vagaries of wild enthusiasm.

We have ever found Mons. Prevost an earnest, zealous and scientific worker in this enterprise, and our State ores him a great debt for what he has done to bring the enterprise into so successful an issue. We are glad, indeed, to herald the success of other coworkers with him. 
A few years more, and we shall see, in our growing State, silk manufactories as flourishing as our woolen factories.

\section{SAN JoSE, October 21, 1864.}

Edtror CaLIfornia Farmer :

As I am receiving orders for silkworms' eggs, through the post office, or otherwise, so often, I thought to write you a few lines in a great hurry on that subject, thinking that they would be of great benefit to many of your readers. Facts always need to be known, and I will state nothing but facts that I can prove any time.

In 1860, when I raised silk for the first time, in Califormia, I sent specimens of it and cocoons to all the Fairs of the State, and the press spoke very highly about it, but I heard a great many persons express thoughts that it could not be done in this State, on account of the price of labor. As here, in California, the price of buying three or four acres of good land does not exceed the price of renting one acre in Europe, I thought this, and employing Chinamen to do the work, would compensate for the difference in the price of labor; but, besides that, I had so much, confidence in the culture of silk in this State, that I have been thinking very much about it, and, by taking advantage of our fine climate, so much in favor of that culture, I changed the old way of cultivating the silk-worm, and adopted a system of cultivation that reduces the labor considerably, and is so simplified that one man can cultivate as 
many worms as eight men could in Europe, with the old system. I have repeated it these last three years, and succeeded always beyond my expectations.

Last year I had an order from a house here, for one hundred pounds of silkworms' eggs, for Italy; it was impossible for me to do anything toward filling such an order, and I sold all I could dispose of at $\$ 12$ per ounce, and kept about half an ounce for my own use, so as to have fresh eggs for this year. If I had enough eggs for that order of one hundred pounds, it would have been, even in reducing the price at wholesale, something about $\$ 12,000$. I do not know of any other culture that the benefits derived could come near it, as you have to work only two months at it, in all.

I am very sorry that I kept such a small lot of eggs, because I see that the demand for eggs continues-as you know I had, through you, an order from Mexico for five hundred ounces, lately. A few days after I had another order for five pounds, from Italy; also two other smaller orders, and we are only at the beginning of the season, because these orders only come, generally during the winter, as it is the proper season for them to travel. I will certainly receive many other private orders soon, but I will not be able to fill any, as I have concluded to keep all the eggs on hand, so as to have a good lot for next year. I am very glad to see that in Europe they will have to draw on California for good eggs, because their wet atmosphere is the cause that their silkworms are diseased, and they will consequently lose most of their crop in using domestic eggs, and thev 
secure a good crop by using sound eggs, imported from countries, as in California, where they cannot be diseased. The dryhess of our climate protects them from the disease, which proves that California is about the very best spot on this globe to raise silk, which can be made very profitable by following what I may eall the "California Silk Culture," which is extremely simple. This process would enable us to compete with any other nation, and help to retain, in our State, many millions of dollars, besides being a great profit to raise the worm for silk only; but we see now that it would be still a greater profit to raise them to supply the Old Country, or any other part of the world where they have a wet climate.

I consider, now, the silk question settled in this State. Only consider : five or ten acres planted in mulberry trees, the quantity of worms that could be fed from them, in view of the luxurious growth of the mulberry in this country. I am happy to be able to say that some gentlemen have started it already on a pretty large scale. I will name here two in Santa Barbarathey are Mr. A. Packard, and also Mr. E. Goux, who have planted, two years ago, three thousand mulberry trees; that notwithstanding the dryness of the season, and the trees being very young, yet made two pounds of eggrs without any trouble; I also received a letter from Mr. Goux, two days ago, which confirms the statement. This is very gratifying, because these gentlemen expect to have a large quantity of exgs next year, if we have plenty of rain this winter to make the trees grow. 
Only think of this and you may form some idea of it, as one female lays about one hundred eggs, and there are about forty thousand eggs to the ounce.

In 1860, when I raised silk for the first time, I also sent cocoons to our highest Seriate Societies in Europe, especially to Paris and Lyons, to have them tested, and I have received certificates from both cities, that the California silk is of the first quality. What do we want more?

I am for home industry, and I feel very happy, now, to know that I will succeed in having that culture established, which will be of great benefit to our State. In . order to encourage this useful, pleasant and profitable pursuit, all over the State, I will occasionally give, through the columns of the CALIFORNIA FARMER, any information that may be desired, in regard to the mode of planting and treating the mulberry tree, for the California Silk Culture.

Yours truly, L. Prevost.

[From the California Farmer, Dec. 2, 1864.]

SILK CULTURE.

THE KAINS-CHEERFUL PROSPECTS-MULBERRY CULTIVATION-PLANTING AND PROPAGATING VARIETIES OF TREES, ETC.

Editor California Farmer :

SAN JoSE, November 30, 1864.

On the 18th, 19th, and 20 th inst., we had the heaviest frosts in San Jose for some years; I measured some 
ice that was nearly half an inch thick on the water. We all expected after such a frost to have good rain, and this time we have not been deceived; it began on Friday last in the afternoon, and continued on Saturday, pouring down all day and night all over our mountains, and in our now blessed valley. We had it also on Monday, heavy and wet, and our rivers and creeks have raised. Yesterday, we had but very little, and we dug some black locust trees and found that the ground was not wet all through.

It has been raining again last night, and also all day to-day, and you have no idea of the effect it has on everybody; you can see the joy on every face, and in fact we must all rejoice and thank the Great Master for having not forgotten us. We are all right, now, and I hope that it is so all over our cherished State. Now, as soon as the rain stops a little, every one can go to work, plow, sow grain, and plant trees-the sooner the better.

In this important moment, I thought that it was necessary to make your readers remember that the advantages of the silk culture in California have been fully demonstrated in the columns of the FARMER-that as time for action and preparation is at hand, if they wish success they must get ready during the good season.

Some of your readers may think that I am writing in order to sell mulberry trees; I wish to tell them that the last drought destroyed nearly all my young trees, and what I have left is hardly worth mentioning. But in order to show them that I am not moved by any speculative motive, but only by the general good, I will give 
them here the varieties and the culture of the mulberry tree, so that everybody can raise and cultivate his own trees. It is a well known fact that the mulberry has a very luxuriant growth in California-does well in nearly every kind of soil, but has a kind of preference for a good loamy soil. We can show shoots here of one year, having from five to seven and more feet in length; this is, I suppose, enough. The mulberry besides furnishing the best food for silkworms, could be made one of our best ornamental trees; but at present we have not to consider it under that point of view; we have to consider it as to its value for feeding and raising silkworms. Here are the best varieties :

1st.-The White Mulberry (morus alba). This is the best variety for the culture of silk, it produces the very best quality.

2d.-Another very good variety is the Morus Moretti, which has a little wider leaf; this kind is a variety of the above. These two varieties are easily propagated from seed, which you have to sow in drills some time in February or March. To succeed you must have fresh seeds, and for that you must get them from a good reliable store.

3d.-Morus Multicaulis has a still larger leaf, but is tender to frost; this variety is very good for feeding the silkworm when young, suppose about for the first two ages. This variety is easily propagated by cuttings.

After the cuttings and seedlings have been growing one year, it will be very well to have them replanted 
in nursery rows, and leave them to grow that way one year, and then transplant them. But to avoid this last work, I think they would do very well, if the best enttings and seedlings were planted so as to do the work but onee; for that you must have a field well and deeply plowed up before planting, as large as necessary to contain the quantity of trees you wish to plant; one acre would hold four hundred and thirty-five trees, in planting them ten feet apart which is about a fair distance for the California silk culture-and for that culture, also, they must be headed at about four feet high.

When any other information shall be needed, I will always be ready to give it. But let us produce our own silk and supply other countries by all means.

Yours respectfully,

L. Prevost.

P. S.-In my letter published in the Farmer, October $28 \mathrm{th},($ No. 14) you make me say that a female lays about one hundred eggs, when, in the letter I wrote "three hundred eggs."

L. P.

[From the California Farmer, Dec. 2, 1864.]

RAISING SILKWORMS IN CALIFORNIA.

Steadily facts begin to develop the adaptability of our State as peculiarly fitted to the raising of silkworms and the manufacturing of silk, and there is no reason 
in the world why California should not be eminently successful in this business, almost immediately, only the public mind has not seized upon it strongly enough to make a morus multicaulis fever; but when it does come, it will have its run, like every other speculation, and then settle down into a quiet and prosperous business.

Some weeks since we published an interesting letter from Mons. Prevost, of San Jose, upon the silkworm, in which he spoke of his success, and of others who had been successful, showing also the demand already. for the eggs, both for home use and for France and Italy, the fact being now established that California can rear a healthier silkworm than most other parts of the world, and orders have come to our State for a very large amount of eggs the past year.

Recently, a vessel from Japan brought to our city sixty-four cases silkworms' eggs, the value being something like $\$ 20,000$. These were imported here to order, to be immediately reshipped to France via Panama, thence to Southampton and to Havre.

There can be no doubt but that the raising of the silkworm and the preparing of the eggs for sale will be a profitable business for this State, as it is a well known fact, that of late years a fatal disease has made havoc with the silkworm of France and Italy, and they will become purchasers of all we have to spare.

With these facts before us, would it not be well to plant the mulberry, and begin the work? Little girls and misses, and young women, will find it a pleas- 
task to feed these pretty worms, and it will be not only a pleasant but a profitable way to spend time; to rear the worms, reel the delicate thread, and spin the silk, will be more honorable employment than spinining street yarn.

We hope attention will be given to this matter immediately.

After the above was in type we were favored with another valuable letter from $L$. Prevost, Esq., which we publish.

We ask the attention of our readers to the very valuable letter of the pioneer silk cultivator of the Pacific, L. Prevost, Esq., of San Jose. This letter speaks volumes, and we rejoice at his success, and feel happy with him at the fulfillment of our own sanguine prophesies in years past. We hope croakers against such enterprises will now stop their throats and learn wisdom.

\section{San Jose, Nov. 12, 1865.}

Colonel Warren, Eaitor California Farmer:

DeAR Sir : For want of time, and other circumstances that you know, it has been impossible for me to write anything to you about silk culture in our State 
Notwithstanding the great success obtained this year, and the great pleasure $I$ had in seeing it earnestly appreciated wherever I have, exhibited the silk and silk. cocoons, and to have received from the Societies the highest testimonials, in the shape of gold medals, etc., I cannot make you understand how happy I am to see my efforts are at last appreciated, and to see that the people of California begin to understand and look to their true interests, for I can predict to them that in future this branch of industry will bring more to the State than all the other productions together. I think I can take the mines in, as they are nothing but a lottery, where very few have a chance; but with the silk there is no deception. Our regular, dry summers, without rain, storm, or electricity, insure you regular, good crops, and the beauty of such an enterprise is that we do not fear any opposition. Any thinking man can understand it, and, as I have said many times, if it was possible, by a miracle, that the whole State be planted next year with full grown mulberry trees, and most of the people engaged in raising silk, you could not convince me that it would lower the price of silk two cents per pound, as we have not only California for a market, but we have the whole world. Silk at the present time is bound to raise in price. It has raised this year twenty-five per cent. ; then it is our interest to encourage as many as possible to go into raising it, as it cannot be but a great benefit to the State, and as we live in the State we will all feel the good of it.

I have sold my silkworm eggs for France, and all I $3^{*}$ 
can furnish for the coming year, but I will keep always what I think I need for California, and to those who will raise and plant mulberry trees, I will furnish them gratis their first eggs; they will only have to let me know the quantity of food they have, to guide me for the eggs to send, and that for several years. This shows how I wish to see competition all over our blessed State.

The cultivation of silk is nothing, under our fine silk climate, and, as you know, and your readers know, I have been able to simplify it so much that as soon as I will have the "California Silk Culture" published, everybody will be able to raise silk as well as other products. I have written already that my "California Silk Culture" will reduce the work on the old system followed in France and Italy, considerably. I have to say now in regard to that point, that I have raised this last season, myself alone, over one hundred thousand silkworms, and each worm making a cocoon, and this is the work of eight persons in France or Italy, where silk is raised so extensively, and where millions and millions of families are living off this work. In Italy the product of exported silk exceeds in value two-thirds of all other exportations together.

Everything is in favor of silk culture in California, and this shows that Nature always does everything right, and is never forgetful; because if the climate is so favorable to the silkworms, it is also extremely favorable with our good virgin soil, to the growth of mulberry trees, which grow very well everywhere in this State, but of course, like everything else, prefer certain soils. When 
at Sacramento I noticed the very best of soil that I ever saw for the mulberry tree, and I have been informed that most of the whole valley is like it. I have observed trees there of six year's' growth that surpass very far anything I have ever seen.

In order to enable everybody to raise their own mulberry trees, I have, as you know, published in your valuable paper, about a year ago, the culture of that tree, either by seeds or cuttings, but I wish to mention here, that if any of your readers wish any more information about that culture, or any information pertaining to the silk cause, on any point that I may have omitted, I wish them, for the benefit of the public, to ask me the question through the CALIFORNIA FARMER, and I will do my best to answer and satisfy them in the same manner.

The enumeration of facts in favor of the silk culture in California are many, and they will be the subject of another letter, as soon as possible; but I will write to you probably next week about the premiums offered by the State on silk. It was not my intention to exhibit anything this year, so I was not prepared, but I intend to prepare for next year, so as to make everybody stop to look at my exhibit. It was only through the suggestion of my friend, Mr. H. F. Williams, that I exhibited at the Mechanics' Fair, and the State and Stockton Fairs. I am very glad that I did so now. It has attracted the attention of the public, so that now we can consider that the impulse is given. But there is one thing that you do not know, which will do a great 
deal towards engaging a large number in this sure and profitable business, and I shall have the pleasure of detailing to you and your readers to-day, what it is. These are the facts:

I had lately the pleasure to have the visit of two representatives of the two largest silk houses in Europe, on their return from China, where they bought a very large quantity of silkworm eggs. They are on their way back to France. They took the cars to see me, and get information about the silk culture in California. These gentlemen are scientific and practical silk-growers and manufacturers. I told them everything about our climate and the silk in California. I have shown them my silk cocoons, and where I have raised them; the mulberry trees, etc. I gave them cocoons and eggs as a present for their houses, and they gave me a fine lot of a very good variety of silkworm eggs from China. Knowing the silk business thoroughly, they were apt to understand and appreciate everything pertaining to it. They were so very well pleased with what they have learned in their visit to San Jose, that they are coming back next summer, each of them with the necessary capital to buy something like one hundred acres each, to raise silk and silkworm eggs on a large scale; and they very likely will be the cause of several other silk-growers to come from Europe.

What do you think, Colonel? Is it not your opinion also, that after this the silk business will be fairly started in California? All this gives me the idea to write to France, to some of the leading papers, about 
silk in California. This I think would induce a good many French and Italian silk-growers to come out and establish themselves here, as we can very easily demonstrate to them the superiority of our climate over theirs. Let me know your opinion about my idea.

I learn that the mulberry plantations of our friends, Messrs. Packard \& Goux, of Santa Barbara, are doing finely, and that they will be able to raise the coming season a very large quantity of silk cocoons.

By what I can guess, my presence at Sacramento will be the cause of the planting of very near a million of mulberry trees. I have not been able to learn to what extent they will be planted in San Joaquin valley, but we already have from last year quite a plantation there by Mr. Glessing.

Now, Colonel, you ought to be proud for having been in favor of that culture, now that the results are known. At first your readers would hardly notice your remarks on it; but they will find that the culture in California will leave far behind all other culture or industry as to product. Only look at it for a moment in the future. Let us look and consider the thousands upon thousands of people to which this new industry will give employment, and consider also that it is an easy work, that can be done by aged persons, as well as by the young folks of both sexes, to raise and to manufacture it; let us consider these rich goods that our ladies are so happy to wear, coming out of our numerous manufactories; lot us look to the immense quantity of goods that will be shipped on board of our yessels, to be car- 
ried away to every part of the world! Oh! how happy should I be if I could live long enough to see all that. I have made my home in California, and nothing now in the world could induce me to leave her-we cannot be separated, except by death.

I cannot close this letter without letting you know an important point that I have learned in the company of those experienced silk-growers, to whom I refer above, and this could be headed-" California. Silk a Superior Article." Their opinion is that our climate and soil being so superior, that by selecting every year the very best cocoons for the eggs, for our own use, we will obtain a California variety that will surpass everything known elsewhere, as to size and quality. We must not forget this.

Now I will close this Ietter, with the hope that your numerous readers will be pleased to know all these facts. They will find me always ready to tell them everything I know that pertains to the prosperity of our beloved State. Yours truly,

L. Prevost.

[From the California Farmer, April 19, 1866.]

SILK CULTURE IN CALIFORNIA.

[We lay before our readers another interesting and valuable letter from the Pioneer Silk Culturist, L. Prevost, Esq., of San José, whose earnest zeal for the cause he has espoused, is worthy of all praise, and 
whose devotion to the best interests of our State over and above his own self aggrandizement, deserves all honor.

Had Mr. Prevost been like some parties who were fierce for great bounties by the State, he would have secured a large sum to himself; but he labored hard and was successful in changing these bounties, and now they will be widely scattered in small sums. May success and honor crown such men.

\section{San Jose, April 16, 1866.}

\section{Col. Warren, Editor California Farmer:}

DeAR SIR : In sending you last week the Cerratonia' seed, I wrote you in a great hurry - a few lines onlytelling you that the news about silk culture was cheering. I am not through yet answering all the letters that came, during my absence, from different parts of the State, and also several from France, on the silk question. I conclude to stop a minute and write you a few lines, to let your readers know what is going on about that important branch of industry. They will excuse me for being obliged to write in such a hurry. I hope to have occasion to talk more with them on the subject.

It appears from my silk letters, that we have in our State all the men for every branch-in fact all the elements among us, from the planting of the mulberry up to the manufactured silk, in all shapes, ready for our ladies.

In the letters from France I see that we will have quite a number of silk-growers, spinners, and manufac- 
turers. I wish to remark to you that one of them had my name through the columns of the CALIFORNIA FARMER, and that in the south part of France. I wish also to inform you of a very important fact, and that is, in a few months we shall have our pioneer silk manufactory. A friend sailed last Tuesday on the steamer to Panama, on his way to New York, to buy all the necessary machinery, and I hope at our next Fair we will have the first California Manufactured Silk. This will be an inducement for many to go into this fine and profitable business, because we are assured of a market at home for our silk cocoons. I think that we will be able to furnish that manufacturer with four or five hundred thousand this year.

You have already published in your columns the cicouragement offered by the State. It is very important to see that that bill has passed in that shape-that it is an encouragement for all that will go into it, all over-our blessed State, and that for four years, this culture being properly encouraged, will induce a great many to go into it, and the culture will be well started, after which it will not need to be encouraged, as it will pay itself such profits that we will soon have silk manufacturies in all the principal cities of the State. Now that such an encouragmeent by the State is given I will give another ; I will part with the California silk culture and give to everybody all that I know about it. I hope in a weck or twelve days to begin to write the California Silk Manual, in which I will give first the culture of 
the mulberry tree, and its propagation by seed and by cuttings; after the mulberry our California silk culture, or the management of silkworms.

Besides writing the California Silk Manual, I will do two public feedings or treatment of worms, from eggs to eggs, or the whole process - the first in one of our halls in San José, beginning the 15th of May next, and the second in the Agricultural Hall at Sacramento, beginning on the 10th of July. In that way our people who need information, will get it. I will do all in my power to make them understand. All those who take an interest in it will have a good opportunity to learn, and when they find that it is so simple under our fine climate, and that it is a work that can be done by ladies and young folks, and also aged persons not fit for harder labor, they will thus be enabled to go into it, and particularly when I will give them the means to do it with a very small capital. This work can be undertaken by all. As to the advantages of our climate over the other countries, I have fully demonstrated in my previous letters. I wish particularly to remark that the beauty of that culture is, that we do not fear any competition; on the contrary, we need it, becauseour market for that article is the whole world, and our climate being so superior, our silk is of the first quality, and consequently we will get the highest price for it.

Instead of sending seven millions of dollars out of the country for imported silk, we must all go to work and do all in our power to retain that amount among 
us, and make the millions sent out come back with a compound interest. Let us do it-we can!!

Respectfully yours, $\quad$ L. Pinevost.

[From the California Farmer, May 10, 1866.]

SILKWORMS-FEEDING AND CARE.

SAN JOSE, May 8, 1866.

Editor California Earmer:

My Dear Sir : A few days after I started to Sacramento, where I have been nearly two months, my wife sold some silkworm eggs to a party from Santa Barbara, and afterwards left my two boxes of eggs in my office, when they should have been kept constantly in the coolest part of the cellar. On my return, I put them back immediately into the cellar; but it was too late; they were prepared to hatch-having been so long a time under the influence of hatching heat, and the other day in going to visit them I found them mostly hatched out and the balance hatching. I have now between eight hundred thousand and a million of them, and as, in and about San Jose there is food for hardly one hundred thousand at present, I am obliged to go to Sacramento, where I have food for them. Thus it will be seen that it will be impossible for me to do the "public feeding" at San Jose this season, as anticipated. It will be reserved for next season. 
I will leave some worms with my wife to take care of, in case anybody wishes to see them there.

I will have a grand exhibition of silk and silk cocoons at our Santa Clara Fair, on the 18th of Septomber, next, and will give there all the information needed on that important subject. I will see that in the future such an accident will not occur again. It has never before occurred with me during the five years that I have been raising the silk in California.

Yours Truly, $\quad$ L. Prevost.

[From the California Farmer, May 17, 1866.]

SILK CULTURE.

Sacramento, May 14, 1866.

CoL. WARREN, Editor California Farmer:

Dean SIR: I arrived at Sacramento with my large family of silkworms. We are, I suppose, about two millions altogether, those hatched and those hatching now. They are doing finely, and seem to be very comfortable; they will soon fill up the whole room. I will do every day all in my power, to show and tell everything about silk culture to all who wish information, so as to enable every one that will attend the whole process, to conduct the business successfully themselves. It is very important for the country that the knowledge of silk culture should be spread all over it, and this would 
be attained if every locality would take steps to appoint a person (gentleman or lady) to be here present during the whole process, and thus they would be able to learn it to all those of their own locality, and in doing this, with very little trouble and expense, silk culture would soon be known all over the State, and thus the whole people would be benefitted. Our women will find in it an agreeable and profitable employment. In France it is a part of the education of young women; they every one of them receive a small lot of eggs, they hatch them, feed the worms and raise the cocoons; thus they are familiar with a work that may be very useful to them afterwards.

Respectfully yours,

L. Prevost.

[From the California Farmer, June 7, 1866.]

THE SILKWORMS AT SACRAMENTO.

We give our readers the following note from Mons. Prevost, from Agricultural Hall, Sacramento, relative to the condition of his "silkworms," and thus keep our readers posted as to their progress.

It will be seen that our pioneer is at the "post of duty," doing all he can, and promises our readers some interesting letters soon, relative to the superiority of his " silkworm system."

We can also inform our friend that the eggs he kindly gave us (which were also hatching) the day he passed through this city to Sacramento, are doing nobly with 
us, and our little band of a few thousand are growing finely, and we shall try and show him some splendid cocoons, as we have a liberal supply of mulberry leaves in our garden, and our daily feeäing is very interesting to us.

Will our friend Prevost please see the letter of inquiries about silk culture in another column, and render us such aid as the cause needs.

Mons. Prevost, as a Florist, will also read with pleasure, the letter from Mr. Hogg, from Yokohama, Japan.

\section{Editor California Farmer :}

SACRAmento, June 6, 1866.

My Dear SIR : I see in your last issue that you have been visiting the silkworms at San Jose, and you say that the little trouble and care under my system, will soon bring that important branch of business into notice. You have said a great truth, because the superiority of my system is now fully demonstrated. A letter from my wife, dated May 31st, says that her worms are making their cocoons; while my worms, of the same age of those I left with my wife, have only begun yesterday. She is then seven days ahead of us here at Sacramento. The reason is, here I cannot follow my system, as we have to depend on others to get the food, they will not allow us to cut the branches. This will be the subject of a letter when I will have time. I have not the time at present, because this way of feeding with the leaves only gives us ten times more work, and it is not half so good. In great haste,

$$
\text { Yours truly, L. Prevost. }
$$


[From the California Farmer, June 14, 1866.]

SILK CULTURE.

Sacramento, June 11, 1866.

Col. Warren, Editor California Farmer:

DeAR SIR: I have read with great pleasure the letter in your last number from your correspondent $H$. If I had a little time, all his questions could be answered, as I see he is right, and has a true idea of the subject. In regard to the cocoonery, I can show you at any time a full plan of those in France, but we do not need here such expensive ones, as we have to do a very little of what they have to do there. It is my intention to write a special letter on that important subject, and give my plans and views on a California cocoonery. I have received the leading French papers on silk, giving information on silk all over the globe, prices, etc., etc., and containing my letter on Silk in California. I have also very important documents on silk, enough to have two or three columns in your paper every week.

Our million of worms here are doing very well so far. Please excuse me for writing to you in such a hurry. The letter from my old neighbor and friend, Mr. Hogg, pleased me very much.

Yours truly,

L. Prevost. 
[From the California Farmer, July 12, 1866.]

SILK CULTURE.

- Leterter from Mons. Prevost about Silkworms at Sicramento.

Brannan Ranch, July 7, 1866.

Editor Farmer-Dear SIr: I have been so much in a hurry all the time at Sacramento that $I$ have not been able to find a minute to write to you before.

As the silk culture is before the people, and as it is important to all to know something about it, the public has a right to know how and why we had the disease on the worms at Sacramento. It will be seen that it is not owing to climatic circumstances but to a combination of a great many unforeseen difficulties that $I$ have been laboring under there and could not avoid.

During the five years that I have been raising the silkworm in California, previous to this year, I have never observed any disease among the worms because I had fresh mulberry feed to give them, but in the Agricultural Hall what had I to contend with?

1st. In the beginning, when I was in need of very tender leaves for my young worms, I was receiving old dusty leaves that worms three weeks old would hardly have been strong enough to eat, so that it is very easy to see that they have been suffering right at the start.

$2 d$. With the exception of a few days, we had constont cold weather from time to time, the Sacramentans say they never saw the like of it before.

3d. I have been obliged many times to feed with 
wet leaves, which was enough to make any worms sickly.

4th. As I had to depend on a great many persons for the food; we were requiring it all from the vicinity of Sacramento, Marysville, Nicolaus, Lincoln, Newcastle, Folsom, etc., etc. The leaves coming in bags were withered and nearly all the time heated-this last condition was sufficient to kill them all.

5th. I have never been able while there to have them fed regularly or full fed. Sometimes fed but twice and other times three times, when they ought to have been fed four or five times a day. It is very extraordinary that under such bad treatment they kept looking and doing well for nearly six weeks, until the 17 th of June.

6 th. On that day all the mulberry food was exhausted and we had no more to give them, so we were obliged to give them "Osage Orange." This forced change from their natural food, the mulberry, started the disease, and they commenced dying by large numbers every day; some of them started to make their cocoons to the number of fifteen thousand.

I feel certain that you and the public, who can judge correctly, will all agree with me, that to have so many cocoons, under a combination of so many bad circumstances, and call that a success, it certainly speaks very highly in favor of our climate for silk culture, because elsewhere one of these reasons would have been enough to have killed them all. I have told many persons that this is no reason to think that Sacramento 
is not as good a place as San José for silk worms. Let us but feed them properly with fresh food, and we will have everywhere the same grand result. Some time after our loss, I was very glad to hear from different persons to whom worms have been given, after my arrival here, and all those who have fresh food on hand, write that the worms have done well and made fine cocoons. This is the confirmation of all I had said before about silk culture in Sacramento Valley. My opinion is that most of our State is generally adapted to silk culture.

By the information I receive, Santa Barbara is also as good as Sacramento and San José valleys. During my stay at Sacramento, I have not been able to show the California silk culture as I wished. I had to explain our trouble, because my way of feeding is with branches, and this is the best for California, for three very good reasons : 1 st, it is a great labor-saving; $2 \mathrm{~d}$, the leaves on them keep fresh a longer time, and allow the worms to eat them all; $3 \mathrm{~d}$, it keeps the worms properly ventilated, and this contributes largely to improve their health.

The reason that I have not been able to show the success of California silk culture, is, that everybody wished to keep every part of their trees so as to make cuttings the coming season, they would allow us to take nothing but the leaves. I am very glad to see the dispositions taken by our people to propagate, but it gave us ten times more work.

In regard to cuttings, I found one way to make a 
great many more, and have every one to grow. I have stated it to a great many persons; but I will publish it in time for the coming season, in order that every one may be benefited by it.

In going to Sacramento I left a lot of the same worms with my wife. In taking eare of them she had to follow my system, knowing no other. She wrote me that she had none sick, and they made their cocoons just seren days ahead of those of the same lot that I had in the hall. This is another item of the California silk culture. When kept vigorous they go to work at their time, and when suffering it keeps them back.

As I had agreed to come and do a feeding in the Agricultural Hall, I eame to fulfill my promises, and made up my mind to let the public know everything the good and bad circumstances-so now every one can see and judge for themselves; and, knowing the facts, they will see very well that there is nothing to disconage any, or injure the cause in any way. Let us plant mulberry trees everywhere, and have plenty of fresh food at our doors, and every thing will be all right; but we canuot expect to do anything without the proper food.

I feel it my duty to state here, before closing my letter, that the officers of the State Agricultural Society have done for me all they possibly could do, and the Secretary, Mr. Hoag, in particular. Without his aid I should have had to give it up, because anything I could sily would be below the level of his courage, energy, and devotion to the noble cause.

'íruly yours, ‘L. Prevost. 
SILK GROWLR'S MANUAL.

[From the California Farmer, August 9, 1866.]

SILK CULTURE-NEW SERIES.

LETTER NUMBER ONE-BY L. PREVOST.

\section{SAN Jose, Aug. 7, 1866.}

Col. Warren, Editor California Farmer:

DeAR SIR: In a previous letter, from Sacramento, I told you that I had plenty of documents upon the important question of silk. I will begin to lay some before the public, and will take from these documents everything that can advance the cause; and arrange every part of them as may apply to California, or any of our States, where the climate is favorable to silk culture. I will begin with a very remarkable address, here before me, delivered by the Rev. D. O. MeLean, before the American Silk Society, in the Hall of the House of Representatives, at Washington, December 12,1839 .

\section{IMPORTANCE OF SILK CULTURE.}

Rev. Mr. McLean begins thus :

- Mr. President-The Committee appointed to make arrangements for the exercises of the evening, have requested me to accompany the resolutions read by your Secretary, with some remarks. Conscious of my inability to meet the just expectations of this Society, owing to the shortness of the time allowed for preparation, I nevertheless consented to perform the service to the best of my ability. Were my ability but half equal 
to my zeal, in the noble cause in which we are engaged, I might then hope to present you something worthy of the occasion. That our country is experiencing great and perplexing embarrassments; and that we are far from enjoying, as a nation, the plenty and prosperity which our almost boundless resources lead us justly to expect, is painfully felt by all our citizens. We may blame our Government or our banks, but whatever agency they may have in our difficulties, they do not directly produce them. Such are our real or imaginary wants, that we consume more than we produce; and as long as this is the ease, neither our Government nor our banks can furnish us effectual and permanent relief. Our imports have exceeded our exports; our consumption has gone beyond our production, for years, in an alarming degree. The commercial balance against us, this year, will probably fall little short of fifty millions of dollars; added to which is the annual interest on State loans amounting to full twelve millions of dollars more. That is, we are this moment in debt to the amount of upwards sixty millions of dollars, besides a debt on time for somewhere near two hundred millions of dollars, and this debt must be paid. Our creditors are themselves embarrassed at home, and they must and will have their money. Here is the cause of the melancholy prostration of business in our whole country, the stoppage of banks, the ruin of merchants, and the downward tendency in the price of all the products of our soil. Look where we will, no permanent relief can be found, but in the actual products of that which will 
liquidate our present debt, and the possession of which will diminish our importations in time to come, or serve as a valuable export in exchange for foreign products. But what can we produce that will promise these desired results?

Shall it be breadstuffs, the staff of life? That we have an immense territory adapted to the production of grain, to an almost unlimited extent, is undoubtedly true; but where shall we find a market for anything like the quantity of grain that would be necessary to meet the annual balance against $u s$, and at a price that would be an adequate return to the grower? The corn laws of England, framed with great wisdom for the development of her own agricultural resources, amount to an actual prohibition of our breadstuffs. Her ports are never open to the introduction of foreign grain, until by reason of actual scarcity, or monopoly, the price reaches a certain maximum measure; then free ingress is allowed to the whole world, when the price falls below the maximum, and her ports close. Other nations of Europe, in most cases, either produce their own breadstuffs, or can procure them nearer home and to better advantage than from us.

Shall we rely, then, for relief on the production of grain? This we cannot do-at least until our national legislature, by wise countervailing regulations, open for us a more certain and steady market than is now furnished in any part of the world. Millions of bushels of wheat are at this moment on hand in the single States of Indiana and Michigan, which would quickly go to 
Europe as a remittance if there was there an open and ready market.

Shall we turn to cotton, the great staple of our nation? Fven this, in all its magnitude, is unequal to produce the desired results. The supply of cotton already equals the demand at remunerating prices. Other nations, as well as our own, produce this article, and will undoubtedly continue to produce it in an increasing quantity as long as it will command adequate returns. India, China, Asia, Turkey, several of the islands of the Indian Occan, Egypt, Mexico, Brazil, and Texas, all produce cotton; and all will continue to produce it while remuncrating prices continue. If we therefore labor to swell the production of cotton further, the result must be such a reduction in the price that it must entirely cease to be a valuable product at all. The cost of production will equal or exceed the price obtained; besides, when more than one quarter of a large and rapidly increasing section is devoted to this article, it is at least questionable whether the principles of political economy do not forbid other portions of our country to depend on cotton, while they continue destitute of any valuable exports.

Indeed, it may be fairly" questioned whether the relation between the demand and the supply of cotton is not at this moment such that the individual interest of cotton growing, as well as the interests of the whole country would be promoted, if one-third less cotton were produced, and the labor necessary to produce this third was devoted to the production of other valuable articles of export. 
What, then, I ask again, shall meet the balance against us? Shall we turn to our rice and tobacco fields? These, indeed, form a respectable item in our annual exports, but they are utterly inadequate to accomplish the result desired; and neither can be materially increased to advantage. Where, then, shall we seek for relief? Is it answered, diminish our imports? True ; but where shall we begin? What do we import now to any considerable extent that is not absolutely necessary to the real or imaginary wants of a great and rapidly growing nation?. Will a prosperous people, with unlimited resources, submit to real or imaginary privations beeause we read to them homilies on political economy? Is it not morally certain, that as our nation inereases our consumption must also inerease, and our importations in a corresponding degree? The only hope of a diminution of imports, is home production. We must produce, for home consumption, some important article, and in this way lessen importations, or we must produce something largely for export that will balance our account current with other nations. Once more, I ask, where shall we turn for relief? What shall we produce? Plainly: whatever it is, it ought to be something which we largely consume, which will command a high and certain market abroad, and which our country can produce. And what article, I ask, is this? You anticipate my answer. I fearlessly affirm, in my deliberato judgment, the production of silk alone will meet the exigeney of the ease. Silk must become a great national staple in America, if we would secure and perpetuate individual and na- 
tional prosperity. When this becomes the case, and sir, I honestly fear, not till then, under the smiles of a gracious Providence, and the benign influence of a paternal government, we may walk abroad with proud independence-secure from the vexations and embarrassments which, to a greater or less extent, invariably attend a debtor nation.

Here is an article which we largely consume, an article which we cannot dispense with, which the nation must and will have, either produced or imported, in annually increasing quantities.

[From the Callfornin Farmer, A ugust 16, 1866.]

SILK CULTURE-NEW SERIES.

LetTER NUMBRR TWO.-BY L. PRETOST.

San Jose, August 7, 1866.

Col. Warrex, Editor California Farmer :

Dear SIr :-Next to food, the chief want of man in every state of society, is clothing. 'Ihis, in all civilized countries is produced from wool, flax, cotton, and silk. The increasing extent to which the silk enters into the clothing of the civilized world is amazing! In our own country it pervades every class of society, and enters largely into the holiday and even daily habiliments of $12,000,000$ of people. The average annual importation of silk into the United States, during the last five years, 
was $\$ 13,273,114$. In the year 1836 it rose to the enormous sum of between $\$ 25,000,000$ and $\$ 26,000,000$. Now the mere abstraction of such an enormous item from our indebtedness would almost render us independent. (This data was made for the year 1839.-ED. F.)

But should we even produce this article to twice over the extent of our own wants, a ready foreign market is open for all that we can produce of the raw material, at most liberal prices. England alone, where lies most of our indebtedness, manufactures silk probably to a greater extent than any other nation. Her manufactured silks amounted last year to the enormous sum of $\$ 72,000,000$. What a splendid prize is this for which to contend. And of the raw article she consumed nearly or quite $\$ 17,000,000$ worth; and the whole of this large supply must be drawn from abroad. England cannot produce the raw silk; she has made repeated attempts, but owing to the humidity of her atmosphere, or to some other cause, she has always failed, until she has given it up in despair. She must, then, rely entirely on other nations for the vast amount necessary to carry on her extensive manufactures. She draws her supplies now mainly from India and Italy, but would unquestionably draw it mainly from us, could we produce it, because we furnish a better article than she can elsewhere procure, as she herself acknowledges. England alone would therefore furnish a ready market at fair prices for all the raw silk which we can possibly produce, even if our productions should far exceed the most sanguine hopes or desires we have ever dared to indulge in; because consumption 
will yet increase in proportion to the increase of production.

During the last four or five years the consumption of the raw material has actually increased about 2,000,000 lbs.

France, too, produces less of the raw material than she requires for her manufactories. In 1835 she exported some $\$ 22,700,000$ of manufactured silks, and imported some four or five million dollars worth of the raw material ; foreign demand, then, does actually exist to an almost unlimited extent; a wide door invites us to enter and occupy.

You may swell the product even beyond the exports of cotton, which the last year amounted to the enormous sum of $\$ 61,000,000$, and not sensibly affect the price of raw silk, certainly not so as to prevent adequate returns for the costs of production. If our embarrassments then are measured by millions, here is an article the home consumption and the foreign demand for which will also count by millions-will meet the exigency of our case. Every State in our Union may remit the annual interest on its foreign loans, in bales of raw silk, aye, and may ultimately remit the principal, too, without exceeding the demand.

Here, then, certainly is an article which we largely consume at home, and which will command a ready market in any quantities abroad. But can we produce it? Why, I ask in reply, can we not? Nature has surely thrown no insurmountable obstacles in our way; we are nearly or quite on the same parallel of latitude 
with the principal silk-growing countries of the world; the mulberry which furnishes food for the silkworms we know will flourish here, because in very many portions of our country it is of spontaneous growth, and even the more valuable kinds which have of late years been introduced into our country, which have been supposed incapable of enduring the rigors of our Northern winters, are found by actual experiments everything that their warmest friends could desire. In the actual production of silk, experiments have been made in every period of our colonial as well as national existence, which have uniformly resulted in the production of silk of as beautiful a texture and luster and as strong a fiber as is produced in any country; especially have experiments been made during the last few years from Maine to Florida, which have triumphantly settled the practicability of producing silk in our country. There is something in the dryness and elasticity of our summers which seems to adapt our country to a peculiar degree to the production of silk; we can produce it, therefore, just as certainly as we can produce corn or wheat. But can we produce it to a profit? Are not the circumstances of our country such that the cost of production will equal if not exceed the value of the article produced?" Here, it must be confessed, is the consideration which must be decisive on the whole subject, both in an individual and national point of view. Individuals will not embark in any kind of business, or having embarked, will not pursue it, if found to be unprofitable. Now, can the introduction of any business 
benefit the nation which does not benefit individuals? The great reason why it is thought it cannot be profitably produced in this country is the fact that labor is here so much higher than in any silk-growing country in the world. How can we produce it as cheap as we can buy it, when the labor necessary to produce it costs three or four times as much as the labor in the silk-growing countries?

There is much plausibility in these objections, I will acknowledge, and there was a time when it perplexed me greatly. There are facts, however, on this subject which seem to me triumphantly to meet all objections to this business drawn from the comparative prices of labor; and I love to deal in facts.

Is it not a fact that manufactured cotton goods are furnished cheaper and better by England than any other part of Europe? Are not the manufactured silks of England furnished as good and as cheap, if not cheaper and better, than the silks of other countries where labor is much lower?

I might instance the production of our finest linens; they are furnished cheaper and better by Holland and Belgium than by any other powers where labor is cheaper. France can and actually does furnish fine woolens cheaper and better than they can be furnished by Spain, although the price of labor is much in the favor of Spain.

One great reason why the price of labor is neutralized, so to speak, is a fact which the history of the world will prove: that a decided superiority and skill is usually 
obtained in the production of a given article by those with whom the price of labor is dearer than with their rivals.

We know the price of labor in any country, other things being equal, is usually according to the skill and industry of those who perform it.

We do not pay a mechanic or laborer a high price for his labor merely because he chooses to ask it, but because we know that the product of his labor will furnish us with that which we know we can sell to a good profit after paying him his wages. Suppose that the daily wages of the East Indian is but a few cents per day: will this advantage counterbalance his want of skill and his destitution of the labor-saving machinery, which pervades every branch of business in our own free and happy country.

The inventive genius of Americans is proverbial, and who can doubt the application of skill and genius to the production of silk? Improvements made here, we know will almost simultaneously pervade our whole country, and will quickly pass to England; but to introduce them into other silk-growing countries requires years, if not generations. France, even polished France, has been talking about internal improvements longer than any other nation, and to this hour she has now considerably little railroad in her whole dominions; even the little kingdom of Belgium far surpasses her in this respect.

In Italy and India it is almost impossible to introduce improvements in any valuable degree ; indeed I appre- 
hend that the low price of labor is in no small degree accountable for this ; and therefore the fact that the low price of labor among those nations who will be our chief competitors in the production of silk will make that production more profitable to us.

Is it not a fact that in England and our own country, where labor is high, the capitalist is enabled to live well and_rapidly increase his means; while in India, France, and Italy, where labor is low, the very reverse of this is the fact; the accumulation of wealth is very slow? What do we care for the competition of India or the nations along the Baltic in maritime trade; while that of England, where labor is nearly as high as in our own country, we fear.

The whaling trade furnishes a striking evidence on this subject. This trade is open to the whole world; yet with all the low prices of labor, even among powerful and enlightened nations, this trade with us has constantly increased, and our merchants have grown rich on the profits of their ships, while with them it has uniformly declined, and the proprietors of the sluggish ships of the North of Europe are scarcely able to live.

But again. How can the price of labor operate to our disadvantage when the silk-growing countries of Europe generally, either owing to their negligence or their climate, are in all cases obliged to make large deductions for disease and death among their silkworms; while our attention, and the balmy nature of our climate, render it unnecessary for us to make any such deductions. Some writers assert that even fifty per cent. is a 
reasonable allowance for the large percentage which they lose. Should it, however, be but one-quarter of this, this consideration alone more than balances the difference in the price of labor.

If they can lose such a percentage and still make a profit on their low price labor, how much greater profit can we make, even if our labor is higher, when no loss is sustained. But again, I ask, how can the price of labor operate to our disadvantage, when we are entirely free from everything like excise duties on trees and silk; a burden which is borne heavily indeed by European silk-growing countries? We have it, on the best authority, that in the Neapolitan territory every mulberry tree pays to the government an annual tax of about sixteen cents, and every pound of silk about thirtythree cents. Even the refuse and unprofitable part of the silk and cocoons pay about one per cent. to the government. Surely if labor costs even nothing there, and it is still profitable to produce silk, it may be vastly more profitable here, with all the high price of our labor. 
[From the California Farmer, August 23, 1866.]

SILK CULURE-NEW SERIES.

LETTER NUMBER THREF-BY L. PRETOST,

SAN Jose, August 20, 1866.

Col. Warren, Editor California Farmer :

Drar SrR-But if we can, if we actually do, grow and manufacture cotton, and sell it in India cheaper than they can produce it, and cheaper than they can elsewhere grow it, why can we not do the same with silk? We know, with all other disadvantages, other nations produce silk to a profit; and while in other things we yield to no nation on earth, why shall we in silk alone?

But we are not left to such a course of reasoning. Conclusive as it is, to my mind, to prove that silk may be profitably produced in our own country, I do not believe we are warranted, as yet, from actual results, to speak with absolute certainty as to the amount of profit, per acre, in the production of silk; still, sufficient is known, from actual experiments, to satisfy any reasonable mind that it can be produced at a profit.

Why should the inhabitants among the inhospitable rocks and stones in Mansfield, Connecticut, enjoy such a measure of prosperity, if the production of silk is not profitable? There more attention has been paid to the culture of silk, and for a longer time, than in any other part of our country, and from personal observation, few portions of our country have received less from nature than this town, and few portions, beyond all question, 
have less poverty and want-perhaps, I might say, few portions are found where the people enjoy more general competence and comfort-and to silk they are confessedly indebted for much of the competence with which they are blessed.

But experiments have been made in various sections of our country during the last few years, expressly with a view to test the profits of this business, and feeling obliged, as I do, to believe the statements of gentlemen who have made such experiments, my only surprise has been that the results have shown such large profits. I could name experiments made in Massachusetts, Connecticut, New York, New Jersey, Pennsylvania, Delaware, Maryland, Virginia, and Ohio ; but they are familiar to all, and they go to prove that silk can be produced so as to yield a very large profit.

But on this subject I have other evidence still, that silk can be produced in our country, notwithstanding the high price of labor, to a large profit-evidence which, to me, at least, is perfect demonstration-I actually produced it myself to a large profit. Last year I actually produced silk at the rate of $\$ 104$ per acre; this year, valuing the raw silk at $\$ 4.50$ per pound, at the rate of $\$ 108$ per acre. The gross product this year was five hundred and twenty pounds of cocoons, or forty-eight pounds reeled silk, the cost of producing which is $\$ 2.25$ per pound, or the value of one male or two female hands, twelve weeks each; which, valuing the silk as above, leaves the minimum profit $\$ 108$ per acre. Now, this I know is no mistake; the silk before 
you will speak for itself. Nor were my knowledge, facilities, or advantages greater than those possessed by any and every member of the community; I am perfectly persuaded that every prudent man may realize the same result.

Now, in view of the foregoing reasoning and facts, can I doubt the practicability of our producing silk at a profit, notwithstanding the high price of labor ; and can I, as a patriot or philanthropist, refrain from urging my fellow citizens to embark in this business? And can any man, who believes these facts and this reasoning, fail to urge the snme thing on his fellow citizens, by his example as well as by his precept, that demonstration which results from the actual production of the article itself will convince. It is not to be supposed but that individual cases of fallure will occur; some may undertake more than they can accomplish, and fail; untoward circumstances may prevent success with others. The visionary and the grasping, who expect at once to amass a fortune in the production of silk, will be disappointed, and will doubtless abandon the whole thing. Those who engage in the business, however, intelligently, with common sense, will, with patience and perseverance, invariably reap a rich reward, and, at the same time, assist in adding millions to the wealth of their country. What more then, I ask, is necessary to induce this whole nation to commençe the production of silk?

PROFITABLE WORK FOR LADIFS, CHILDREN, ETC.

I advert to two or three considerations which, in my own view, are of great importance to this subject. 
The first is, the employment which the production of silk will furnish to that portion of our community which are destitute of profitable employment. All the means of human enjoyment, and all the accumulations of wealth, are, in one form or other, the product of human labor. The happiness and wealth of nations are, therefore, promoted in exact proportion to the active industry of the community. In order that readily extended prosperity exist, it is absolutely necessary that industry pervade every department of society; and that industry should be directed to objects adapted to those who labor, and are capable of producing wealth, then something must be produced by all. No community, as a mass, can grow rich, no large number of families can permanently thrive, when one, two, three, or more members in each family are entirely unproductive. Suppose one quarter of the community devote their energies to speculation, all they gain is abstracted from others in some way; they produce nothing-their country must grow poorer-they must be sustained by the labors of the other portion of the community, and permanent prosperity cannot exist. As nations and large communities are made up of families and individuals, in order to promote national prosperity, it is absolutely necessary that industry pervade the domestic circle-that all the members of our families should be usefully employed. Under the present state of society and the existing subjects of industry, however, profitable employment cannot be furnished to the whole 
of the domestic circle. In the days of our fathers there was, indeed, no want of such employment. The music of the spinning wheel and the noise of the shuttle and the distaff were heard-in all their dwellings. The numerous labor-saving machinery, the product of the last preceding age, introduced into almost every department of business, has entirely superseded these in domestic life. The circumstances of a very large portion of our. farmers are such, and the state of society is such, that there is now an absolute want of suitable and profitable employment for the female members of their families. They cannot, in consistency with their education and rank, take hold of the culinary department, and perform the drudgery of domestic duties; if there are many such in the family, even this would not furnish them employment; and the actual consequence is, that many an affectionate, prudent, and laborious father has actually sunk beneath that dearly cherished but unproductive part of his charge. Every community, therefore, that would secure permanent prosperity, must seek - employments on which they can profitably bestow domestic labor; and where, let me ask, is there an employment that promises so much in this respect as the production of silk? 
[From the California Farmer, August 30, 1866.]

SILK CULTURE-NEW SERIES.

LETTER NUMBER FOUR - BY L. PREVOST.

San Jose, August 26, 1866.

Col. Warren, Editor California Farmer:

DEAR SIR-The production of silk seems designed for female hands. It is suited to their ability, and promises as large returns for the labor bestowed as any other employment. In every period in the history of silk it has actually received the fostering encouragement of female influence. Queens and noble ladies have been its patrons, and the noblest daughters of our land would be honored by devoting their time to the production of silk in some of its stages. May we not hope that an article which enters so largely into the wardrobe of our wives and our daughters, which more than other fabrics adorns their persons, will receive their fostering care? Indeed, vast as may be the importance of the introduction of silk culture to our country, I despair of witnessing its complete success until our fair countrywomen actually engage in its production; and one of the most cheerful signs of the time is, that this to some extent, is already the case. When your daughters shall walk abroad in silks which their own hands have aided to produce, then the culture of silk as a source of national wealth will no longer be doubtful. Is it a fact, that grazing and dairy-making sections of our country are usually more independent 
than even grain-growing regions; and where will you find the reason if not in the fact that in the former case there is profitable domestic labor, and in the latter there is not? If the tenants whose abodes are among the hills which are covered with bleating flocks and lowing herds, are found continually making excursions down and buying up the beautiful valleys beneath them, what may we not expect to see when portions of these hills are covered with mulberry trees, and millions of skilled operators working unceasingly by day and by night, under the fostering care of female superintendence?

But there are also other members of the domestic circle, besides those already referred to, whose labor is almost utterly unproductive, for want of proper objects on which to bestow that labor. In almost every family there are children, and aged and infirm individuals, whose labor is of little value on the farm, and these are the persons who can almost entirely take charge of the cocoonery, with a little direction and superintendence. Even children can do much toward gathering the leaves and feeding the worms. Even the aged and decrepid, with the aid of ingenious contrivances for moving along by the shelves, can perform the work of the most athletic laborer. Surely that community cannot but grow rich when the labors of all are made productive. Other communities may be convulsed with every fluctuation in trade; this can smile with complacency in the midst of plenty; while all are debtors to them, they to none.

On all plantations of the South, too, there are un- 
doubtedly many ehildren, aged and infirm slaves, and mothers, who are of little or no value to their owners in the production of sugar and cotton, perhaps it would be safe to say, on almost every estate, the labors of one or several able-bodied field hands are consumed in supporting those whoso labor is of no considerable value on the plantations, who cannot because they are physically unable, perform the labor which alone is required. Now if these could be furnished with an employment by which they could simply support themselves, what a vast saving it would be to the planter. But how much more would his interest be promoted if it is demonstrated that the labor of such a class, when applied to silk, is even more profitable than the labor of the most athletic field hands; and that this will be the case every enterprising planter who will make the experiment will unquestionably find. In the present state of the cotton trade, this is an aspect of the subject of the deepest importance to every cotton grower.

I know much mystery hangs around the whole subject of producing silk, in the minds of most of our farmers; accustomed to deal in the heavier products of the soil, the delicacy of the article causes them to distrust their ability and skill in its production; they read or have heard of large and expensive cocooneries with nicely adjusted shelves, and spinning frames, with furnaces and flues, with hygrometers and thermometers, and verometers, and hourly feeding by day and night, and they are actually frightened from the undertaking, or even from an honest and serious examination 
of its practicability; but these appendages do not belong to the subject. I can speak at least from some little practical experience. The production of silk in the form of the cocoon, is an exceedingly simple thing. There is not a farmer in our land, who has not sufficient accommodations either in his house or outbuildings, to produce from one hundred to thousands of dollars worth of silk; and no fixtures in most cases will be needed but such as he himself, with his hammer and saw, can furnish. Care and attention are indeed necessary, but these are equally necessary in order to secure the most successful results in any business. This is a business concerning which experience alone can give us our best and most valuable information; much undoubtedly may be learned from books and the experience of others, but we cannot hope for the most successful results until we have had some little experience. Some who are engaged in no other employment, may at once commence large establishments; may expend freely in fitting up in the most perfect and convenient manner for the accommodation of the worms, and with care and prudence may entirely succeed even on a large scale, the very first year, without any previous practical knowledge. Still, in the general introduction of the business among our farmers, prudence requires that they should commence cautiously and on a small scale. A single ounce of eggs will produce a crop sufficiently large for most persons the first season ; attention to these will teach much respecting the habits and peculiarities of the silkworm; and will enable 
the culturist to make intelligent provision for the wants and necessities of a large crop the subsequent season.

But is it not a fact, that some portions of our older States are almost depopulated ? Not only do our youth, but many of our very best citizens, with heavy hearts, desert their homes, their comforts, and their friends, to seek, in new and distant States, the means of subsistence and support for growing families, which the cultivation of silk alone might have supplied in aburdance at home.

The advocates of silk are far from wishing to see other products of our soil diminished; but they do wish, by their example and their precept, to add another to the existing list of our productions; they do wish to develop our resources, and add to our population an hundred fold ; they do wish to retain in the possession of our citizens all the millions which are annually paid for foreign silk; they do wish to see productive industry pervade every department of life, and the condition and comforts of all our citizens improved; and if ever an enterprise promised joy and prosperity to the whole community, especially to the poor, this is that enterprise. How can the production of a rich and valuable article, the use of which pervades every class of society, which will give employment to thousands and tens of thousands of industrious people, which will pour millions into our treasury, how can this fail to better the condition of the poor as well as of the rich?

I know that it is difficult to introduce to the extent of millions, any new branch of industry among any class of men-it is not the work of a day; patience and per- 
severence will alone accomplish it. Do I mistake the signs of the times, when I predict, as I here publicly do, the speedy and triumphant success of the silk culture in our beloved country. To my own mind, the prospect before us is bright with promise; I look forward but a little, and my fondest anticipations are more than realized; I behold this single product flowing to all our ports through a thousand channels, and peace and plenty pervading all our borders, with no second in the magnitude of its results.

An eminent senator, on a memorable occasion, promised all our farmers silken purses filled with gold shining through their meshes; but, alas! the worthy senator gave us nothing with which to procure either the purses or the gold; but here is the silk to make the purses, and here is the gold-the returns of silk-to fill them.

[The foregoing discussion shows the importance of silk culture, and its benefit to our nation; and I hope it will serve to convince as well as please the greater portion of your readers.]

Respectfully yours,

L. Prevost. 
[Farmer, September 6, 1866.]

MANUFACTURE AND CULTURE OF SILK-NEW SERIES. LETTER NUMBER ONE.-BY L. PREVOST.

SAN Jose, Sept. 3, 1866.

Col. WARREN, Editor California Farmer :

\section{DEAR SIR:}

PIONEER SILK MANUFACTORY.

It pleased me very much to see in your last number an article on our "Pioneer Silk Manufactory." I will avail myself of the opportunity to write to-day on that important subject, which I consider as a great event for the silk cause in California, and consequently will advance greatly the interests of the State. It furnishes us the means of beginning that great work of retaining among us these seven millions of dollars sent out annually for importing silk for our ladies. It settles the question, as everybody can see, that we have now at home a market for all the cocoons we can produce. Our friends, Meyer \& Newman, in offering to manufacture our silk, will induce a great many to go into its culture.

SELECTION OF SOIL FOR THE MULBERRY.

To all those who are about to start in that rich industry, I desire to tell them for their benefit that the most important point to begin with is the selection of the soil for the mulberry. It is a fact that it grows most any where in California, but more or less, a deep ruch, light, loamy soil is needed; in such a case we can 
obtain as much food from one acre as from two or three acres of other soils; in that mulberry soil, trees seven years old measure from two to three feet in circumference, and shoots one year old, from ten to twelve feet long; and we have any amount of such soil in all the valleys of California. I have remarked a great quantity of it in our beautiful and healthy valley of San Jose, but have observed it more generally in the Sacramento valley. We can say that we have hundreds of thousands of acres of such soil in California, and it is incalculable the quantity of silk we can produce-we could supply the whole world with this article. But I must return to the main subject of this letter.

\section{SILK MANUFACTURE.}

The silk manufacture may be divided into two branches: first, the production of the raw silk; second, its filature and preparation in the mill for the purposes of the weaver and other textile artizans. The threads, as spun by the silk worm and wound up in the cocoon, are all twins, in consequence of the twin orifice of the nose of the insect, through which they are projected; these two threads are laid parallel to each other, and are glued more or less evenly together by a kind of glossy varnish, which also envelops them, constituting nearly twenty-five per cent. of their weight. Each ultimate filament measures about one-twothousandth of an inch in average, fine silk, and the pair measure fully oneonethousandth of an inch in the raw silk, as imported from Italy, France, China, etc. ; several of these twin 
filaments are slightly twisted and aglutinated to form one thread called a "single."

The specific gravity of silk is 1,300, water being 1000. It is by far the most tenacious or the strongest of all textile fibres, a thread of it of a certain diameter being nearly three times stronger than a thread of flax, and twice stronger than hemp.

\section{SILK MANUFACTURE IN ENGLAND.}

Until the year 1826, the English silk manufacturers in general labored under very grievous fiscal burdens. Foreign "organzine," or twisted raw silk, paid an import duty of $14 \mathrm{~s} 7 \mathrm{~d}$ per pound; raw Bengal silk, $4 \mathrm{~s}$, and that from other places, $5 \mathrm{~s} 7 \mathrm{~d}$; Mr. Huskinson introduced a bill at that time, reducing the duty on organzine to $5 \mathrm{~s}$, and the duty on other raw silk to $3 \mathrm{~d}$ per pound; the total prohibition of the importing of French manufactured silks, which gave rise to so much contraband trade, was also converted into a duty of thirtythree per cent. ad valorem. During the reign of the prohibitory system, English silk weavers had no variety of pattern to imitate and no adequate stimulus to excel, on account of the monopoly which they possessed in the home market. Also, the inferiority of their production was a subject of constant pride and congratulation among the Lyonnais; and, accordingly, the English could not stand their competition anywhere. At that time, the disadvantage on English silk goods, compared to French, was estimated in foreign markets at forty per cent.; of late years, it certainly does not exceed twenty, notwith- 
standing the many peculiar facilities which France enjoys for this her favorite staple.

THE SILK WORM-HOW IT LIVES, SPINS, DIES, AND ITS RESURRECTION AND PROPAGATION.

The silk worm is, like its kindred species, subject to four metamorphoses: the egg, fostered by the genial warmth of spring, sends forth a caterpillar, which, in its progressive enlargement, casts its skin either three or four times, according to the variety of the insect. Having acquired its full size in the course of thirty or thirty-four days, and ceasing to eat during the remainder of its life, it begins to discharge a viscid secretion in the form of pulpy, twin filaments from its nose, which harden in the air; these threads are instinctively coiled into an oval nest round itself, ealled a cocoon, which serves as a defense against living enemies, and the changes of the temperature. Here it soon changes into a chrysalis or nymph state, in which it lies swaddled, as it were, for about fifteen or twenty days; then it bursts its cerements and comes forth, furnished with appropriate wings, antennæ, and feet, for living in its new element- the atmosphere. The male and female moths couple together at this time, and after separating, the female lays the eggs and soon dies, their whole existence being limited to two months. The cocoons are completely formed in the course of four days, the finest being reserved as seed worms. From these cocoons, after an interval of fifteen or twenty days, the moth makes its appearance, perforating its tomb by knocking 
with its head against the end of the cocoon, after softening it with saliva, and thus rendering the filaments more easily torn asunder by its claws; such moths, or oritias, are collected and placed upon a piece of soft cloth or paper, where they couple and lay their eggs.

HOW TO PRESERVE THE EGGS, ETC.

The eggs, or grains as they are usually termed, are enveloped in a liquid which causes them to adhere to the piece of cloth or paper on which the female lays them; from this glue they are readily freed by dipping them in cold water and wiping them dry. They are best preserved in the egg state at a temperature of about $40^{\circ}$ Fahrenheit. If the heat of Spring advances rapidly in April, it must not be suffered to act on the eggs, otherwise it might hatch the caterpillars long before the mulberry has sent forth its leaves to nourish them. Another reason for keeping back their incubation is, that they may be hatched together in large broods and not by numbers in succession. The eggs are made up into packets of an ounce or somewhat more, which in the south of France are generally attached to the girdle of the women during the day and placed under their pillows at night; they are, of course, carefully examined from time to time. In large establishments they are placed in appropriate store-rooms, where they are exposed to a temperature gradually increased till it reaches the eighty-sixth degree of Fahrenheit's scale, which term it must not exceed (but in California we do not need artificial heat). Aided by the heat, nature completes her mysterious work of 
incubation in three or four days; the teeming eggs are then covered with tender mulberry leaves on which the newly hatched worms creep up instinctively.

\section{TREATMENT OF COCOONS.}

The cocoons destined for filature must not be allowed to remain for many days with the worms alive within them, for should the chrysalis have leisure to grow, mature, and come out, the filaments at one end would be cut through and thus lose half of their value; it is therefore necessary to extinguish the life of the animal by heat, which is done either by exposing the cocoons for a few days to sunshine, or by placing them in a hot oven; a heat of $170^{\circ}$ Fahrenheit is sufficient for effecting this purpose.

Eighty pounds French, or eighty-eight English, of cocoons are the average produce from one ounce of eggs, or one hundred pounds from an ounce and a quarter; but Mr. Cobzer, of Alsace, obtained no less than one hundref and sixty-five pounds. The silk obtained from a cocoon is from 750 to 1,150 feet long; the varnish by which the coils are glued slightly together is soluble in warm water.

\section{OF SILK HUSBANDRY IN GENERAL.}

The silk husbandry, as it may be called, is completed in France within six weeks from the end of April, and thus affords the most rapid of agricultural returns, requiring merely a little capital for the purchase of the leaf. In buying up cocoons and in filature, capital may be laid out to great advantage. 
The most hazardous period in the process of breeding the-worms is at the third and fourth moultings; for upon the sixth day of the third age and the seventh day of the fourth, they in general eat nothing at all; on the first day of the fourth age the worms proceeding from one ounce of eggs will, according to Bonafous, consume upon an average, twenty-three pounds and a quarter of mulberry leaves; on the first day of the fifth age, they will consume forty-two pounds, and on the sixth day of the same age, they acquire their maximum voracity, devouring no less than two hundred and twenty-three pounds; from this date their appetite continually decreases, till on the tenth of this age they consume only fifty-six pounds. In general, the more food they consume, the more silk will they produce.

There are three denominations of raw silk, viz: organzine, tram, and floss. Organzine serves for the warp of the best silk stuffs, and is considerably twisted. Tram is made usually from inferior silk, and is very slightly twisted in order that it may spread more and cover better in the weft. Floss, or bourre, consists of the shorter, broken silk, which is carded and spun like cotton. Organzine and tram may contain from three to thirty twin filaments of the worm; the former possesses a double twist, the component filaments being first twisted in one direction and the compound thread in the opposite; the latter receives merely a single slender twist.

Each twin filament gradually diminishes in thickness and strength from the surface of the cocoon where the 
animal begins its work in a state of vigor, to the center, where it finishes it in a state of debility and exhaustion, because it can receive no food from the moment of its beginning to spin by spouting forth its silky substance. The winder is attentive to this progressive attenuation, and introduces the commencement of some cocoons to compensate for the termination of others. The quality of raw silk depends therefore very much upon the skill and care bestowed upon the filature. The softest and purest water should be used in the cocoon kettle.

The quantity of the raw silk is determined by first winding off 400 ells of it, equal to 47 metres, round a drum one ell in circumference, and then weighing that length; the weight is expressed in grains, 24 of which constitute one denier; 24-deniers constitute one ounce, and 16 ounces, one pound, poid de marc. This is the Lyons' rule for valuing silk. The weight of a thread of silk four hundred ells long is two grains and a half. When five twin filaments have been reeled and associated together, raw silk is so absorbent of moisture that it may be increased ten per cent. in weight by this means; this property has led to falsifications, which are detected by including weighed portions of the suspected silk in a wire cloth cage, and exposing it to a stove heat of about $78^{\circ}$ Fahrenheit for twenty-four hours, with a current of air; the loss of weight it thereby undergoes demonstrates the amount of the fraud. There is an office in Lyons called the "Condition," where this assay is made, and by the report of which the silk is bought and sold. The laws in 
France require that all the silk tried by the "conditions" must be worked up into fabrics in that country.

The raw silk as imported into England in hanks from the filature, requires to be regularly wound upon bobbins, twisted, and reeled in their silk mill ; these processes are called "throwing" silk, and their proprietors are called "silk throwsters" -terms probably derived from the appearance of swinging or tossing which the silk threads exhibit during their rapid movements among the machinery of the mills.

As I will have to attend the Fairs, I will have to stop for a while. I will resume in a few weeks with letters on silk and its reeling, and other points pertaining to that important industry.

SILK CULTURE.

SAN Jose, November 14, 1865.

Editors Independent:-In fulfillment of my promise, I write you a letter on the very important silk question. It is not necessary to go back to the important points in favor of silk culture in California, which I have already published. I will confine myself to the present. It is very gratifying to me to see that silk culture is duly appreciated, and that the public begins to understand and look to its true interests. The soci- 
eties this year have shown their appreciation of the importance of that culture for California, by giving me the highest prizes, gold medals, etc., and I feel very grateful to them for having so well appreciated and rewarded my efforts. In 1860, when I raised silk for the first time, I sent silk and silk cocoons to every Fair all over the State, and though they gave premiums and diplomas for things of no importance, they did not award any premium to the first California-raised silk. So, you see, I was not encouraged at the first start. I say that I was not encouraged by the societies generally; but there was one that did encourage me-the San Joaquin Valley Agricultural Society, whose name will be recorded in big letters in the history of silk in California. That Society gave me a diploma for the first silk produced in this State. The officers and members of that Society understood their mission, and I remember it.

We cannot too much encourage our friends to go into this branch of industry, which is bound to surpass in value, for exportation, all other California products taken together. They can enter into it with more certainty of success than in mining operations, because they have no opposition or failure to fear. The regularity of our fine, dry summers, without rain, storms, or electricity, which are the enemies of silk culture, insures regular, good crops every year. The beauty of this new industry for California is, that it cannot be overdone. I say it is the only business in which we need not fear opposition or failure, because if it were possible to plant the whole State next year with full grown mul 
berry trees, and everybody engaged in raising silk, it would not lower the price of silk two cents per pound, as we have not only California but the whole world for a market. Therefore it is our duty to encourage and help all who wish to engage in this business. For my part, I intend doing this : I will furnish persons desiring to start silk culture in their locality, with their first silkworm eggs gratis. They will only have to write me their address and the amount of food they have, so as to guide me what number of eggs to send.

The work necessary to raise silkworms in California is very little, as our climate is so favorable to that culture that it enabled me to simplify it considerably. In proof of this I need only state that I have this last season raised over one hundred thousand silkworms, every worm making a cocoon; and all this with my own work alone. This is the work of eight persons in France or Italy. Our California silk culture is so simple, that as soon as it is published extensively, everybody in the State will engage in raising silk as well as any other production. If we consider it a moment, the quantity of silk that could be raised in California is immense; and it would afford employment to thousands of families, in raising as well as in manufacturing it. It is an easy work that can be done by aged persons, as well as by the young of both sexes. Then our ladies would have a right to feel proud in wearing dresses made of silk raised by their own hands. In France and in Italy silk is raised very extensively, and millions of families are living by this work. The silk exported from Italy 
surpasses in value by two-thirds, all other exportations together.

A remarkable fact is, that with our climate so very favorable to silkworms, we also have a soil well adapted to the growth of mulberry trees. They thrive almost everywhere in this State; but the best soil for them that $I$ have yet seen is in the bottom lands of the Sacramento valley. A large quantity of those trees will be planted there the coming season. I suppose that some will also be planted in the San Joaquin valley, where there is already quite a large plantation-that of Mr. Glessing, commenced last year. But the largest plantations in California are those of A. Packard and E. Goux of Santa Barbara. Those plantations were made three years ago, and are now in fine condition. 'These gentlemen will raise, the coming season, a large quantity of silkworms, and will probably turn them to eggs. My own exhibit of silk, from five years raising, proves beyond a doubt that California is the very best spot for that culture. This, and the testimony which I receive from others, shows that this new industry for California is now fairly started.

Two gentlemen, experienced, scientific, and practical silk growers, on their way back from China, where they had been to buy a large quantity of silkworms' eggs, recently came to see me to get information about silk in California. I told them all the facts, showed them the cocoons and where I raised them, and also the mulberry trees. Being gentlemen who understood the silk business perfectly, they agreed with me that we have the 
best silk country in the world, and were so pleased at learning this fact that they are going to return here next summer with the necessary capital to buy one hundred acres of land each, to raise silkworms' eggs and silk on a large scale. These gentlemen are the representatives of the two largest silk houses in Europe, and are now on their way back to France. From them I learned a very important fact, namely, that our climate is so superior for silk culture, that by selecting our very best cocoons for eggs, year after year-for our own use -we could, after a few years, obtain cocoons that would beat everything known, for size and quality, that is to say, a superior article. In this opinion I fully concur. The coming of these gentlemen from France will probably induce other silk growers to come also, which would be a great benefit to the State.

L. Prevost.

SILK CULTURE-LETTER FROM MR. PREVOST.

\section{San Jose, April 19, 1866.}

Editors Independent:- I wish to inform you and your numerous readers of the progress of silk culture since my last, so that all who wish to take an interest in that branch of industry may be guided and benefited thereby. Having been absent from home some seven weeks, I found, on my return, a great many letters from 
different parts of the State, making inquiries in regard to silk culture. By these letters I am satisfied that we have in California all the men necessary to carry on successfully this new branch of industry, in all its departments, from the planting of the mulberry to the manufactured silk. In addition to this, in my letters from Europe, I find that silk growers, sllk spinners, and silk manufacturers are preparing to come to this country, and I am advising them to bring with them all the necessary machinery of their trade. I am about to write all the facts about silk in California to go through the press in Europe, with the expectation that it will incite immigration. We have room for millions, and their presence would be of vast benefit to the State, as in the pursuit of which I speak, having the whole world for a market, we have nothing to fear from competition.

A very important matter bearing on this subject, is the fact that an act has been passed by the last Legislature in such a shape as to give great encouragement to all who engage in the business, for a term of four years. At the expiration of that time, the culture of silk will have been well started, and, resting on a selfsustaining basis, will need no further outside aid and encouragement.

Now that the State has given encouragement, I will do all in my power likewise to foster the business. It is a well known and admitted fact that what our people need is information upon this subject. This, while in Sacramento, I promised to give, and towards that point, I will, in a few weeks, write a "California Silk Man- 
ual," in which I propose to give the most approved and simplified modus cperandi of the culture, management and propagation, by seed and cuttings, of the mulberry tree, and afterwards, the culture of silk, and management of the worms according to the best rules of experience, in our fine, suitable climate. Besides the Manual, I will, this coming season, do two public feedings of the worms, going through the whole process, and giving the public all the information I can, thereby enabling those who desire so to do, to go into the business with safety. The first feeding will be given in one of our halls at San José, and will begin the 15th of May next. It will take six weeks to go through the whole process. The second feeding will be done at Sacramento on a larger scale, and will be commenced in Agricultural Hall on the 10th of July next. So you will perceive that, in this way, all those who wish to study and learn the subject, will have opportunities of so doing.

Another important point which your readers will undoubtedly be pleased to learn is, that in a few months we will have, at San Francisco, a "Pioneer Silk Manufactory." A gentleman sailed by the steamer of the 10th instant for New York, to buy there all the necessary machinery, looms, etc.; and it is anticipated that at our next Fair, we will exhibit our first California manufactured silk. They will have several hundred thousand silk cocoons to begin with, and by another year we will be able to give them more work to do. Until the present time the objection has been that, in 
raising silk cocoons, we would have no market for them; but that objection does not exist any more, as every person can now see that we have a market at home. Taking all these things combined, we may consider the culture of silk established all over the State, because it requires but a comparatively small capital to go into the business. It is a business that can be undertaken by any one. No farm onght to have less than five, ten, or more acres planted to mulberry trees. The building needed to raise the worms will be an excellent farm building, to be used for storing anything during the fall, winter and spring, as the worms need it only in June.

As I have already stated, the culture of silk is the only business in which we do not fear competition, and the more we can engage in it the better, as our market for the article is the whole wide world. As the business is so well adapted to our State, it cannot remain any longer a secret. Every one must become acquainted with it, and I consider it a duty to tell and show all we know about it. I think it is the duty of all who become acquainted with it to teach it to their neighbors, as, in doing so, everybody, in a few years, will become familiar with a pleasant and enriching pursuit. One merit of it is, that it can be done by ladies, and young and aged persons. In France it is a part of the education of young ladies. They each receive a small lot of silkworms and are required to tend and feed them, thus learning what may become very useful to them in after life. I hope that we will soon be 
able to return the seven million dollars sent out for the purpose of importing silk.

L. Prevost.

SILKWORMS, COCOONS AND SILK.

Mr. Prevost, of San José, the pioneer introducer of silkworms into California, expects to attend our District Fair, as the following letter received by Dr. Holden, President of the San Joaquin Valley District Agricultural Society, from that gentleman, shows.

"SAN Jose, August 29, 1866.

\section{Dr. E. S. Holden, Stockton.}

DEAR SIR: I was just about to write to you when yours of the 21st instant was handed to me, with a complimentary ticket, for which I thank you. It was, and is my positive intention to attend your Fair; and I hope to have a good place selected for me-one that will correspond with the importance of what I propose to exhibit. I will have a good lot of my silk cocoons; also some from other persons, raised in different portions of our silk State. I will likewise have reeled silk, silkworms, and probably bring the first piece of silk cloth made in California. I will, at the Fair, give all the information that may be needed about mulberry 
trees, silk, etc. I will be at Sacramento, and perhaps will have the pleasure of meeting you there.

$$
\text { Yours truly, }
$$

\section{Prevost."}

[From the Stockton Independent, November 6, 1866.]

\section{SILK CULTURE.}

Those who contemplate planting mulberry trees and the propagation of silkworms, in San Joaquin county, will find the following letter, written at San Jose, on the $3 \mathrm{~d}$ instant, by L. Prevost, interesting.

Editors Independent:- Since I returned from the Fair in Stockton, I have been confined to bed quite sick; but I am getting better every day, although I am still very weak. After some work on the part of the citizens here, and of General Naglee particularly, we have succeeded in getting the pioneer silk factory located here. We have given those engaged in the enterprise, twenty-five acres of land close to the city, and in a fine healthy location. I have discovered that a great number of persons from San Francisco have been visiting the parties preparing to manufacture silk, and asking them what price they will pay for cocoons; and not having consulted the present prices, they have put the price too low. I think I can be of some service to all those who intend to go into the culture of silk, 
in giving them the regular prices, which I translate from Le Moniteur, (silk monitor) published in Lyons, France. That paper is considered the standard among silk raisers. It contains correspondence and translations, regarding silk, from all parts of the globe. From its columns I translate the price of cocoons, as follows :

POUNIS.

PER POUND.

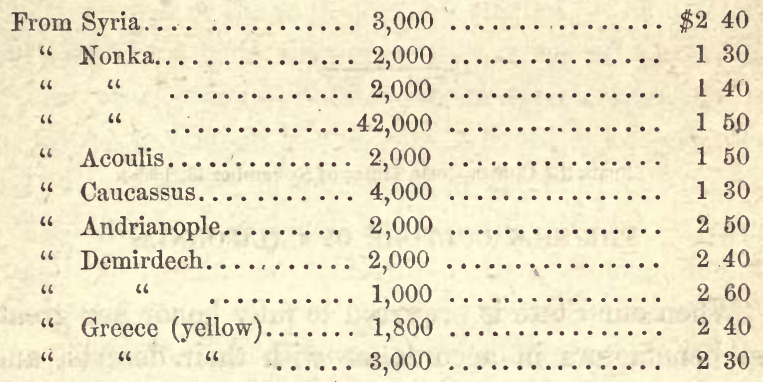

Receiving two of the best papers printed on silk culture, I consider it is my duty just now to translate, from time to time, all the principal articles for the benefit of those engaged in the silk business, and to keep them posted about anything of interest, and particularly about the prices. Silk is different from many other articles. The market for silk is the whole world, and varies but very little in one country from another. It sells always according to quality. Our climate is so very favorable to its culture, that I have no doubt but in time, we will all be so well acquainted with it that we will raise a quality for which we will obtain the highest prices. As soon as it is known abroad that 
California produces cocoons in quantity, silk agents will visit our State, as they do every other silk-producing part of the world, and buy them up. In the California Silk Manual, that I am preparing, I will put all my experience, of six years raising in this county, in its columns, and do my best to assist every one in raising silk of the best quality.

[From the Contra Costa Times of November 18, 1865.]

THE SILK CULTURE OF CALIFORNIA.

When our State is prepared to fully honor her greatest benefactors in accordance with their deserts, and the value of the benefits they have conferred can be fairly estimated, none, we think, will have precedence of Prevost, the pioneer silk culturist. We have before referred to his labors, which have so indisputably demonstrated the superior advantages which our climate offers for the prosecution of this branch of industry, but need not apologize for again urging the matter upon the attention of our readers, many of whom are favorably situated to profit by the experience which Mr. Prevost has gained, and which he is anxious to impart to all who will aid in extending this culture, which those most familiar with the subject are confident will be developed to rank with the greatest industrial interests of the State, and eventually place California first among the 
silk-producing countries, as she now is among the goldproducing.

Familiar with the silk culture in Europe, and a practical horticulturist, Mr. Prevost was early satisfied that the climate of this, his adopted State and home, was favorable to silk growing, and having tested the problem of its capacity to furnish food for the worms in the thrifty growth of the mulberry, he started his plantations and sent abroad for silkworm eggs, none of which, for several years, though obtained from various quarters of the globe, produced any worms. From a lot received in 1860, however, he succeeded in hatching and raising a small number, by which he obtained his first cocoons, samples of which, sent to Europe, attracted attention on account of their superior quality, due to the peculiarity of our climate, the advantages of which, so far as the health of the worms and certainty of crop, and quality of silk would be concerned, did not fail of appreciation by those largely interested in the silk business there, where it was seriously threatened by disease in the family of silkworms, inevitably incident to all climates subject to rains during what is termed the "feeding season." But the economy of labor, which the absence of rains during this season enables the culturist to effect here, was not realized by them, and has only been fully demonstrated by the experience of Mr. Prevost, which may be thus summed up. The conditions of our climate are favorable to the growth of the white mulberry (the best silk food). It insures healthy worms ; certainty of crop, both of silk and worms ; silk of superior and even 
quality, and a saving of three fourths of the labor required in other countries; and when these advantages are considered, in connection with the fact of the unlimited market for the product and the trifling cost of shipment, in comparison with its value, to any part of the globe, it is hardly possible to overestimate the benefit which the State is destined to realize from the extension of the culture which Mr. Prevost has so perseveringly labored to introduce and perfect.

Mr. Prevost might rest easy with the "good thing" he has secured in European orders for silk eggs, the monopoly of which he might enjoy for years, at prices almost equal to their weight in gold; but, with the spirit of a real benefactor, he desires that his fellow-citizens shall know and share the advantages which their climate offers for the prosecution of this interesting and profitable branch of industry, and he is ever ready to impart information of value to those who may desire it; and, as will be seen by the letter quoted below, he will also furnish gratuitously the eggs required to start with to all who will, for a number of years to come, engage in the business, and provide trees for feeding the worms. And this offer, if reckoned only at the money value of the eggs, is larger than any of the liberal premiums which the State has provided for the encouragement of new branches of industry.

The following is the letter referred to, written in response to inquiries relating to the mode of propagating the mulberry, with a view to preparing a plantation, or orchard; but as we presume the readers of the "Ga- 
zette" are, many of them, equally interested with ourselves in whatever relates to this matter, we quote it for their benefit.

\section{Chas. B. Porter, Esq.,}

Dear Sir: On the 19 th of October I wrote you a few lines in great haste, stating that I had not time then to answer your letter; but I will try to do it now, and be as brief as pośsible.

In regard to mulberry trees, they have to be transplanted the same way and at the same season as fruit trees, that is to say, as early as possible after the first good rain. They grow almost anywhere, but prefer a light, deep, and rich soil. The seed ean be sown during the winter in localities where there is no frost; otherwise sow it early in the spring. I would give the preference to cuttings, as they grow faster than from seed; they are as easy of propagation as any other tree cuttings; they also need to have sufficient moisture to make them grow well, and be protected, if possible, against the very hot sun, till they have good roots. If any of your friends wish some good fresh seeds, they will find them with Messrs. Francois \& Co., seed store, 605 Sansome street, San Francisco, who are importing them. I have trees, but not many, most of them being engaged. As soon as the plants have good roots, either from seed or cuttings, they can be transplanted during the winter. The morus alba is the very best for silk worms, but it is good to have some multicaulis, to feed the worms when young, as it is tender; and if the trees are in a good 
soil and well cared for, you can begin to feed from them the third year; after which you will have more food every year, and consequently more silk worms. The reason that the preference is given to the morus alba everywhere, where silk is cultivated Jargely, is because it contains more substantial food and produces a silk of better quality. So to give you an idea of it, I enclose you a small sample of what is obtained from its bark; it is almost equal to floss silk, and can be spun the same way. I believe this answers the questions in your letter, but for the benefit of your readers allow me to add a few lines.

The fact that California is the best spot on the globe to raise silk profitably, I have fully demonstrated by my five years' experience ; and also the fact that the superiority of our climate for the silk culture enabled me so to arrange the work that one man can do as much as eight formerly did, cannot be doubted, as I have myself, without help, raised over one hundred thousand silk cocoons. This is the work of eight persons in France or Italy. I am now very glad to see that the importance of this branch of industry begins to be understood, as the highest prizes have been awarded to me, in the shape of gold medals, etc. The culture of the silkworm is bound to be more beneficial and more important to California than all the others together, taking the mines in, because those engaging in it will not be exposed to deception; and the regularity of our fine, dry summers, without rain, storm, or electricity, insures regular good crops. I have a thousand things to tell about the 
advantages of silk culture in California, if I had time to write, but the impulse is given, and as I am posted in the progress and what is going on about silk culture in California, I am able to say with assurance that experienced silk cultivators will come next season from France, to raise it here on a very large scale. I was visited by the representatives of two of the largest silk houses in Europe on their returning from China, where they purchased hundreds of millions of silkworms' eggs. Being practical silk growers and manufacturers, they understood very well the superiority of our climate, and were extremely pleased with what I have been able to show and tell them, as they can appreciate the truth of it. We must do all we can to encourage everybody to raise silk, because this article is different from many other products; it cannot be overdone. We do not fear any opposition, for if it were possible that by some miracle the whole State should be covered next year with full grown mulberry trees, and most of her inhabitants engaged in raising silk, you can not prove to me that it would lower the price on silk of two cents per pound, as we have the whole world for a market. This article, on the contrary, is bound to rise; it advanced last season twenty-five per cent., on account of the disease in silkworms in Europe, in consequence of their wet summers. This is the reason they are obliged to obtain eggs from countries where the worms are not diseased, so as to keep up the stock and obtain their silk crops.

I have sold all my eggs for Europe, and they are 
engaged by the same house for the coming years; but I reserve what I want, and to encourage our people to propagate and plant as many mulberry trees as they can, I will furnish every one in our State their first silkworm eggs gratis, for several years to come, and they will only have to let me know what amount of food they have, to guide me in sending their eggs.

I shall publish my California Silk Culture, and it is so simple that every one will be able to follow it. I think, too, that it may be a good plan for me to write letters to France, to let the facts about silk culture in our State become as widely known there as possible, so that silk growers may see the inducement to come here and prosecute the business. This would be a great benefit to the State, as the quantity of silk that can be raised in California is immense, and this would bring millions to the State, instead of sending our money abroad to import the article. I am for home industry, and consequently, against importing. I have made this my home forever, and I shall die satisfied, if I can live long enough to see that I have been of some help for her prosperity; my time and energy. will always be devoted to this end.

In order that every one will be enabled to raise their own mulberry trees, I have published the mode of culture, either from seed or cuttings, in the California Farmer, some two years ago, and at the same time in the French paper. But if any point pertaining to that important branch of industry, that you may think use- 
ful to the public, remains unexplained, I shall feel great pleasure in answering your interrogatories.

$$
\text { Yours, etc. }
$$

\section{Prevost.}

[From the San Jose Mercury, April 26, 1866.]

SILK CULTURE.

Editor Mercury:

Dear Sir: In your last issue you have an article from the daily Union of Sacramento, about silk culture, stating that I am going, this summer, to establish a cocoonery or feeding of the worms before the public in the agricultural hall there.

This is true; but it is very important to all those residing nearer to San Jose than Sacramento, to know that I will give a public exhibition of the process of silk culture here first, and go to Sacramento after. These are my arrangements, and what I have agreed to do.

1st. I will write first the "California Silk Manual," in which I will give the culture, management, and propagation by seed and cuttings of the mulberry tree; and afterwards the California silk culture, or management of the worms, according to my simplified method for our fine climate.

2d. I will do two public feedings of the worms, the first at San José, at our City Hall, under the general supervision of our Santa Clara Valley Agricultural So- 
ciety, commencing on the fifteenth of May next; and the second at Sacramento in the Agricultural Hall, under the general supervision of the State Board of Agriculture, commencing the tenth of July next. It will take six weeks at each place to go through the whole process. Thus all those in the State that wish to learn how to raise silk, will have an opportunity. Nothing will be neglected on my part towards instructing them in all I know about the business so as to enable them to conduct it successfully.

I wish to impart to your numerous readers a few very important facts that have occurred since my last letters published about silk culture.

1st. I have been gone some seven weeks to Sacramento, and I have the pleasure to state that "An Act encouraging Silk Culture in California," has been passed, and is in such shape, that it is an encouragement for all those who will engage in that business for the next four years. This is the best act for the interests of the State, passed in our last Legislature, because our climate and soil is so superiorly adapted for silk culture, that it will bring a large emigration to this State.

2d. Another important fact is, that within three months, we will have at San Franciseo our California Pioneer Silk Manufactory. My friend, Mr. Newmann, has sailed by the steamer of the tenth inst. for New York, to buy there all the necessary machinery, looms, etc. He and his brother, who is here also, have already been in that business ten years. I expect that 
at our next Fairs, this fall, we will be able to show California silk of California manufacture. This will insure a market at home for all the silk cocoons we can raise.

3d. I am receiving, every day, letters on questions about silk, from all parts of the State. This shows that our people begin to feel an interest in that rich branch of industry; and from these letters I see that we have in the State all the men necessary to carry it forward in all its branches. And in my letters from Europe I see that silk growers, silk spinners, and silk manufacturers are preparing to come to this State.

In my previous letters on silk, I have fully demonstrated the superiority of our climate, and our advantages over the other silk countries.

By the above facts it is very easy to see that the silk culture will be established all over the State shortly. Already plantations have been made in different parts of the State, and particularly last season; but we can anticipate that the next season hundreds will go into it, because they will know how to do it; and also know that they are encouraged by the State. Hence, within a short time we will be able to retain among us the seven millions of dollars sent out annually for the importation of silk only.

As the time is short between now and the time $I$ am to engage in the enterprise publicly at San Jose, all the papers in our section of country that take any interest in the public welfare are earnestly requested to copy, in order that all may be properly notified of the fact. As it is a work for ladies, they can come 
when it is impossible for their husbands to come. Silk culture can be undertaken by every one, poor or rich; and is a business in which we do not fear competition. On the contrary, we need it, and the more who engage in it the better. It will certainly bring a large emigration to this country. Yours truly,

L. Prevost.

\section{SAN Jose, April 24, 1866.}

SILK CULTURE-CHANGE OF PROGRAMME.

Editor Mercury: A few days after I started for Sacramento, my wife sold some silkworms' eggs to a party from Santa Barbara, and left my two boxes of eggs in my office, when they have to be kept constantly in the cellar. On my return I put them in the cellar, but they were prepared to hatch, having been so long a time under the influence of hatching heat; and the other day, on going to visit them, I found them mostly hatched out, and the balance hatching. I have between eight hundred thousand and a million; and as, in and about San Jose, there is hardly food for one hundred thousand, at present, I am obliged to go to Sacramento, where I have food for them. Then it will be impossible for me to give a public feeding at San Jose, as anticipated, this season, and I shall have to defer it until next. I will leave some worms with my wife, in 
case that somebody may wish to see them. I will have a grand exhibition of silk and silk cocoons at our Santa Clara Valley Fair, in September, and will give there all the information needed on that important subject. I will see that such an accident does not occur again. It never has occurred before during the five years that I have been raising them.

Yours, respectfully,

L. Prevost.

SAN JoSE May 6, 1866.

SILK FACTORY AND SILK RAISING.

We are informed by L. Prevost, of San Jose, who is so deeply interested in the production of silk, that his friend Joseph Newman has recently returned from the East, with a complete set of machinery, looms, etc., to take the silk from the cocoon and manufacture it in all forms and styles. The machinery is stated to be of the latest and most improved kind, and he intends to produce from it the first piece of silk manufactured for exhibition at the State Fair. On visiting the principal silk factories in the East, Newman observed that some of the manufacturers employed as many as three thousand hands. As we have the best country in the world for the raising of silk, Prevost is in hopes that in a short time we will raise enough of it to employ as 
many or more hands in the manufacture of our own product. It can easily be done. A large number of persons are interesting themselves, in good earnest, in the raising of silk, and the next season will witness a large development of this business, especially now that we have in California a silk factory, and a home market for all the cocoons which can be produced. In this connection it is all important that proper soil is selected for the cultivation of the mulberry. On this subject, Prevost remarks, in a communication to the UNION :

"The mulberry will grow most anywhere in California, but has a decided preference for a rich, deep, light, loamy soil. Such soil will produce as much food from one acre as you would get from three or four acres of other soil. Then calculate the great economy of work, etc., and the great profit. We have hundreds of thousands acres of such soil in all our valleys in California. I know plenty of it in our fine valley of San Jose, but I have remarked it particularly and more generally in your Sacramento valley. The quantity of silk that can be raised there will be immense, as it does not matter if the lands are overflowed when the trees are once started.

"I have news from the different localities in our State, where I have sent silkworms' eggs, and every where, where they had fresh mulberry leaves to give the worms, they have all succeeded.

"It would take a long letter to enumerate all the profits that will be derived from the fact of our manufacturing our own silk. 
"All our farmers, who are on their own land, ought to select the very best part of it to plant mulberry trees, as the raising of silk can be done by their children. They will find that, in that culture, we have no competition to fear. On the contrary, the more engaged in it the better, as we have the whole world for our market."

[From the Sacramento Daily Cnion, July 12, 1866.]

THE SILKWORMS AT AGRICULTURAL HALL.

Messrs. Editors: I have been engaged in feeding silkworms, and raising silk in California, since 1860 , and have never seen any disease among my worms until this year, at Sacramento, and I feel it to be my duty to state to the public some of the facts connected with my effort at Sacramento, and the reasons of my trouble and disease among the worms.

In the first place, they hatched by an accident, which I have heretofore explained, some two months before I intended to have them; but as I had agreed to make a public feeding at Sacramento, to assist in introducing the business in the State, I thought it best to undertake it, even though I had some doubts about its success. The worms, hatching as they did, could not be properly separated, and those of the same age only kept together, as should be the ease ; but I was compelled to keep and feed all together, though sqme were over a week older 
than others. For this reason it was necessary to feed them all the time they were molting, which is very detrimental to the successful molting and health of the worm.

Again, young worms require the very tender and young leaves, and I found it impossible to obtain such in Sacramento ; most of the trees there being of some age; and standing in or near the streets, the leaves were covered with dust, and were generally only fit to feed worms when nearly grown. After the food was exhausted in Sacramento, I had to ship leaves from Marysville, Nicolaus, Lincoln, and other places, and it frequently happened that they did not come when expected and when I needed them; and a number of times they came heated and soured, and in this condition they were fed to the worms. This, of itself, was more than sufficient to cause them all to be diseased. I felt most certain it would do so, but I was compelled to feed them-as I could get no other-and I was only surprised that they kept in so good condition until the 17 th of June, when wo could get no more mulberry leaves, and were obliged to feed them all on the Osage orange.

From that time the disease spread rapidly, and while I am satisfied it was the heated food that originated the disease, I am also satisfied that this change of food, from the mulberry to the orange, caused it to spread with greater violence, and become more fatal. T'aking all the circumstances together, my greatest wonder is, that the worms made any cocoons at all. In most any 
other climate than that of California, instead of fifteen thousand cocoons, they would not have made any.

My ill success at Agricultural Hall should in no manner discourage any one from engaging in the business of silk culture, as I am well satisfied that all disease can be avoided, and the business made a success in Sacramento and many other parts of the State, as well as at San Jose, where all my trials have been successful. But to be successful anywhere, fresh leaves right from the mulberry tree, and plenty of them, are absolutely necessary. And here I am very happy to be able to prove my opinion in this matter correct, by a very opportune example. I gave, among others who applied for them when I first came to Sacramento, to Wilson Flint, some worms, and on the twenty-eighth day of June, when Secretary Hoag and myself visited Flint, I was very much pleased to find that he had had excellent success with them, there being no disease among them, and nearly all had made very large and good cocoons. Others, also, have been equally successful, and in every case success has attended all who had plenty of fresh leaves to feed them.

I was not able in Sacramento to follow the California system of feeding. My mode of feeding is with branches containing the leaves, so placed as to cause the worms to climb upon them to get the food. The advantages of this system are: first, to save labor; second, the leaves keep fresh much longer; and, third, to give the worms plenty of fresh air.

Before closing this letter, I wish to return thanks to 
the citizens of Sacramento, generally, for the interest they manifested in the enterprise, and particularly to those who were so kind as to give the free use of all the mulberry leaves they had. I am also under obligations to the State Board of Agriculture for the use of the hall, and other kindnesses extended.

\section{Prevost.}

[From the Tehama Observer, January 3, 1866.]

S I L K .

We invite the special attention of our readers to the very interesting letter on silk, contributed by L. Prevost, Esq., of San Jose, one of California's pioneer farmers. What he says can be depended upon as the results of long experience in this State, and a thorough knowledge of the climate and productions of this and other countries. We take pleasure in saying, for his information, that there are thousands of acres in Tehama County of such land as he deems best adapted to the growth of the mulberry-in large tracts near the Sacramento River, and in smaller parcels along the many creeks. If Mr. Prevost, or Col. Warren, will have the politeness to forward to us the numbers of the Califormia Farmer containing the several articles alluded to in the letter, we shall be pleased to acknowledge the favor, and republish the articles for the advantage of our readers. If any of our readers wish to offer any remarks on this important subject, or on any other question-such as wool, cotton, flax, tobacco, fruit-of general interest, we will be most happy to hear them. 
[From the Tehama Observer, January 3, 1866.]

I. PREVOST ON SILK CULTURE.

\section{SAN JoSE, January 20th, 1866.}

Editor Tehama Observer,

DEAR SIR: Please accept my thanks for having. sent me the Observer, containing an article on "Silk Culture." I wish that all editors who publish anything on the subject would do the same.

My five years raising silk here have demonstrated beyond any doubt that California is the best spot on the globe for raising silk. In one of my letters to the Farmer, lately, in enumerating the advantages that we have here over France and Italy, I have fully established that we can produce silk here for the half of the cost there; and we will have the highest price of the market, our silk being of first quality - as I can prove by certificates from the highest scientific silk societies in Europe, to which I sent samples of silk cocoons and reeled silk to be tested.

Here, we have nothing to disturb the worms. Our climate is so very superior, that I was enabled to simplify the culture considerably. I made a new system, adapted to the California climate, by which one man can take care of and raise as many silkworms as eight men would in France or Italy under the old system, that the moisture of the climate obliges them to follow.

A very remarkable fact is that our climate, which is so favorable to the silkworms, is also extremely 
favorable to the growth of the mulberry trees, with which we feed them. It thrives here in California everywhere, but prefers a light, loamy, and deep soil. When at Sacramento, the first thing that attracted my attention was that very best quality of soil there; and after I had been shown some mulberry trees growing there, I found that I was not mistaken. In measuring the shoots of one year's growth, most of them were from ten to twelve feet long, and some as long as fifteen feet. Who can beat this? It surpasses everything ever seen before. I am told that there is any amount of such land in the Sacramento Valley, and I suppose it extends up to your locality, and perhaps further. I would like very much to know it. Many other valleys in California are probably as good.

It is impossible to calculate the hundreds of millions of dollars worth of silk that we can raise in Califormia; the silk being such a rich product that, in a few years, it will bring more to our State than all other products together; and I feel happy to see that our people begin to understand it, by the numerous letters that I am receiving every day on this important question.

Mr. Wilson Flint came to see me yesterday. I learned from this gentleman that he has already one hundred thousand mulberry trees planted, and that from cuttings and from seeds he expects to have about three hundred thousand mulberry trees. He has made arrangements to plant three hundred acres of his superior bottom lands, to begin with, and more after. He intends to have not only the largest silk establishment in California, but on the globe. 
With such inducements, we will soon have a silk factory in California, and our California ladies will soon, I hope, wear silk raised and made by their own hands.

To enable every one to raise mulberry trees for their own use, I published in the California Farmer, nearly two years ago, the culture of that tree by cuttings and by seeds.

Any information desired by any of your readers on this important industry, I am ready to give.

$$
\text { Yours, respectfully, } \quad \text { L. Prevost. }
$$

SILK CULTURE.

$$
\text { San Jose, Cal., April 23, } 1866 .
$$

Editor Tehama Observer,

Dear Sir: I have before me a copy of your paper, of the third of February last, in which you publish the letter I wrote you on "Silk Culture." I do not know if you have published anything since relating to that important branch of industry; if not, I consider it my duty to let you know very important facts. I see with great pleasure, in your editorial, that your section of country is, as I expected, similar to the soil that I have remarked round Sacramento City. Then you will soon see. silk culture established around you ; and I will feel 
happy to have contributed to the prosperity of your valley. Here are the facts alluded to.

I. I have been up to Sacramento about seven weeks, and I have the pleasure to inform your readers that "An Act to encourage Silk Culture in California" was passed at the late session of the Legislature, and is in such a shape that it is an encouragement for all who will engage in that rich industry, and is operative for four years. This is the best act of our last Legislature for the direct interest of the State.

- II. As I see the silk culture properly encouraged by the State, here is what I have agreed to do, to encourage it also: First, I will write, in a few weeks, the "California Silk Manual," in which I will give the culture, management, and propagation by seeds and cuttings of the mulberry tree ; and after, our simplified California silk culture or management of the worms.

III. I will do two public feedings of the worms; the first in San Jose, in our City Hall, commencing on the fifteenth of May next; and the second at Sacramento, in Agricultural Hall, commencing on the tenth of July next. It will take, at each place, to go through the whole process, six weeks. This will give an opportunity to all those who may desire, to learn how to raise silk in California. Knowing the places where I am to do it, and the dates of commencing, those living in the interior, in any section of the country, will go to the place nearest their residence; and if they are desirous to learn, nothing will be neglected on my part, to 
enable them to conduct the business-in showing and telling them all I know about it.

IV. Another very important fact that I wish to bring to the notice of your readers is, that inside of three months we will have at San Francisco our California Pioneer Silk Manufactory. This shows that we will have at home a market for our silk cocoons. Many persons have been telling me that it was no use to raise silk cocoons, because we had no manufactory, and consequently no market for them here. This objection does not exist any more, my friend Mr. Newman having sailed on the steamer of the tenth inst., for New York, where he will purchase all the necessary machinery, and it is anticipated that at our next Fairs, in the fall, we will be able to show the first piece of California silk, and of California manufacture.

V. I am receiving every day a great many letters on questions about silk from all parts of our State. This shows that a great interest is felt everywhere in this important industry. In the pile of letters on the subject that came during the time I was at Sacramento, I see that we have among us, in our State, all the men for every branch of this business, from the planting of the mulberry to finishing the manufactured silk. I also see in my letters from Europe, that silk growers, silk spinners, and silk manufacturers are preparing to come. This I am glad to see, because it will be a great benefit to the State, as the beauty of that industry is that it is the only one in which we do not fear competition; on the contrary we need it, and the more there 
are engaged in it the better. It is, then, our interest to encourage and help our neighbors to go into it. Our market for silk is the whole world, and we are bound to get the highest price for it, as our silk is of first quality; and another great adrantage is that we can raise it here for half the cost that it is obtained in France or Italy. I do not know if you have the letter in which I enumerated our advantages over the other countries; if not, and you desire it, I will send you a copy of it, and you and your readers will be convinced of what I say.

VI. Large plantations are already made in different parts of the State. A good number of them were commenced last season, the largest being that of Mr. Wilson Flint, of Sacramento. It is in connection with Mr. Flint that I am doing the feeding of the worms at Sacramento.

Now, Mr. Editor, reflecting a moment on the above facts, we ean say that the silk culture is virtually established all over the State, as our people will soon know how to do it. It is my opinion that there will be hundreds of new plantations the coming season, and those who set them out will do well; because, besides being a good business, they will get more of the premiuns offered by the State. It makes me hope that within a very few years we will be able to keep with us the seven mil. lions of dollars that we are now annually sending out for the importation of silk only. These are the wishes with which I remain,

$$
\text { Respectfully yours, L. Prevost. }
$$


[Mercantlle Gazette, December 18, 1866.]

SILK AND SILKWORMS IN CALIFORNIA.

L. Prevost, the persevering pioneer of silk culture in this State, writes from San Jose in part as follows.

We cannot too much encourage our friends to go into this branch of industry, which is bound to surpass in value, for exportation, all other California products taken together. They can enter into it with more certainty of success than in mining operations, because they have no opposition or failure to fear. The regularity of . our fine dry summers, without rain, storms, or electricity, which are the enemies of silk culture, insures regular, good crops every year. The beauty of this new industry for Calfornia is that it cannot be overdone. I say it is the only business in which we need not fear opposition or failure, because if it were possible to plant the whole State next year with full grown mulberry trees, and everybody engaged in raising silk, it would not lower the price of silk two cents per pound, as we have not only California, but the whole world for a market. Therefore it is our duty to encourage and help all who wish to engage in this business. For my part, I intend doing this: I will furnish persons desiring silk culture in their locality with their first silkworm eggs gratis. They will only have to furnish me their address, and the amount of food they have, so as to guide me in the number of eggs to send.

The work necessary to raise silkworms in California is

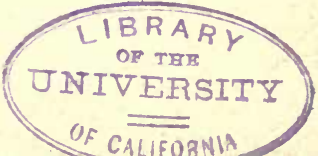


very little, as our climate is so favorable to that culture that it enabled me to simplify it considerably. In proof of this, I need only state that I have this last season raised over 100,000 silkworms, every worm making a cocoon; and all this with my own work alone. This is the work of eight persons in France or Italy. Our California silk culture is so simple that, as soon as it is published extensively, everybody in the State will engage in raising silk as well as any other production. If we consider it a moment, the quantity of silk that could be raised in California is immense; and it would afford employment to thousands of families, in raising as well as in manufacturing it. It is an easy work, that can be done by aged persons, as well as by the young of both sexes. Then our ladies would have a right to feel proud in wearing silk dresses made of silk raised by their own hands. In France and in Italy silk is raised very extensively, and millions of families are living by this work. The silk exported from Italy surpasses in value, by two-thirds, all other exportations together.

A remarkable fact is, that with our climate so very favorable to silkworms, we also have a soil well adapted to the growth of mulberry trees. They thrive almost every where in the State; but the best soil for them that I have yet seen is in the bottom lands of the Sacramento Valley. A large quantity of those trees will be planted there the coming season. I suppose some will also be planted in the San Joaquin Valley, where there is already quite a large plantation-that of Mr. Glessing-commenced last year. But the largest planta- 
tions in California are those of A. Packard and E. Goux, of Santa Barbara. Those plantations were made three years ago, and are now in fine condition. These gentlemen will raise the coming season a large quantity of silkworms, and will probably turn them to eggs. My own exhibit of silk, from five years raising, proves beyond a doubt that California is the very best spot for that culture. This, and the testimony which I receive from others, shows that this new industry for California is now fairly started.

'Two gentlemen, experienced, scientific, and practical silk growers, on their way back from China, where they had been to buy a large quantity of silkworms' eggs, recently came to see me, to get information about silk in California. I told them all the facts, showed them the cocoons and where I raised them, and also the mulberry trees. Being gentlemen who understood the silk business perfectly, they agreed with me that we have the best silk country in the world, and were so pleased at learning this fact that they are going to return here next summer with the necessary capital to buy one hundred acres of land each, to raise silkworms' eggs and silk on a large scale. These gentlemen are the representatives of the two largest silk houses in Europe, and are now on their way back to France. From them I learned a very important fact, namely, that our climate is so superior for silk culture that, by selecting our very best cocoons for eggs year after year for our own use, we could after a few years obtain cocoons that would beat everything known for size and quality - that is to say, a 
superior article. In this opinion I fully concur. The coming of these gentlemen from France will probably induce other silk growers to come also, which would be a great benefit to the State.

[Mercantile Gazette, January 9, 1866.]

SILK CULTURE.

Of cotton and silk we have made a successful beginning: of the former about 800 acres raised in 1865 , while of silk and silkworm culture the following communication received from L. Prevost, of San Jose, states that-

"Having noticed in your valuable paper an article alluding to the culture of the silkworm in California, and remarking your appreciation of the importance of this interest, I desire to give you briefly a statement embodying the result of five years' experiments. I stated several years ago my belief that the climate of California was superior to all others for the raising of the silkworm, and the attention I have since given this subject only strengthens that eonviction. It is also gratifying that this opinion has received the complete endorsement of two practical and scientific silk growers, representing the largest silk houses of Europe, who called upon me on their return from China and other portions of the globe. After examining the silk cocoons I had raised, they pronounced California the best country in the world 
for silk culture. Why this is so, is chiefly the absence of rain-storms, thunder, etc., during the feeding of worms in June. The first time I raised the silk, it was the prevailing opinion that it could not profitably be done, owing to the high price of labor. I was aware of the difference in this feature of California from other silk-growing countries; but it is equally a fact that for the price of renting one acre of land in Italy or France two or three acres can be bought here. This, with the employment of Chinese, equalized the labor question. To enumerate in detail a few of the advantages California possesses over other silk-growing countries, I note the following facts: In France and Italy, notwithstanding all the care which the climate forces growers to give the worms, they are more or less diseased-in the best years, calculating their loss at least 25 to 30 per cent., and often running as high as 75 per cent., while in California we have no loss of worms from disease, though treating them roughly. The climate so favorable to their culture is equally so to the growth of the mulberry tree, surpassing anything I have witnessed elsewhere. Of course the more food we have the more worms we can raise. In the silk countries already named, the land having been cultivated for centuries, is exhausted, and to sustain it a great outlay of money is required to properly manure and enrich the soil. Here all this is unnecessary, as well as the crection, as in other parts of the world, of very large and expensive buildings, with costly apparatus. A structure not costing one-quarter the amount usually expended answering 
every purpose, and which can afterwards be used for the storage of grain, etc. Neither is any outlay required for artificial heat. I simply transfer the eggs from the cellar to the garret, and the heat of the sun through the roof will make them hatch in three days. But above all is that by the absence of all elaborate apparatus, etc., thus simplifying the culture of silkworms, one person here can do the work of eight under the old system. You will remember I am not giving you crude ideas, but settled facts; and any reasoning person reflecting for a moment, considering the above named points, cannot fail to see the great advantages we have over all other silk-growing countries, not only raising our silk at half the usual cost, but as for reasons before given, being a superior article, we will get the highest market price. Then let us stop sending our millions to foreign countries, estimated at not less than from eight to ten millions of dollars annually; for as the Southern States are adapted to the raising of cotton-and we have our cotton States-so let California be our silk State. To parties in any part of the world who wish to engage in a sure and profitable business, easily understood, and one in which young and old can alike engage, I can say, come to California and raise silk. As soon as there is enough silk cultivated here we will have our domestic manufactories, and the ladies of California can be justly proud of wearing silk raised and manufactured in our own State. That this may be so, and that I can see our own manufactured silk shipped to other countries, bringing in return the thousands we now send away, are the wishes of your correspondent." 
ON SILKWORMS AND THE CULTURE OF SILK.*]

The Committee on these subjects have endeavored to perform the duty designated, but regret their inability to do full justice to the important trust confided to them.

Their especial attention was called to the exhibition of silkworms and cocoons, by L. Prevost of San José, who has, in the opinion of the Committee, most successfully demonstrated that California is one of the best, if not the very best silk producing country in the world. They have learned to their own satisfaction, not only from those who know something of Mr. Prevost's operations in this line, but, also, from personal observation during a visit to his cocoonery in San Jose, that Mr. Prevost is justly deserving of the highest premium the Institute can award him, for the commendable zeal and perseverance he has exhibited under the greatest difficulties, in successfully inaugurating this new branch of industry in our State. The demand, both for silk and silkworm eggs, is so extensive and constantly increasing, that the business cannot be overdone, but its successful prosecution must, in time, give employment to many thousands of our people, with a net profit of millions of dollars annually.

Mr. Prevost's simple narrative of his early efforts and drawbacks was exceedingly interesting to the Com-

* Report of the Committee on this suhject to the San Francisco Mechanies' Institute, at their Fifth Industrial Exhibition in 1865. 
mittee, and they induced him to commit to writing some of the leading facts, together with some remarks by Hentsch, which are hereby submitted, in the hope that they may not be lost or forgotten.

The Committee deem themselves not oversanguine of the great results to flow from the introduction of this important branch of industry into our State, when they hope and believe the day is not far distant when a gratified people will, through their Legislature, offer some public recognition of the services rendered by $\mathrm{Mr}$. Prevost.-Awarded a gold medal.

FACTS ON SILK IN CALIFORNIA.-BY L. PREVOST.

After I had passed a summer in California, I came to the conclusion that it was one of the very best countries in the world for raising silk, as well as wine, etc., etc., but the difficulty was to obtain, first, mulberry trees, and, afterwards, silkworm eggs. In 1863 or' 64 , I had occasion to meet with Mr. Henry Hentsch, who had the same opinion of our beautiful climate, and its adaptability for silk cultivation, and he, himself, began a conversation on that important subject. From that conversation was born the culture of silk in California. Mr. Hentsch imported the mulberry seed from France, from which I raised a number of fine mulberry trees. Mr. Hentsch was informed as soon as the trees were of some size, and he made arrangements to import silkworm eggs from China. They arrived here dead-it was impossible to hatch one of them. The following year he imported another lot from the same place, and 
with the same result. After this second attempt I was a little discouraged, finding that it was impossible to import eggs in good condition, and expecting to have no further use for my mulberry trees, I had the most of them destroyed, keeping only a few.

The third year, Mr. Hentsch imported eggs again from the same place, and at the same time from France. I was then very sorry to have destroyed so many of my mulberry trees, as the eggs from France proved to be in good condition, and hatched out very well. At that time I had a friend here, Mr. Miller, who was a competent silk cultivator, to whom I showed the eggs. He pronounced them good, and also agreed, for the first time, to help me, which he did. The worms did well, and produced fine cocoons of silk of the first quality, as I can prove by certificates from the two highest silk societies in Europe, to whom silk and silk cocoons had been sent to be tested.

Up to this time we have not been able to discover any indications of disease, which is most extraordinary; it must be the good influence of the climate of California operating as we expected. As I had no other room for the purpose, I have been obliged to raise the worms in a green house, which was extremely hot in daytime, and nearly freezing at night. Under such unfavorable circumstances, not one worm would have lived in Europe. Now, any thinking man can judge what success we might reasonably expect if we had a proper room in which to raise them.

The first year I made silk was in 1860 . I sent bou- 
quets of cocoons and silk to about every Fair all over our State ; they attracted the attention of visitors, but I received no encouragement. On the contrary, I heard many say that this culture could not be pursued profitably in California, on account of the high price of labor. I was aware of the apparent truth of this before I attempted the production of silk, but I thought for this kind of labor Chinese might be employed, who are used to the work; and, beside that, I knew that the price for buying three or four acres of land here does not exceed the price of renting one acre in $\mathrm{Eu}-$ rope, where silk is raised in large quantities. This advantage, I expected, would more than compensate for the difference between the price of labor in Europe, and Chinese labor here, because the silk grower in Europe has to deduct from his profits the rent of the land every year. But the question of labor is now fully settled, and silk can be raised in California with great profit. Calculating on the great superiority of our climate, I thought to try to take advantage of it, and I have succeeded in simplifying that culture even beyond my expectation. One man here can raise and take care of as many silkworms as eight men can do in Europe. As my mode of culture is adapted to the climate of California, I propose to call it California Silk Culture. It could by no means be employed either in France or Italy, where they have rains during the season of feeding, but might be used in any place where there is a climate similar to this.

The culture of silk in California is so simple that any 
one may understand it. It is easy work, and can be done by quite young persons, either male or female; the ladies, therefore, may have the pleasure of raising their own silk.

It will be a great pleasure to me to have contributed something towards the retention in our State of the millions of dollars that are paid out for the single importation of silk. Not only may we raise silk for our own consumption, but we can, in California, raise silk for the world, and export it. This article must increase in value; this year it is increased twenty-five per cent. in price in Europe. It is an article in which we need not fear competition; we need not be afraid to see our neighbor raising it, because, if nearly everybody was raising it all over the State, it would not lower the price two cents per pound. This year, when the price of fruits is exceedingly low, allows us to show the advantage of the mulberry over fruit trees, as the fruit must all be consumed within a certain time or it is lost, which is very far from being the case with the silk.

I have been engaged in my experiments in California silk culture three years, and this year raised over one hundred thousand cocoons.

Several gentlemen have made large plantations, so as to pursue this business hereafter on a larger scale. Among them I can name Mr. A. Packard, and also Mr. Q. Goux, of Santa Barbara, who have planted three thousand mulberry trees, and Mr. Glessing of San Joaquin Valley, whose plantation dates from last year. 
Besides what may be done with the silk, we have a constant demand for eggs by the European culturists, as there they have the disease, and to insure a crop have to get their eggs from countries where the disease does not prevail. By not using sound eggs their crop is very much exposed; but, besides all that, and all they can do, in their best years their losses are generally twenty-five per cent., sometimes fifty per cent., and, in very bad years, as high as seventy-five per cent. Here we suffer none of these losses, and, as there is nothing to cause disease, every worm makes a cocoon. This also merits some reflection and consideration in favor of the superiority of our climate. It would be quite too long to enumerate every thing in.our favor, but I cannot help remarking that the principal point is that the mulberry tree grows here most luxuriantly, and I believe, also, that our virgin soil produces leaves of the best quality. In order that every one may be able to raise his own mulberry trees, $I$ have published a treatise on the culture of that tree; both by seeds and cuttings, in the California Farmer, and also in the French paper. It is calculated that an ounce of silkworm eggs contains forty thousand; I have produced several millions of eggs this season, and they were all sold at the rate of ten dollars per ounce to be sent to France, and those for years to come are engaged for the same house. If I had them by hundreds of pounds I could sell them immeriately. The eggs are in great demand, also, for Mexico; I had an order for that country for five hundred ounces, but, of course, 
was unable to fill it. The largest order I had was for one hundred pounds, for Italy, and when I received that order I had only three ounces to sell. All this shows that in the future, besides supplying a large export demand for silk, we will also have to export largely of eggs.

The variety of mulberry to cultivate to obtain the best quality of silk is the white mulberry (morus alba) and its varieties, particularly the moretti. As to the multicaulis, I would recommend it only when the worms are very young, but not afterwards. The feeding of the worms continues only thirty-two or thirty-four days, when they make their cocoons, and twelve days after that they come out butterflies, and lay their eggs for the following year. They have to be kept in a cool, dry cellar to prevent them from hatching.

Each female is expected to lay about three hundred eggs. 'Three hundred good cocoons weigh about one pound, and an ounce of eggs can produce one hundred and sixty-five pounds of cocoons; twenty-eight ounces of selected cocoons give two ounces of eggs.

REMARKS OF MR. HENRY HENTSCH.

The memorandum of Mr. Prevost contains valuable and correct information about California silk culture. The main point on which the report must attract the attention of the community is this, that California has one of the best, if not the very best climate in the world for producing silk successfully, on account of the absence of rains and storms during the months of 
May, June, and July, which, prevailing in Europe, kill millions and millions of silkworms annually.

The second point is, that it does not require any capital-or, at least, very little-merely the purchase of the mulberry trees, which may be planted around the farms, cottages, and country residences.

The shade of the mulberry tree is as good as the shade of the cotton-wood tree, and the fruit is very good for poultry. When the trees have grown up, the children and women may start in the silk trade, as it requires only the labor of gathering leaves to feed the worms, and that occupation takes only six weeks. It would be useless to go into further detail, as the practice is ten times more valuable than the theory. There are in California a great number of Italians and Frenchmen who understand the silk-raising business, and it will be very easy to have information and directions when wanted.

The point to be first attended to is the planting of mulberry trees, which involves but a trifling expense for the present, and may prove of very great value in a few years.

\section{Henry F. Williams, Samuel 'Tyler,}

Committee. 


\section{CHAP'TER I.}

OUR CLIMATE-ITS SUPERIORITY AND ITS ADVANTAGES.

I wish you, gentle reader, to allow me to have a talk with you on our climate, as it is impossible for me to write this book without beginning with that genial silk climate. I have already written and said that we were in the best silk country in the world; and I still maintain the proposition. This will oblige me to make a few general remarks, on what I consider the most important point; because our strength here is simply in the superiority of our climate for the silkworm, and the adaptability of our rich soil for the mulberry. It has been said: "Wherever the mulberry finds a congenial climate and soil, there also the silkworm will flourish." Such climate and soil has California in a pre-eminent degree.

The silkworm requires a pure atmosphere for the preservation of his health; and we have it here.

It has been observed in Toulouse, the healthiest part of France, that the silkworms raised in the huts of the poor peasants, and.enjoying the pure air through the cracks and broken windows, were better than those raised by the rich. This shows that they need pure air. We can supply them with any amount of such air.

But who gave me the idea that we were in a silk country? In 1850, after I had seen the first summer, it was the observing our fine climate without rain from May to October; and, consequently, without storm and 
thunder-without any shock of electricity; in fact, nothing to trouble the silkworm: on the contrary, any amount of sunshine, that causes the mulberry leaves to be of the first quality. This contributed largely to their health, as healthy food makes healthy worms.

Having no other room that I could use in 1860, when I raised the first silk in California, I had to -do it in a little green-house-a very bad place to raise silkworms, as they need to be in as even temperature as possible; but in no other place does it vary so much as in a green-house, as you have a suffocating heat during the day, and it is very cold at night. From what cause have I succeeded so well in such a place? Our climate!

For two years I have raised them in my garret. It is well established that the silkworm needs plenty of air; there I can give hardly any. Why then have they succeeded so well there also? From the climate.

Another fact, in which all the silk-growers are agreed, is that the room in which you are to raise your worms must be free of smells, and particularly the smell from the kitchen! Mrs. Sauffrignon, in San José, raised worms in her kitchen near her large stove, on which she has to cook for a large family; and there she had large, strong, lively and healthy worms, who made the finest and best cocoons that we had on exhibition at the Fairs this year. How is it that she had such a result in a kitchen? The answer is, from our climate. The worms, eating fresh mulberry leaves 
grown constantly under the rays of a genial sun, can't fail to be healthy and make good cocoons.

I could put here many more examples, but I think these are all-sufficient to prove the superiority of our climate for silk culture.

I do not mean by the above to advise any one to do the same ; on the contrary, I will do all I can in this manual to make every one understand that they must not do it: I have done it simply because I could not help it. The above facts are merely to show the power of our fine climate. It was also the climate which induced me to change the culture from the system pursued in France and Italy, in order to curtail the work. Such a superior climate offers us many advantages. These advantages are enumerated in a letter that I sent to the "California Farmer," dated December 21st, 1865, and published in the first number of January last; it reads thus :

"Dear Sir-In my letter of November 12th, which you published in the 'Farmer' of November 17th, I say the enumeration of facts in favor of silk culture in California are many, and they will be the subject of another letter as soon as possible; and, as it is too cold to work outside, I concluded to remain indoors and devote a few moments to that purpose.

First-The question of labor we settle at the start. That question, before I made any silk, was settled in my own mind. I was aware of the difference in the price of labor here, compared with that in France and Italy, but thought that we could make up the difference 
by first employing Chinese to do the work, as it is labor to which they are accustomed.

Second-That the price of buying two or three acres of land in California does not exceed the price of renting one acre in France or Italy, where silk is raised largely; because if any one goes into the silk culture with the intention of making it a business, he is not obliged to do so in the neighborhood of cities where land is high; he can do it where land is cheap and can be had for a mere trifle. It does not necessarily lie near a railroad or a fine wagon-road, because in this branch of industry there is no teaming, as a man can carry on his back or on a mule many thousand dollars' worth of silk. The most important point is to find the suil more suitable for the growth of the mulberry tree, no matter where the place is. This will render very valuable some very fine rich little valleys that happen to be between the mountains.

It is very important to understand that in France and Italy the silk-grower has to deduct every year, from his profits, the large rent he has to pay. ' It was my intention to have the question of labor settled at the first start. Now, any thinking man reflecting and considering these two facts will see, at once, that not only they make up for the difference of price of labor in case we should be obliged to raise silk with as much work as they have to bestow in the above named countries, but leave a good balance in our favor; and what I have to say now will all be proof in favor of silk culture in California, and show that we can raise silk here cheaper 
than in any other country, and not have to sell it cheaper: on the contrary, California silk, by the superiority of the climate, is bound to be a superior article, and consequently will command the market in all parts of the world. This question having been settled we will leave it, and go on to the advantages which we have over others.

Third-We come to a great point that deserves attention. It is, as I have said in some of my previous letters, that in France and Italy, with all the care which the climate forces them to give to the worms, they are more or less diseased; and, in their very good years, they cannot calculate their losses at less than twenty-five or thirty per cent.; and, in bad years, fifty per cent.; and I have been told that in very bad years the losses have been as high as seventy-five in one hundred worms. What do you think of that? Should not this fact alone be enough to make everybody wish to go into the silk business, when we consider a moment the power of our fine climate on the silkworms, that even after treating them here very roughly, we have no disease to observe, consequently no losses, and every worm makes his cocoon? It is very simple and easy to understand why it is so, because they have there, during the feeding time, rain, thunder and lightning-which are the enemies of the worms ; whereas here, as everybody knows, at the time of feeding, (June) we have nothing of the kind, nothing to create disease among them. That is where our superiority over other countries lies. We have a fine and regular dry season at that time, and it is this regu- 
larity that insures to us in the future good crops, and no loss or failure to be apprehended ; all those living in California can see that this is the truth.

Fourth-The climate that is so favorable to silkworms is also, in the same proportion, as favorable to the growth of the mulberry tree; and this is very important, because we cannot expect to raise silk without the mulberry tree, for it is the foundation of that culture; and the more we grow the more silk we can raise. The mulberry tree grows almost everywhere in California, but when it happens to be in the soil that suits it best its growth is extraordinary; there is no other tree to compare with it: you can hardly believe when you see it. The bottom lands of the Sacramento Valley are about the best that I know of for the mulberry to grow rapidly. Our valley has some favorable spots also, and I started a few weeks ago to see two mulberry trees that $I$ heard of, and was very much surprised at finding them so large; being, I suppose, the largest in the State. 'The proprietor assured me that he planted them only about seven years ago. This is also a positive evidence that in the growing of mulberry trees we surpass all other countries.

Fifth-In the silk countries referred to above, the land has been cultivated so many years that it is exhausted. They have to buy manure, which sells there very high ; they have then to cart it, and sometimes from a great distance; they have the work of spreading it on the ground and putting it in ; and the labor; and the 
buying of the manure is costly. We have no need of that here, as we have a virgin soil to plant in.

Sixth-They have to erect very large and costly buildings, for the sole purpose of raising their silkworms. In these buildings they have all kinds of apparatus, all of which costs a large amount of money. We have no need of all this ; our only requirement is a room to raise our worms in, but not a costly one ; and, as to the apparatus, we do not require any at all.

Seventh-They have to use artificial heat, which is also very costly. We use nothing of the kind here ; when we need more heat it is 'for hatching the eggs. When I want mine to hatch I take them simply from the cellar to the garret, and the heat of the sun through the roof is sufficient to make them hatch within their regular time.

Eighth-We now come to the most important part, and that is to turn the mulberry leaves into silk. This requires much labor in France and Italy, but here it is almost nothing. As I found our climate so very favorable I thought I would take advantage of it, and succeeded certainly beyond what I expected, having been able to change the culture to one adapted to our climate, and in reducing the labor to one-eighth of what is required by the old system. It seems to be so extraordinary that some persons would hardly believe it; but it is a fact, and I am ready to prove it at any time before any committee that may be appointed for that purpose, composed of the very best and most competent men in the country. I will here state to my readers 
that I wish them to remember that my rule is to write nothing but what I am convinced of, and what I can prove; this being well understood, I wish them not to forget it. I am not a writer, but I do the best I can to be understood and convey my ideas. Now this great reduction of labor, if it was well understood, is enough to induce every one to go into that important branch of industry. I will simply say here, let every reasoning man peruse and reflect on the above facts, and $I$ am sure that he will become satisfied that we can here produce the silk with profit, for half the price that it can be done in France or Italy. But we have no reason for selling it at half price; our elimate being so favorable for it the California silk is bound to be a superior article, and consequently will command the highest market price."

\section{CHAPTER II.}

\section{SILK IN CALIFORNIA.}

It is my intention, in about two years, to write the History of Silk in California ; as I have been raising it here for six years, and am consequently acquainted with all the incidents of its introduction and culture into this State. I have many interesting documents, letters, etc., to publish, all of which will show how I have been discouraged at the start, instead of being encouraged, 
as should have been the case in such an important culture. But all this had no influence on me. I had such a firm confidence in our beantiful silk climate, that I did not take any notice of all that, and still persisted. And more, (I must confess it to you in secret) I could not help having a certain contempt for all those that had objections to it, as it appeared to me like refusing to acknowledge that it is daylight at noon.

As it will require a large volume for the history of Silk in California, I do not intend to put it here; but I think that I must say a few words about it, being as brief as possible.

After I had spent the first summer here, in $\mathbf{1 8 5 0 ,}$ I judged that it was a silk climate, and took occasion to speak about it to different persons. In the fall of 1852 , I had a long conversation on that subject, for the whole evening, with Henry Hentsch, Esq., of San Francisco. He was, and had been, also of the same opinion; but there were no mulberry trees to be found in the State to try that culture. It was then agreed that $\mathrm{Mr}$. Hentsch should import the seed from France. When they came, in 1854, I sowed them, and they grew out finely. After the trees were of sufficient size, I told Mr. Hentsch that it would be good now to import silkworms' eggs. He procured some from China; but the eggs were bad, or had been spoiled on the voyage; none of that first importation hatched. 'The year after, some more were proeured, with the same result. For the third time, Mr. Hentsch ordered some more, again from China, and at the same time ordered some from France. 
They all arrived here early in the spring of 1860 . When they arrived I showed them to a friend, Mr. Jacob Muller, a competent silk-grower; he thought that the eggs were good, at least some of them. It proved afterwards that the Chinese were not very good, as one or two dozen only hatched; but the lot from France hatched out finely. My friend Mr. Muller helping to get this lot of worms through, they produced fine and superior cocoons. Samples of these I forwarded to France, and they were found to be of first quality.

The same year (1860) I sent cocoons, bouquets of cocoons and real silk, to all our Fairs, all over our silk State; but the officers of the different societies at that time did not understand their duty, and the importance of that rich culture, as they were giving silver goblets, etc., (as their lists of premiums show) to things that could not advance the interests of the State one dime, and did not even give a diploma to the first California silk, with the exception of one, the San Joaquin Valley Agricultural Society, which had the honor of giving a diploma to the first silk producer in California.

Since 1860 I have always raised the silk, but never observed any disease among the worms, notwithstanding that $I$ have raised them in bad places, not being able to have any thing better. I have changed the mode of feeding so as to curtail the work. This will be described hereafter, at its proper place.

In 1865 I raised about one hundred and five thousand worms, and consequently the same amount of cocoons, and had a great number of visitors, among whom was 
Mr. Plum, the President of the Mechanics' Institute in San Francisco. He urged me strongly to exhibit at their Fair; but as I was not satisfied with the results of my first exhibitions, I did not care to do so any more. When their Fair was open, not seeing me coming, my old friend Mr. H. F. Williams, of the same Institute, came with two other gentlemen and persuaded me to go, and I made there a fine exhibition of silk, silk cocoons, silkworms, and silkworms' eggs; and then for the first time I had the pleasure of seeing my humble efforts appreciated. The next day our leading papers had fine articles on silk; and my exhibition attracted the attention of the visitors, as I had the crowd all the time. A gold medal has been awarded to it. At the request of their presidents, I went to the State Fair, and also to Stockton; and at both places it created as much interest as in San Francisco, and gold medals were also given. Besides a good many plantations made before, since these exhibitions the silk culture has been fairly started.

Last year, also, Mr. Newman, a practical weaver, came to see me, and from the information I gave him, some time after, in connection with one of his friends, Mr. W. W. Meyer, he went to the Eastern States to buy all the machinery necessary for a silk manufacture. He came back this year, in July, with the machinery. Two looms have been put up in San Francisco, and the first pieces of silk manufactured in California were ready in time to be exhibited at our Fairs in September last. Now, with some inducements on the part of our 
citizens here in San José, we have succeeded in having that Pioneer Silk Manufacture located here. They are progressing rapidly, and already a large frame building is erected, where they are busy unpacking, cleaning and fixing the machinery. They are now also busy at the main building for the manufactory. It is a brick building, forty-five by eighty, and is to be two stories high.

I have this year again exhibited reeled silk and silk cocoons from different varieties, and also good samples of cocoons, raised in different parts of the State, by different persons, who never had silkworms in their hands before, and who had all succeeded. This is conclusive proof of the superiority of our climate for silk culture, because those who have never done it before are liable to make many mistakes. But no matter here; the worms make their cocoons anyhow ; and now, with the Manual, everybody will be enabled to undertake the culture of silk with full success.

Then let us begin it in taking first the mulberry tree, which is the foundation of that rich culture. 


\section{CHAPTER III.}

HISTORY OF SILK-ITS ANTIQUITY AND COMMERCE.

Silk, or the splendid material produced by the silkworm, was first known in ancient times as ser or serica, in China. It was there first discovered in its own native forests of the mulberry trees. In that country it was called $s e$, and by transition, ser by the Greeks, and sericum by the Romans ; and hence, by the different nations of Italy, France and England, it-is variously called seta, soie, and silk, at the present day.

The silkworm, or bombyx mori, is a precious insect, which is thus denominated from morus, the plant on which it feeds.

The cultivation of silk commenced in China seven hundred years before Abraham, and two thousand seven hundred years before Christ. The Emperor Houng Ti, "The Emperor of the Earth," who reigned over China more than one hundred years, taught the Chinese to construct houses, ships, mills and other useful works; and the Empress Si Ling Chi, to contribute also to the welfare of the Empire, aided by the women of her household, gathered the silkworms from the trees, took them to her apartments, fed them with leaves of the mulberry, and, being sheltered, they yielded silk superior in quality to that produced in the forests. She also taught them its manufacture, and how to embroider. Raising silk, and its manufacture, and the weaving, 
continued to be the principal occupations of the succeeding Empresses. Apartments were appropriated to this purpose in the imperial palace; and soon, from the highest rank of females, it became the occupation of all ranks in China; and ere long the Emperor, the learned class, the Princes, the Mandarins, courtiers and all the rich were attired in the splendid fabrics of silk, until finally silk became the great and inexhaustible source of the wealth of China. From China it was exported to India, Persia, Arabia and the whole of Asia.

The expeditions of Alexander to Persia and India first introduced the knowledge of silk to the Grecians, three hundred and fifty years before Christ; and with the increase of wealth and luxury in the Grecian Court, the demand for silk prodigiously augmented. Persia also became rich in the commerce of silk, which they procured from China. The ancient Phøenicians also engaged in the traffic of silk, and finally carried it to the east of Eurove.

At Rome, and so late as A.D. 280, a silk attire of purple was accounted by an Emperor as a luxury too expensive even for an Empress; its value being equal to that of gold by weight. .

In the sixth century two monks arrived at the Court of the Emperor Justinian, at Constantinople, from a missionary expedition to China. They had brought with them the seeds of the mulberry, and communicated to him the discovery of the mode of rearing the silkworms ; and although the exportation of the insect from China 
was forbidden on pain of death, yet by the liberal promises and persuasions of Justinian, they undertook a new expedition, and at length returned through Bukaria and Persia to Constantinople, in 555, with the eggs of the precious insect concealed in the hollow of their canes or pilgrims' staves, which they had obtained in the far and still more distant country. Until this time the extensive manufactures of the Phoenician cities of Tyre and Berytus had received their supplies of raw silk through Persia from China. Even to the days of Justinian, according to ancient historians, no person at Constantinople knew that silk was the product of an insect. It was generally supposed to be produced from the bark or leaves of trees, or growing like the finest hair from their branches.

In Greece, the culture and manufacture of silk soon overspread the country. The noblest families aided by their example. The people of Thebes and Athens, from the time of Justinian, cultivated and manufactured silk for four hundred years; and the Venetians, in the height of their prosperity and commercial glory, carried supplies of silk from Greece to the whole West of Europe. On the downfall of the Roman empire, Arabia became the seat and center of sciences, of arts and civilization. The establishment of the Turkish power in Asia, about the middle of the sixth century, and the subsequent wars, caused great interruption to the caravan trade between China and Persia; and after the conquest of Mahommed II., the Saracens or Arabians planted the mulberry and encouraged the culture of 
silk everywhere throughout their dominions, both on the islands and on all the shores of the Mediterranean; silk and mulberry trees were introduced into Spain and Portugal by the Arabians, on their conquest of those countries, in 711.

From Greece, the cultivation of silk was introduced to Sicily and Naples. Roger, king of Sicily, in his invasion of Greece, in 1146, introduced, by compulsion; many silk weavers and manufacturers, whom he carried to Palermo. In twenty years the manufactures of Sicily became famous, being adorned with various colors and figures, interwoven with gold and embellished with pearls. Here it long mysteriously remained; and it was not till 1540 that it had extended to Piedmont, and indeed to all Italy. So extensive is its cultivation at the present day throughout Italy, that, according to Count Dandolo, two-thirds of their whole exports to all countries consist of silk.

Its first introduction into France was in 1494 ; but no very important results succeeded until, in 1564, Traucat, a gardener of Nismes, established the first foundation of a nursery of white mulberry trees, with an effect so successful, that from this source the cultivation extended within a few years, over the whole of the southern provinces of France; but its final, and more complete establishment in France, in 1603, is due to Henry IV., who encouraged the formation of nurseries and the manufacture of silk, even in the northern as well as middle provinces of the kingdom, and whose name is held in perpetual remembrance, for his noble deeds of 
goodness, and works of usefulness. Olivier de Serres shares equally with him the glory of the effectual work, which was, at first, opposed even by Sully, from mistake and misapprehension. Colbert, in a succeeding age, continued his fostering care. Both Colbert and his illustrious predecessor, by bounties judiciously bestowed, caused both the mulberry tree and its culture to strike deep and permanent roots in the soil of France.

Once established, it has stood, unmoved by every revolution and storm, unprotected and alone, while all things else have fallen. This important industry has flourished until, finally, silk and its manufacture has become one of the most productive resources of the wealth and power of France.

It was estimated, that in the year 1835, silk from France, to the amount of fifty millions of franes, was exported from that country to the United States alone. Yet, in France, although they raise so much silk, they still import annually to the amount of seventy millions of francs of raw silk, or nearly one-third of all they consume in their manufactures.

In England, the climate, from its humidity, or other causes, is found to be unfitted to its growth. For this reason alone, the trials to raise it there have failed. Yet, from 1821 to 1828 , according to an authentic work on the silk trade, they imported of raw silk, 24,157,658 pounds, worth $\$ 120,787,580$; of this amount $\$ 59,881,283$ came from Italy alone.

The sudden and extraordinary extension of the silk manufactures, both in France and in England, has been 
mainly ascribed to the machine invented in France, by Mr. Jacquard; then the powerful impulse thus given has been assigned to the Jacquard loom. This loom is stated to perform all those labors which had heretofore been confined to the most skillful hands, with important economy of time and labor in the preliminary steps; and is so decidedly superior to all other looms for all the curious varieties of figured silk weaving, that it has superseded them all throughout France and England.

Yet, in our own country, so highly favored in all respects by nature, the successful introduction of the silk culture is mainly due to individual exertion; but the day is not far distant, when the cultivation of the mulberry and the growth and manufacture of silk in the United States will become a very important source of wealth to the nation. The work has wonderfully begun, and is now taking deep and permanent root in our soil.

According to the report of the Secretary of the Treasury, the value of silk imported into the United States during the year ending the thirtieth of September, 1835 , amounted to $\$ 16,597,980$, this being the original or first cost in the foreign countries (this must be more than double that amount now). During that year only $\$ 486,562$ worth of this great amount was exported; most of it was imported from Italy, Switzerland and France.

The millions that we are now expending for importing silk ought to be preserved in the country. It would be a good policy to take steps in view of retaining such a vast amount, by every means that the Government has 
in its power. Such amounts would soon pay our national debt; it should certainly be a good policy to take off duties from things needed by the poor classes, and have very high duties on the imported article manufactured. I am in hope that our Congressmen will understand their duty, which is to have in view the prosperity of the country, by placing a very high tariff on the manufactured silk of importation. This will injure nobody, but enrich the country, as the effect will be to start the culture and manufacture of silk everywhere in the United States where the climate is favorable. In California alone we can raise silk, not only to supply the whole wants of the nation, but for the rest of the world.

\section{CHAPTER IV.}

HISTORY OF THE SILKWORM.

The silkworm, or Bombyx Mori, is a caterpillar, its body formed of twelve membranous rings, which support the legs, which are sixteen in number, and in pairs. Six of these are in front and inflexible, and situated beneath the first rings, and are each covered with a scale. The other ten are flexible and membranous, having their positions beneath the remaining ring; these are called climbers and holders, and are provided with sharp hooks or claws, to aid in climbing. The head has a horny covering like a scale, the jaws are very strong, 
the teeth, sharp, serrated, or indented like a saw, the mouth is vertical and peculiar, and not horizontal, as in most other beings. Two broad objects in its forehead, which might be mistaken for eyes, are but bones of the skull. The eyes are small, fourteen in number, seven on each side of the head, and near the mouth; the organs of respiration are eighteen in number. Equidistant, and situated along the body, are holes, or openings, nine on each side, which serve for breathing.

The substance of which the silk is composed is a liquid, transparent gum, of a fine yellow color, and is contained in separate sacks of slender dimensions. Each of these vessels is about ten inches in length, and wound in the stomach in spiral folds. Near the jaws, two ducts convey the silken fluid; these, uniting in one, serve to compose the silken thread, which is usually from four hundred to twelve hundred feet in length.

The eggs of the silkworms are of a dark lilac or slate color. The silkworms are at first black, and extremely small; as they advance in age and size they cast off their outer covering or skin, usually from three to four times, at different periods, according to the variety. 'These successive changes are called moiltings, and the times intervening are termed ages.

In a colder temperature the duration of the several periods is prolonged; but in a warm climate, the period or season of the first moulting, which terminates the first age, usually occurs on the fifth or sixth day of its existence; the second on the eighth or ninth day; the 
third on the thirteenth or fourteenth day, and the last on or about the twenty-second day.

At each of these critical periods the silkworm remains in a torpid state, eating little, or absolutely nothing, for a day or more. At the end of about ten days from the last period, or in about thirty-two or thirty-four days from the beginning, the insect, now fully grown, is about three or four inches in length, transparent, of a yellowish white or pearl color. Having now completed their fifth, or last age, they eat no more, but ascend to the leaves or brushwood which are placed for the purpose, and commence the formation of their cocoons, and in the construction of these the insects work busily and incessantly, night and day, during about four days. This labor finished, the insect in the center becomes transformed to the chrysalis state.

The vitual functions of the silkworm are accelerated by warmth, and the time occupied in passing through. the various mutations is hastened, not only by the increased temperature, but materially by the degree of attention which is bestowed on the insects. In Madras, according to Dr. Anderson, and where the climate is very warm, the silkworm passes through all its evolutions in twenty-two days; here there is a saving of time as well as of labor, but none in regard to food, as it is admitted the silkworms consume the same amount of cocoons, be the term of their life of a longer or shorter duration.

The cocoon is usually from an inch to an inch and a balf in length, of an oval form, the color yellow or 
straw, or pure white, according to the variety. The outer covering is like the finest wool, and is called floss. It is easily detached, and being removed, the end of a thread is discovered, of extreme fineness.

After an interval of from fifteen to twenty days' repose, the moth ejects from its mouth a liquor which moistens the gum, and dissolves the adhesiveness of the texture of the ball; and by frequent motions of its head, it loosens and forees aside the filaments, without sundering a single silken thread, until it reappears, transformed to a large butterfly, of a greenish white color, with four wings; two eyes, and two black feathery horns or plumes; unshrouded in this its last and perfect form. Both male and female, they come forth to the light of the day, and take no food to the day of their death.

The butterfies generally come out of their cocoons between seven and nine o'clock in the morning. At that time they have to be paired, and in the afternoon at about five o'clock, they should be separated. In all cases, they must be handled by the wings, with care, so as not to hurt them. As soon as separated from the male, the female begins to lay the eggs. Each female is supposed to lay about three hundred, and sometimes more. These eggs firmly adhere to the paper on which they are ; and are arranged in a handsome and circular form. In a few days after its multifarious labors are ended, the insect dies.

The silkworms remain in a chrysalis state a length of time corresponding with the temperature of the climate. 
In England they remain thirty days ; in France, twentyone ; in Spain and Italy, eighteen or twenty; in our Middle States, about the same; in California, twelve to fourteen; and in India, but eleven days.

The silkworm, like other caterpillars, is a cold-blooded insect; its temperature is that of the atmosphere in which it breathes. Sudden changes from cold to heat are very injurious, yet it has been found that the silkworm is capable of enduring a great degree of heat. I have remarked them to be very lively when my thermometer was from eighty to one hundred, and some days as high as one hundred and seven. This heat ought to have been maintained as uniformly as possible, yet it was impossible in my garret. Such a degree they must have sometimes endured in their native forests. But when they need more heat, it is at the moment of making their cocoons. If at any time while they are performing this most important labor they are permitted to suffer from cold, they cease from their labors, and remain inactive, or move but slowly, as may be diseovered while the cocoons are yet transparent. It has been proved, on dissection of the silkworms which thus suffer and become torpid through cold, that the glutinous matter in their silk reservoirs had become so congealed and tenacious from cold, as to resemble strong tendons, which sufficiently accounted for the inability of the insect to draw forth the silken filament; yet no sooner is the temperature increased, than they will resume their labors with increased activity; but will again desist, if exposed again to cold. If neg$8^{*}$ 
lected at this critical period, they assume in due time the chrysalis form, but for want of sufficient strength leave incomplete their silken tomb.

Many persons have erroneously imagined that light is injurious to the silkworm; but the very reverse of a belief so contrary to nature, is evidently true. In its native state, it is of course habituated to the most perfect light; indeed, a due proportion of the reviving light of day has been found essentially necessary to its perfect health. In the perfect light of day, when the sun shines, the leaves of the mulberry and other trees inhale vital air, or that pure, etherial substance, which by being inhaled, gives life and heat to the animal system; while in the darkness, they evolve mephitic air, which is destructive and incapable of affording nourishment.

Although the silkworm will endure a great degree of heat, yet when this heat is combined with excessive moisture, the effect appears to be at least as deleterious to the insect as mephitic air. If a silkworm be confined in a close vessel, surcharged with moisture and heated to eighty-eight or ninety degrees, it will soon reject food and show strong symptoms of distress; the muscles will soften, and evaporation will become obstructed; the power of contraction, which resides in the skin, and which governs the secretions, which are indispensably necessary to its existence, will cease, and it will shortly perish; while a warm-blooded animal, if sufficiently supplied with pure atmospheric air, will endure an equal degree of heat, combined with an 
equal degree of moisture with but little inconvenience.

But if a silkworm be introduced into a jar charged with carbonic acid gas, which would cause a bird or any other warm-blooded animal to die instantly, although the worm will soon exhibit signs of suffering, yet it will live from ten to twenty minutes; and on being withdrawn from the receiver, in due time it will exhibit no signs of injury, but be apparently as healthy as before.

Some have supposed that noise disconcerts them; but this appears to be a mistake, or at least not sufficiently proved: on the contrary, the experiments of the Abbe Rosier, in France, tend to show that it does not trouble them at all.

\section{CHAPTER V.}

THE MULBERRY-(Morus).

The Mulberry, or Morus of the botanists, is a genus comprising many species. It derives its name from mor; in celtic, black. Its origin has been assigned to China, but several species have been found growing in the wild state in America.

It was cultivated at a very early period of time, in western Asia, and in Europe ; but at first only for its fruit. This is a berry of a roundish and oblong form; in color varying from white to red and black; its pulp envelops numerous small seeds. 
Most of the varieties of the mulberry are esteemed dessert fruit. When perfectly mature, they are grateful to the taste, and very wholesome. The syrup is useful in mitigating inflammation of the heart ; the juice, when perfectly fermented, affords a pleasant vinous wine; mixed with apples, it makes a delicious beverage called mulberry cider, of a deep red color, like port wine.

The wood of the mulberry is compact, elastic, and hard, and susceptible of a fine polish ; it is, therefore, sought after by the upholsterer, the carver, and the turner. The strength of the timber renders it valuable to the joiner, and also for building boats ; its power of resisting the action of the water, has been compared to that of the oak.

The roots of the mulberry tree are of a yellow color and strike downwards, and the tree is extremely longlived. Mr. De Saint Fond saw, in 1802, one of the original or parent trees of all the white mulberry trees of France, which the followers of Charles VIII had brought from Italy, on his invasion of that country in 1494. Mr. Lachaux has eaused this tree to be encompassed by a wall, to evince his respect and veneration, and to serve as a monument to a tree so inestimable.

Whoever would enter extensively and at once on the cultivation of silk, let him first of all bestow his attention on the culture of the abundant supplies of food; this principal and essential food being no other than the material leaves of the various species of the mulberry tree. Not every kind, however, is equally suitable. 
Linnæeus has enumerated seven species of those which were known in his day; and among these there are two species, the Tinctoria and Indica, which are not used as the food of the silkworm. Those most esteemed and known are the Morus Alba, or white mulberry, the Morus Multicaulis or Chinese mulberry and the Morus Moretti. I will, then, describe only these three varieties, as being the best.

The nourishment which is contained in the mulberry leaf is not completely developed till the leaf is fully grown. According to the analysis of Count Dandolo, the leaf contains : 1st, the fibrous substance ; $2 \mathrm{~d}$, the coloring matter; $3 \mathrm{~d}$, water; 4 th, the saccharine substance; 5 th, the resinous substance. The saccharine substance is that which nourishes the insect, augmenting its growth and size; the resinous, that which "separating itself gradually from the leaf, and attracted by the animal organization, accumulates, cleans itself, and insensibly fills the two reservoirs or silk vessels." The proportion of this nutriment depends upon the variety of the mulberry, the age, the soil, and the moisture or dryness of the season. Now, I will describe the three best varieties of mulberry trees for silk raising.

First, Morus Multicaulis, or Chinese mulberry, or also many-stalked mulberry. The tree grows vigorous, upright, and beautiful ; the leaves, large, soft, and tender, are petiolate, cordate, accumissate, serrated towards the summit, marked with nerves, always entire. Their upper surface is convex or curled, of a deep and beautiful shining green. The 
form and dimensions of the leaf vary in different soils; in a dry and arid soil, they are of a diminished size ; their form elliptical, and without the heart-shaped indentation at the base; their breadth being six inches, and their length eight; but in a light, rich, and friable soil, the produce of the foliage is most abundant; the leaves large and cordiform, measuring often more than a foot in breadth and fifteen inches in length.

That variety is sometimes called the Perrotet Mulberry, in honor of Mr. Perrotet, agricultural botanist and traveler of the marine and colonies of France, who has introduced this plant into Europe. Mr. Perrotet has been sent out by the Government of France on a voyage of botanical research, a national ship having been provided especially for his use. This tree was first discovered by. him at Manila, the eapital of the Philippine Islands, whither it had been brought by the Chinese from China, as a tree of ornament as well as of usefulness. The Chinese are justly entitled to the credit of its introduction hither. From Manila the morus multicaulis was first introduced by Mr. Perrotet to the Isle of Bourbon, and from thence into Cayenne; and, finally, it was brought by him to France in 1821 .

The morus multicaulis differs from all others in the uneommon vigor of its growth, and the property which the roots possess of throwing up numerous flexible stalks, the great length which these stalks acquire in a short space of time, and the facility with which it is propagated from layers and cuttings; also from the remarkable size which the thin, soft, and tender leaves speedily 
acquire, and the promptitude with which they are renewed.

The fruit is long, black, and of good flavor. This mulberry should be cultivated low in rows, and never suffered to rise high. A few years will be sufficient to raise considerable fields of it in full vigor in California, sufficient to support an immense quantity of silkworms. Second, Morus AlBa, or white mulberry, a native of China, but for centuries naturalized in Italy, and therefore also called the Italica. This tree is of rapid growth, and extensively known for the uses of its leaf as the food of silkworms. The leaves are pointed, cordate, serrate, entire, or lobed, but vary in the different sub-varieties, sometimes even in the same tree, in different ages, being at times lobed, when young, but when old, entire; and very often they are entire and lobed on the same tree at the same time.

The bark of the wood is of an ash color. The fruit is white, roundish, oblong, of an insipid taste. The tree, as before noted, is valuable for its timber, and exceedingly long-lived. In cold climates it grows slowly, yet its growth is more rapid, and it comes into leaf earlier than the morus nigra, and is not, like that variety, incommoded by a profusion of fruit; and although the black mulberry is preferred in Persia, Count Dandolo affirms that the white mulberry was found to produce the finest silk of the kind known in Italy. It is also affirmed, that if the leaves of this species, and those of the rubra and nigra, be presented to the insect at the same time, it will eat first the white, next of the red, and last 
of all, the black. In Malta, the white mulberry grows much more rapidly than in Italy; but, in India, where the mulberry tree is an evergreen, its growth is so rapid that large quantities are sown and mown in the same season, and from these, sprouts are again produced for a second brood of silkworms. Varieties are known in silk countries which are produced from the white mulberry, and are only to be extended by layers or euttings.

The bark, according to Rosier, may be converted into linen of the fineness of silk. For this purpose, the young wood is gathered in autumn, during the ascent of the second sap, and immersed for three or four days in still water; it is then taken out at sunset, spread on the grass, and returned to the water at sunrise; and this being daily repeated, it is finally prepared and spun like flax.

By a letter that $I$ have received lately from one of the great silk growers in France, I see that the white mulberry continues to have the preference over all other varieties, and is now extensively cultivated there.

Third, Monus Moretrr. This new and valuable variety of mulberry was first discovered about the year 1815, by Mr. Moretti, Professor in the University of Pavia ; and from a single young tree, he had, in 1826, multiplied them to 120,000 . 'The leaf is ovate, sharp pointed, entire, cordate at the base ; it is thin, smooth on the under and especially on the upper surface, which is of a beautiful and rather deep shining green; it is not so thick as that of the large white mulberry, called, in 
France, the admirable, and it is thinner than those of the Spanish mulberry, morus nigra. It is neither wrinkled nor plaited, is, in general, ten inches wide and twelve inches long. The fruit, which is at the first violet, becomes at maturity perfectly black, but is sometimes white. This mulberry will be most profitably cultivated in the form of a hedge, and from the remarkable size of its leaves they are gathered with the greatest facility. Their superior quality has been proved by the experiments of Mr. Gera and Count Dandolo, who assert that "they produce silk of a more beautiful gloss and finer quality than common silk."

It is well established that the morus alba is the variety cultivated for silk nearly everywhere, and is generally considered as producing the best silk; but after my own observation, my opinion is that the moretti will be the very best variety for California, for many reasons. First, I remarked it to be a very vigorous and strong grower, wherever I have met it in the State ; it is also more hardy than others. Second, as it is an improved variety of the alba, it is very easy to understand why it produces silk of a superior gloss. Third, because one of its large, thick, substantial leaves contains as much food as a half dozen of the others, and, consequently, the whole tree produces more in proportion. Fourth, the thickness of its leaves is the cause that they do not wilt so fast, and keep fresh a longer time, and they afford the worms plenty of time to eat the whole. This last point ought to be taken into consideration under the influence of our dry atmosphere. All the above quali- 
ties of that fine variety will certainly be appreciated by our silk growers, and I should not be surprised to see it, in a short time, very extensively cultivated throughout California.

This, and the alba, and also the multicaulis, are the principal varieties that we should cultivate for silk in California, because it is fully demonstrated and known that they produce the best quality of silk; and, besides that important point, there is another. We are satisfied that these three varieties thrive most luxuriantly in our silk State, as I have been able to ascertain in different parts of the State, in my travelings for the silk cause.

\section{CHAPTER VI.}

THE SOIL.

Without fear of being contradicted, I think that I can say here, that in California we possess, not only one of the best, but the very best soil for the mulberry tree. For my part, I never before saw mulberry trees with such a growth as they have in California. In regard to soil, in one of my letters to the "California Farmer" I wrote thus:

"To all who are about to start in that rich industry I desire to say for their benefit, that the most important point to begin with, is the selection of the soil for the mulberry. It is a fact, that it grows almost anywhere 
in California, but, more or less, a deep, rich, light, loamy soil is needed. In such a soil, we can obtain as much food from one acre as from two or three of other soils. In that mulberry soil, trees seven years old measure from two to three feet in circumference; shoots one year old are from ten to twelve feet long, and we have any amount in all the valleys of California. I have remarked a great quantity of it in our beautiful and healthy valley of San José, but have observed it more generally in the Sacramento Valley. We can say that we have hundreds of thousands of acres of such soil in California. The quantity of silk that we can produce is incalculable; we could supply the whole world with the article."

But I do not mean by the above to impress on anybody that valley land is alone suitable for the mulberry, as I have observed along our foothills, and even on the hills, very fine mulberry soil ; and I would also recommend to those who have plantations there, to select always the soil, and give it a deep plowing, and plant early.

In Europe, it is on the hills that they generally obtain their best silk, but they have rain there often, which stimulates the growth of their mulberry trees planted in the mountains ; and it is very easy to understand why the silk from the mountains is better than that produced in the valleys. But by doing, in regard to mountain soil, as I have said before, I have no doubt that we will succeed, and I will earnestly recommend it to be tried. In case of success, we shall certainly obtain there a very 
superior article. Sunny exposures on the declivities of hills must be preferred; those especially which slope to the south and east are the most favorable.

The eocoons of mountainous countries are deemed superior to those of the plains ; although not so large, they are usually of a whiter color. Trees planted in the hills are neither exposed to suffer from the early and later frosts, nor are the leaves liable to become spotted or diseased from mildew.

One of the principal things we must have in view to succeed well, is the preparation of the soil in which to plant our trees. The soil, before planting, must be thoroughly and deeply cultivated, because the roots of the mulberry tree strike downward, and consequently need a deep plowing.

But, in regard to the preparation of the soil in California, there is nothing better than the admirable address of G. N. Sweezey, Esq., delivered before the Northern District Agricultural Society at Marysville, on the 4 th of September last. I cut from the "California Farmer" the following paragraph :

" Having built my house and out buildings and done my fencing, or before, if not prepared to fence, I would in the month of March or first of April, with suitable teams, proceed to fallow the lands I designed for my orchard, vincyard, shade trees, grain, and pastures, at least so much as I could conveniently put in the following fall and spring. In ploughing these lands for fallows I should run the plough to the beam of subsoil, which would be the best. The deeper these lands are 
ploughed the more productive they will be, and the greater amount of moisture they will retain. Here, you will find, is the great secret in treating and cultivating these dry lands. They must be ploughed deep and rendered loose and friable in order to retain moisture. If allowed to harden and bake and crack, the evaporation passes off as does that from water poured upon a heap of bricks ; but if the soil is well pulverized, it will hold moisture like a sponge, and retard and retain the evaporation constantly passing upwards, and what is more, will allow the tender roots and fibers to permeate the soil in every direction, licking up the moisture, and to penetrate down to where the soil is damp and cool. At the same time I am ploughing my fallow I would procure my grapes and other cuttings, preparatory to rooting them for the next spring's planting. I will have to prepare these myself, for if I purchase nursery plants as now prepared, my labor will be in vain, as the ground to be planted will be dry before they have commenced sprouting deeper down than such plants can be set. These plants I will make from twenty-four to thirty inches long, and will put them out in nursery rows, laying them almost horizontally in the soil, so that the end designed to root shall not be more than six inches under ground, while the other end protrudes not over two buds. In this way I shall obtain a long plant, when rooted, which I should not do if they were placed perpendicularly in any soil adapted for nursery purposes, as such soil is cold and wet at a 
small depth below, and would consequently rot the cuttings within six or eight inches of the surface."

That address is a very important document, and every farmer ought to have it. But I only put here simply what concerns the preparation of the soil, as it completely suits my views; because mulberry trees will certainly do pretty well in a soil prepared as above.

I think I have said enough to make every one understand that the soil in which you intend to plant your mulberry trees must be well and deeply cultivated, as by all I know and what I have seen, deep ploughing is indispensable in California, in order to retain a proper moisture through our dry season. It is the cheapest way, as it saves you the labor of irrigating, and is ten times preferable.

\section{CHAPTER VII.}

MULBERRY CULTURE.

The mulberry tree is propagated by seeds, by cuttings or slips, by layers, and in Europe also sometimes by grafting; but I think that we have no need of grafting in California, where the mulberry is so easy to grow, easier even than the willow.

First, BY sEEDs. The seeds are obtained by washing the bruised pulp of thoroughly ripened fruit. The trees that are left for that purpose must be shaken every day; 
the fruit is mashed in a tub with water till thoroughly incorporated, and the mass, being largely diluted, is poured off, its place being supplied by new quantities; till the water comes off clear and the seed perfectly clean. It is then dried on cloths in the shade, and when perfectly dry, it is preserved and kept in a dry, cool place.

Good mulberry seed will sink to the bottom after steeping a short time in water, and one ounce will usually produce from eight to ten thousand plants. Previous to sowing, the seeds should be soaked twentyfour hours in tepid water, then mixed with fine, moist sand, and exposed to a moderately warm temperature, and sown as soon as they commence to germinate. Take the mixture (seed and sand) and sow them immediately in well-prepared, fine soil, kept free from weeds.

They do better in drills, and are easier to take care of. The rows should be from two to three feet asunder, and the seed planted at an average distance of about half an inch. Cover them but half an inch deep; press the earth a little, so that it may retain sufficient moisture at its surface.

The best time for sowing will vary much in California according to the locality; the farmer will have to exercise his own judgment about it, because we have many places where there is frost, and plenty others where there is none. It must be borne in mind that when young trees begin to spring out through the earth they are very tender, and the least frost would kill them. 
Then I would advise those that are in a locality where there is no frost, to sow some time in January or beginning of February, so that the young trees may be benefited by the rains; they will then make a fine growth through the season. And to those who live in a locality subject to frost, I would say: sow in the spring when the frost is over; but it will then require close attention to keep your rows sufficiently sprinkled till they are a few inches high; but as January and February are the best months in which to sow the seed in order to have good trees through the season, it can be done in our frosty localities. But now that you know the danger, you understand very well that it is necessary to protect the young plants coming out against the frost. We have such light frosts here, in this country, that they are only dangerous for very young seedling trees at the time they are coming out and very tender, because when they are five or six inches high, the frost never injures the trees any more.

When your young trees are coming out, you must hoe with care between the rows and weed carefully during summer; thin them out where needed, and, if your seedlings have been well taken care of, you will have in the fall fine young trees that you can transplant where they are to grow.

Second, BY cutrings. This is the best and surest way to propagate the mulberry, because they are not subject here to be injured by frost, or hot sun, or anything else. In this way you can propagate more largely the best varieties of mulberry, whereas by seed you 
cannot, as they vary very much, and from twenty you can hardly find two that look alike.

As to the old way of making cuttings and planting them, every one knows; but in this part of the culture, as in all the rest, we have to work according to the locality we are in and the climate we are under. The old way of making cuttings, with one-third sticking out above the ground, I consider very bad under our dry atmosphere, to which tops are exposed. The action of that dry atmosphere and of our burning sun dries them and kills a great many, as the cutting is simply a piece of wood with no roots to supply it with moisture.

For the benefit of all, I will here note the result of my observations on that subject. Have your cuttings about six or eight inches long, the tops cut near one eye or bud; plant deep enough to have the top covered about half an inch. This is sufficient to prevent the action of the sun, etc., and in this way you will have them all grow, if planted in a proper soil ; that soil I have described before. You must not forget that for the cuttings also the soil must be well prepared.

Now, at the beginning of the silk culture, what do we need? Plenty of mulberry trees. My new and simple way of planting cuttings (I may say, according to our climate) will greatly help to secure that result; and I hope that it will give a great impulse to the mulberry culture, as we can propagate it fast without any trouble.

Another advantage of propagating the mulberry by - cuttings is, that it is a stronger grower, and, conse- 
quently, will allow to begin to feed from them the first year, and thus pay for their cost.

If you plant your cuttings in a nursery to be transplanted the year after, the rows must be from three to four feet asunder, and the cuttings in the rows six or eight inches apart. But in a good mulberry soil, in selecting the best cuttings and planting them, as I say above, I think that there would be no danger to plant them at once where they have to grow. Yet, in whatever way, you must take care of your cuttings, not allow the weeds to grow, pass the cultivator between the rows, and hoe carefully, remembering that the cuttings must not be touched before they have good roots, because if you hit them any way, you break the young and very tender roots and prevent them from growing. Keep the surface of the ground loose by working it, and it will retain a sufficient moisture; but in some localities and soils, if it is too dry, give them water. Your eare and attention will be well compensated by the good growth of your cuttings.

'Third, BY LAYERS. According to our C'alifornia culture, the trees have to be cut only a few inches from the ground to make them branch out more freely; this will greatly favor the propagation by layers. I have observed that the mulberry tree is easier to grow from layers than many other trees; then it does not require so much trouble or work for the bending of the branches.

I would recommend simply to do thus: have your branches all round the trees you wish to propagate, laid out horizontally, corered about two inches deep, their 
extreme ends only being left out; many branches will require a hook to keep them down to their places. After the branch is covered with fresh earth, pressed down to it, the operation is done.

The result of having young layers fixed in this manner, will be that nearly every eye will produce a tree, with plenty of roots, if they are in a good mulberry soil, and kept with sufficient moisture. I would recommend to have that operation done early, say in February, although it could be done after that time. In the following fall you take them up, and with your pruning shears separate the trees, and you will be astonished at the quantity produced in that way; then we will soon have enough mulberry trees to plant the State all over, by these different modes of propagating.

Everything considered, it is my opinion that we have no other tree so easily propagated in California as the mulberry. Then we have no reason to look for any substitute, as it is well established and demonstrated that it is the very best and most natural food of the silkworm; besides, the fact is also well demonstrated by nature, as no insect can live upon its leaves, but the silkworm. 


\section{CHAPTER VIII.}

PLANTATION OF THE MULBERRY, ACCORDING TO OUR CALIFORNIA SILK CULTURE.

Before thinking to raise any silkworms, we have first to plant the mulberry. I have shown before what soil must be selected to plant it; and how to prepare that soil, and also the different modes of propagating it; and in this last part I add the results of my observations in California, by which we can come in a very short time to have mulberry trees enough in California to cover the whole State.

The mulberry tree is, of course, but little known in this country, so recent is the awakened interest in its culture ; but it will certainly prove to us a source of great wealth, and it should receive the attention that it merits. It will add another, and decidedly the greatest and most valuable staple to our agriculture, the true source of wealth to any country - a staple that will conduce more to the happiness and comfort of our whole country than any other. And I can say here, that there is not another staple that offers such general advantages, and could contribute so largely to enrich the country, as the culture of the mulberry tree, and the raising of silk. But as I have said before in some of my letters, everything must be cultivated in its proper place; and as California has been designed by nature for that rich culture, let us then cultivate it all over the State. 
We already have our cotton States, why not have also our silk States?-because any other State which possesses a climate similar to ours, is convenient for silk culture, and our simplified California silk culture could apply to it. But I think that it is very difficult to find another place so wonderful, and so particularly adapted for silk culture, as California. Here we seem to have everything in our favor-the best climate for the silkworms, and the very best soil to cultivate and raise the mulberry, which furnishes here an abundance of that precious and healthy food that they need : all these advantages, I think, cannot be surpassed in any country.

It is the superiority of our climate that allowed me to simplify the work, and reduce it considerably.

I will show at the chapter on the worms how and why that culture will have to be adopted here, under the influence of our dry atmosphere, besides the great advantage it has of reducing the work, which is most important.

In other silk countries, not so well favored as California, the climate forces them to feed their worms with leaves only; while here in California, I am feeding with branches, and the worms are doing better that way than when fed with leaves only, which I will demonstrate in its proper place. But we must have our trees planted in view of our California silk culture, in order to facilitate the gathering of the branches. 
HOW TO PLANT.

The ground being prepared, as I have said before, take your plants that you have grown from seeds, or cuttings, or layers, and plant them. Here in California, according to your locality and soil, I would recommend that the rows be from ten to twelve feet apart; but in the rows I would put them double, or from five to six feet. Every six rows, I would make the distance between the rows six or eight feet wider, because it is necessary to leave room enough to pass with your wagon to load your branches in; because, if you had to run too far it would be a loss of time, and it is to your advantage to plant in such a way as to render the work easier and quicker.

For our California culture, it is necessary in planting to have your trees cut at about three or four inches above the level of the ground, because they must be kept low, so as to render the gathering of the branches easy; and another advantage of keeping them very low is, that they produce more branches, and consequently more food.

For the gathering of the branches you must have good pruning shears, as they are the best for that work to do it well and quickly. In gathering your branches, I wish to call your attention to a very important point, and that is, if you cut all the branches at the time of feeding, the effect will be to stop the sap, which is furnished by the roots, and ruin your trees, that, under such a treatment, would hardly live two years; and you 
know now, that the mulberry tree is a long-lived tree, often continuing healthy several hundred years.

But it is very easy to avoid injuring the trees, in gathering the branches, by proceeding thus: the first time, with your pruning shears, you cut only about onethird of the branches of your trees, removing always the largest branches, and cutting each time only what you need for your worms and no more, as they should have fresh food every time.

You proceed in that manner every day, in cutting only about one-third; and when you have been through all your trees, you come back and begin again where you first began, and cut again another third in the same manner; and doing so, by the number of young branches left on your trees, the sap continues to run up, and your trees do not suffer from the gathering of some of their branches.

Low Mulberry Tree Plantations, therefore, in their formation, is the mode which I shall recommend for general adoption in California, for the following reasons : First, it is necessary for our mode of feeding in California, as it renders easy the gathering of the branches. Second, they arrive to a state of productiveness with comparatively little expense of time and tillage. Third, sufficient sun and air are admitted to the tree to render the leaves of the first quality, and to enable them to put forth early. Fourth, the ground is more suddenly and completely filled and occupied than by planting standards. Fifth, they are easier to be managed and controlled. Sixth, the produce of leaves, on the same 
quantity of land, is more than double, than from standard trees in their best state, when the labor is much lessened. Seventh, women and children can gather the food with perfect convenience from low trees, which they cannot so easily do at all from large trees.

Rosier and other modern writers of France, particularly recommend this mode in preference to all others.

John P. Cushing, Esq., of Belmont, in Watertown, a gentleman who has resided many years in China, has stated that the most approved mode of cultivating the mulberries, as practiced in that country, consists in keeping them-low by annual prunings, like plantations of raspberries. The same mode, according to Mr. Loudon, and also Mr. Bonafoux, is practiced in India.

This system of keeping the trees low is certainly the best, and the only one we can follow with advantage for our California silk culture.

\section{CHAPTER IX.}

\section{MULBERRY TREES EVERYWHERE.}

The mulberry tree is the best, the most useful, and, consequently, the most valuable of all the trees known; mure particularly in California, where it grows so easily and so rapidly. I will try to demonstrate here, and show how and why we ought to plant it everywhere, in 
showing its merits and superiority over all the rest, by enumerating a few facts.

1st. Because it is the easiest tree to propagate, and, as it grows so rapidly in California, it will be the cheapest.

$2 \mathrm{nd}$. Because most of the varieties of the mulberry are esteemed dessert fruits when perfectly mature.

3rd. Because the syrup made from its fruit is very useful in mitigating inflammation of the throat.

4 th. Because, also, when the fermented juice of its fruit is mixed with apples it affords a delicious beverage called mulberry cider, of a deep red color like port wine. The black mulberry is the best variety for that purpose.

5th. The juice of its fermented fruits produces a pleasant, vinous wine by itself alone.

6th. It ought to be planted also for the value of its wood, which is compact, elastic, and hard, and susceptible of a fine polish; it is therefore very useful to the upholsterer, the carver, and the turner.

7 th. The great strength of the timber renders it very valuable for the joiners generally.

8th. The quality of its timber makes it also very valuable for the building of boats, its power of resisting the action of the water being equal to oak.

9th. One, also, of its merits is, that the tree is longlived : it is fully demonstrated that it lives several hundred years.

10 th. Its bark can be converted into linen of the fineness of silk. I have in hand some of that kind of silk, 
produced from the bark; it looks as fine, and as good and strong as the floss silk from the cocoons.

11th. It is very valuable for feeding milch cows. Every one has seen in our principal papers, under the heading of mulberry for forage, that " a German farmer of Ohio, during the late season of drought, cut down a number of black mulberry trees for his cows, and was surprised to find that they gave more and richer milk than when fed on grass; the butter had a peculiarly pleasant flavor. In California this fact may be of great value; the tree, by growing deep into the earth, reaches more moisture, and can resist drought better than grass, and the dairyman would thus be enabled to provide green forage the year round, even from dry soil." Many farmers were ruined by the loss of their cattle, not long ago, when we had been two years without rain, and then if we had mulberry trees planted everywhere, we could have saved those thousands of thousands of cattle that perished from hunger. Let us begin, then, to plant everywhere, and such a calamity will never occur again.

12th. As an ornamental tree it ought to be planted every where, because there is none that can be compared to it. We are planting in California a great quantity of ugly and common trees, that are good for nothing, and that are called ornamental trees, when they really ornament nothing at all, and which are certainly very far from being as fine looking and ornamental as the mulberry tree. Some of these common trees, instead of being ornamental, I consider a real and regular nuisance. Such is the cottonwond tree, that we find planted 
in many of our cities to ornament their streets, and, instead of that, renders them dirty, and everything in their neighborhood. Then it would bo certainly hundreds of times better to cut down immediately all these dirty trees, and plant mulberry trees in their place, and then only, we will have fine-looking, ornamental, and clean trees to look at; as on the others, myriads of insects live upon their leaves, while with the mulberry tree, no insect can live upon its leaves but the silkworm.

13th. As the mulberry produces also a quantity of fruit that the birds, are fond of, this is another reason why they should be planted everywhere, around the gardens, farms, and particularly orchards, as a protection to other fruits. The damage done by birds to fruits generally, and particularly to cherries, is well known by all. This damage will be greatly reduced, because the quantity of fruit they eat from the mulberry they will not have to eat elsewhere.

14th. Another reason again, why all the farmers ought to plant it everywhere around their premises is, as I have said before, because the trees produce a large quantity of fruit, that keeps falling off the trees for a long time. The hens and other fowls generally like it, and devour it, and it is considered a good and wholesome food for them, and the same for other animals about the farm; in fact, their fruit is perfectly wholesome in every respect. This point ought to be taken into consideration by our farmers, and make them understand that it is for their interests to quit planting trees that are good for nothing. 
15th. Even one of the above facts is enough to prove that it is a useful tree; but all these facts together are more than sufficient to persuade any reasoning person that the mulberry tree ought to be planted everywhere in California : but it is not all, and we come now to the most important point. Besides the above facts in its favor, it is the tree that produces that wholesome food for the insect that produces the silk, which is the finest and richest of all fabrics, and which has made so many countries rich; and as California is found to be so favorable to that culture, we will certainly be the first and most important silk State of the Union.

Now, I have said, at the beginning of that chapter, that the mulberry tree is the best, the most useful and valuable of all the trees known. I am in hope that all my readers will now agree with me that it is the truth, as I think it would be very difficult to find another tree of such importance.

Now, we will leave the mulberry tree for the silkworms.

\section{CHAPTER X.}

COCOONERY, OR MAGUANERIE BUILDING, TO RAISE THE SILKWORMS IN.

Since 1860 I have been raising silk in California, but never had the means to have a cocoonery. I have been 
obliged to raise the first silk in a greenhouse, having no other room that I could use. A greenhouse is a very bad place for using the worms, becanse there is a suffocating heat during the day, and it is very cold at night. I have been raising them that way for four years; and since, two years in the garret of my new house, which is not a good place either, as I am not able to give them air enough there; but, however, it is better than the greenhouse. In both places, I have succeeded in raising them without any sign of disease, which shows the superiority of our climate, because, in many other silk countries, under such circumstances, they would not have been able to raise any. But, besides that, I have given worms and sent silkworms' eggs to different persons in the State, with a few verbal, and sometimes a few lines of instruction in a letter, and they have all succeeded in raising the silk; and persons that have never done it before, some of them, have raised their silkworms in their bedroom, some in their kitchen, others in different rooms, or rather a shed. All this cortainly demonstrates fully, that under our fine silk climate, silkworms can be raised in any room, and almost everywhere in California.

\section{IMPORTANCE OF A COCOONERY.}

For any one that wishes to make a profitable business of it, a good cocoonery is indispensable; because, although the climate allows us here to raise silkworms in almost any way, it is, however, well established and known, that the silkworms need plenty of air, room, 
and particularly a temperature as regular as possible. All these points cannot be attained without a good cocoonery, built with special reference to them.

In a good cocoonery we are certain of obtaining more silk from the same number of cocoons, and the silk finer, and of superior quality, besides rendering the feeding of the worms easier, and consequently it can be done with less trouble and work.

A good cocoonery has also the advantage of protecting the silkworms against their natural enemies, which are the bird, principally, and all the poultry, rats, mice and ants.

\section{A GOOD COCOONERY IS NEEDED ON EVERY FARM.}

I wish to show and impress upon every reasoning person, that a good cocoonery is indispensable on every farm, and that such a building would be of great benefit to each farmer, not only for the raising of silkworms, but also for other products, because at the feeding time, which is in June and July, you have no need of the building to store anything in, and during all the balance of the year that building can be used to store all the grain, hay, corn, or any other products that need to be protected against the inclemency of the weather, or the depredations of cattle, squirrels, gophers, rats, mice, etc., etc. It is evident that for the storage of all this only, such a building ought to exist on every farm; and the saving of the crops will certainly more than compensate the farmer for the erection of it, because they can build it small or large, according to 
the size of the farm and the business carried on, or intended to be. But, as it would not cost any more, it should be necessary to have the interior of that building arranged in view of using it for storage and silkworms, and that is very simple. Only have all the posts for the shelves of a regular size and length, kept together by means of wooden pins or screws, all also of the same size, or any other way that you may find better; but remember that they must be arranged in such a way as to make it very easy to put them together and to take them apart. Then, after you put them up, when you want to feed your silkworms, and after the feeding and cleaning is done, in a few hours' work you can take the whole thing apart, and have them piled in one or more corners of the building, as you find it most convenient; and then you have the whole room ready for your storage, or anything else.

Many farmers have to pay storage for their grain; but the moment they have a cocoonery, they will save that much, besides the other advantages.

\section{PLAN OF A CALIFORNIA COCOONERY.}

As our fine silk climate enabled me to simplify the culture of silk, and our California silk culture is different from that of other countries, we also need a California cocoonery to suit our culture, and also different from the others. I would then suggest or propose the annexed plan :

The building is fifty feet wide by one hundred feet long, and is two stories high; the walls to be brick, but 
hollow, according to Mr. Goodrich's-patented system. These are my reasons for recommending hollow walls: First, they are nearly one-third cheaper, as only two bricks are needed instead of three. Second, it is more healthy for the worms. Third, and the principal, it has a more even temperature, which is exceedingly favorable to silkworms. - It is necessary for a complete success that we do all we can to have in our cocoonery a temperature as regular as possible.

About eight windows will be needed on each side of the first, and also of the second story.

\section{SHELVES, POSTS, ETC.}

The posts to support the shelves ought to be from three to four inches in diameter and eight feet apart; the cross pieces to support the boards about one inch and a half thick by three inches wide, and, of course, just eight feet long.

We can use inch boards sixteen feet long, the cross pieces being eight feet apart, the board will be supported in the two ends and in the middle; the boards need to be in sufficient number to make the shelf eight feet wide.

The shelves need to be two feet six inches from one to the other. The wormus on the three first can be fed while standing on the floor, and for the three others above, at that point the cross piece needs to be longer, so as to put a good board on the ends to take care of them, and the same way in the second story.

The galleries between the shelves, to take care of 
the worms, are four feet wide in the center, but those alongside of the walls only three feet. The rafters are laid across for a second floor, but they are only boarded, where the galleries are, for attending the worms; the object of this arrangement being to allow the air to circulate everywhere.

In order to be able to regulate the temperature and have plenty of air, I wish a kind of second roof on the top should be raised at about twenty inches from the other, and projecting on each side from four to five feet. This gives the appearance of a double roof. With some hinges, lids can be hung that we can open and shut at will.

In the cocoonery it is very important to have nothing that would give a bad smell, and more particularly tobacco. That drug is a regular poison for the worms, and no one that smokes or chews tobacco should be allowed to go into a cocoonery, as the breath, which is impregnated with that drug, is very injurious to worms.

The cocoonery should be built in an airy situation, because what the worms need most is plenty of air and space. In regard to space, I see that Count Dandolo says, that he considers the following estimate as affording sufficient space for a million of silk worms, or in this proportion for a greater or less number: for the first age, two hundred square feet of surface; for the second age, three hundred and seventy-five stuare feet; for the third age, eight hundred and seventy-five square feet; for the fourth age, two thousand and 
sixty-two feet, and for the fifth age, about five thousand feet of surface.

In other silk countries, less favored than California, they have to use in their cocooneries any amount of different apparatus; but we have no need of all that here.

At one end of the building and under the roof, I would recommend to have one room, finished off, of some twenty feet square, more or less, according to the capacity of the building - it should be lathed and plastered; that room to be used as a hatching room, and for the first week's feeding, and also for the millers.

I have already designated the enemies of the silkworms, but I wish you to remember particularly that mice destroy from the egg to the miller.

\section{CHAPTER XI.}

SILKWORMS-THE DIFFERENT VARIETIES OF.

As there are many varieties of silkworms, we will have to find which is the best for California; and in order to decide that satisfactorily, I have made arrangements to receive this season, five of the best varieties that are in cultivation in Europe, which I will try the next season, and then I will inform the public of the results. I already have in hand my first variety, which is very good; but I expect to find among the 
others something better, which will produce still larger cocoons, according to the information I have.

I have now a variety from Japan, that I expect to be their annual variety, that I will be able to try the next season also. In Japan, as in other silk countries, they cultivate several varieties; some better than others. If this kind is their annual variety, according to the accounts $I$ have of it, $I$ know it will be a good sort. But, last year, I received a variety from Japan, which I tried this last season. It belongs to the class of worms called trivoltines, because they hatch several times during the season; and in California the eggs of that variety hatch eight or ten days after the females have laid them. I have made this last season three crops of that variety, each time coming to perfection. Their cocoons are of a pure white, but small, and for that reason I cannot recommend them to be cultivated. For my part I will not cultivate them any more, for two reasons: First, the fact of hatching so readily, keeps you busy all summer after them; and certainly one good crop of a good variety, (which is only one-third of the work) is more valuable than three crops of those. Second, their cocoons being too small, are consequently of little value, as they produce the short silk; and you must all know that short silk brings the small price and long silk the larger price; and I prefer long silk.

Some eggs of that Japanese variety, that were left in my garret, have hatched out for the fourth time.

$\mathrm{My}$ old, or first variety, produces yellow cocoons, but 
very superior to that Japanese sort, in size and quality. Until we find something better, it is the best variety that we could cultivate at present. I received that variety at the first, from France, but its origin is China.

There are many other varieties of silkworms; I will mention a few here. Besides the silkworms of one crop, or annual, we have also those of two crops. These go through their various mutations in twenty days, and produce fine white silk, which has the valuable property of retaining its clear white color. It produces two crops, though the quantity is less than that produced by the large, dark colored, or by the large white worm.

At the silk establishment of the British East India Company, at Jungepore, in Bengal, besides the common silkworm, which produces but a single crop annually, they have also another silkworm called dacey, which produces eight crops or harvests, and is supposed to be indigenous.

There is a variety of silkworm found in Friuli, so very large that two of them, when fully grown, will outweigh five of the common kind, and their cocoons weigh almost in the same proportion; the quantity of food is one-tenth less in proportion to the weight of cocoons produced, than for the common kind, but they require five or six days longer in their evolutions, before they begin to spin their cocoons, which are heavy, and measure almost 1,300 yards. One hundred cocoons weigh a pound, and one thousand and ninety-one will yield a pound of pure reeled silk. 
The arrindy silkworm is another species entirely different from any other described or known, and is called arrindy from the name of the plant, the palma christi, on which the insect feeds. It is peculiar to the districts of Dinapore and Rangpore, in the interior of Bengal, where it is reared by the natives in a domestic state, as they do other silkworms. The palma christi is largely cultivated in India, as it is also in many parts of France, and some other countries, for the abundant produce of oil which is obtained from its seeds, known in commerce as the castor oil. This plant is therefore cultivated for the double use of seeds, and also of its leaves.

The cocoons it produces are remarkably soft and white, or yellowish; and the filament is so exceedingly delicate, that it cannot be wound, as are other cocoons, but must be spun like cotton. The cloth woven of this substance, is white, coarse, and of a seemingly loose texture, but of incredible durability; it is used for the clothing of both men and women, and will wear constantly for fifteen or twenty years. Hot water dissolves its texture, causing it to tear; it is therefore washed only in cold water.

The palma christi; or castor bean plant, flourishes most luxuriantly in California; and, under our fine climate, that variety would certainly do well here.

The wild silkworm of India is a species which cannot be domesticated. They are so abundant in many parts of Bengal, and the provinces adjoining, as to have afforded the natives of those countries, and particularly 
the Brahmins, from time immemorial, considerable supplies, of a most durable, coarse, dark colored silk, which is woven into a fabric called tusseh dootie. This kind of cloth might prove very useful here, and be beneficial to the country, as a cheap, light, cool, and durable dress is much wanted-such a dress as this silk affords, and such as is worn by the Brahmins of India. Once introduced, our climate being so favorable, the species would certainly flourish, unaided by the care, and undisturbed by the attentions of man; but for that we must have large quantities of mulberry trees planted to let them spread over.

\section{CHAPTER XII.}

MODES OF RAISING SILK IN DIFFERENT COUNTRIE8.

Before giving our California silk culture, I thought it would be well briefly to sketch the different modes of raising the silk in other countries. It will give my readers some light on the subject, and enable them to appreciate our culture, by comparison.

The general saying is: give the silkworms air, fresh and pure; let them be comfortably warm and dry, and cleanly ; and with sufficient space to prevent them from contact, with ample supplies of healthy food. These directions alone are sufficient to insure the most perfect success. 
Although the art of making silk was for ages involved in obscurity, it is now stripped in a great measure of the dark vestments in which it has been so long and so mysteriously vailed; specimens of sewing silk of different colors, and of the most perfect beauty, have been produced by N. B. Stacy, Esq., of Burlington, Vt., in 1836, and that unaided by any experience, and with no other instruction than that which books afford. Mr. Stacy has succeeded in raising and manufacturing several pounds of sewing silk of superior quality, yet he had never before seen a silkworm, a cocoon, or reel, and was himself astonished to find no mystery in the business. The cocoons produced by him were very large, requiring but little more than two hundred to the pound. $\mathrm{He}$ is persuaded that the main profit depends on full feeding, and making the greatest possible amount of silk from every insect.

In some parts of China, where the climate is more suitable, the silkworms are suffered to remain at liberty, on their native mulberry trees, where, uncontrolled and unaided by man, they pass through their various mutations among the branches. When the cocoons are formed, they are collected from the trees, except a few which are left for reproduction.

The experiment of raising silkworms in the open air was tried in Languedoc, France, by Mr. Martely, of Montpelier, in the garden of the College of Jesuits, of that city, in 1764. In that year twelve hundred francs were appropriated, by the Minister of France, to defray the expenses of the experiment, which succeeded per- 
fectly. In 1765, the sum of eighteen hundred franes was appropriated to defray the expense of another trial; but owing to the unfavorable state of the weather, and the heavy and incessant rains, the experiment in this instance totally failed ; and though the rearing of silkworms in the open air has not been attempted any more in that quarter, yet its partial success taught the cultivators new and important lessons, in regard to a more perfect system of ventilation.

In China, when the mulberry tree has sufficiently put forth its leaves, the rolls of paper on which the eggs of the silkworms have been preserved, are daily suspended in the sun: the side on which the eggs are placed being turned from its rays. At night the papers are closely rolled up and placed in a warm situation; and this being daily repeated, the eggs hatch in about four or five days. But in high latitudes, the Chinese regulate the temperature of apartments with stoves, that the eggs may hatch simultaneously.

The houses for silkworms are in dry situations and in a pure atmosphere, and remote from noise. The rooms are made very close, but with ample means of ventilation, and the doors open on the south. Each room, or chamber, is provided with nine or ten tiers of frames, on which the rush hurdles are ranged one above the other; on these the insects are fed during all the different periods of their growth. Stoves are also provided in the corners of the apartments, to preserve a uniform and equal temperature; or coals are carried in a cha- 
fing dish, from time to time, backwards and forwards, through the room.

In China, the wants of the young worms are supplied with unceasing attention; they are fed during the night as well as the day, forty times during the first twentyfour hours, and thirty times during the second day; but fewer and fewer on the third day, and afterwards. Sagacious observers, from their long experience affirm, that as the growth of the silkworms is accelerated and success assured by the abundance of their food; also, that the quicker the silkworms are brought to maturity, the greater is the quantity of silk which they produce. If the silkworms which are produced by each drachm in weight of eggs are suffered to linger, either through cold, or neglect and famine, for thirty or forty days, before they begin their cocoons, the product of silk will be ten ounces; but if their maturity is completed in twenty-eight days, the product will be twenty ounces; while the same quantity of silkworms, in a warmer temperature, which being fully fed and well attended, have completed their growth in the short time of twenty-five days, will produce twenty-five ounces of silk.

The Chinese are fully sensible of the importance of preserving the most perfect degree of cleanliness in their establishments, and are exceedingly careful on this head. When the insect is prepared to spin, mats are provided, and in the center of each a leaf is affixed, an inch in width. This is wound round in spiral form, till the mat is covered; a space being left between each circle of one inch, it having been found that less silk is 
wasted, in the receptacle of these dimensions, than where more space is allowed; also, at such periods they exclude the outward air and light, believing the silkworms spin their cocoons more diligently in darkness.

Seven days after the silkworms have commeneed their cocoons, they are collected together; and a suffcient number being reserved for breeding, the remainder is placed in layers, in large earthern jars with salt, in the proportion of one-fortieth part of the whole weight of cocoons between the layers. The whole is covered with large dry leaves, and the mouths of the vessels are closely stopped.

The long, shining cocoons produce silk of superior quality. These are separated in reeling, by the Chinese, from those cocoons of a thick form and dark color, which are of an inferior quality. In China and in Han-ChooFoo, according to Sir George Staunton, women only are employed in the fabrication of flowered and embroidered satins, and vast numbers are employed in very extensive factories.

In the hot climate of India, the silkworms are reared and sheltered in buildings, and beneath sheds of an open and airy structure, the sides being composed of lattice work, and the roofs covered with thatch; their breadth being generally fifteen feet, with a path through the center of sufficient width. The height is usually eight feet or more, and on either side; and one above the other, and in tiers of from twelve to sixteen deep, are the stagings, formed of shelves or shallow boxes of bamboo, in which the silkworms are placed. The posts; 
which support the stagings, rest in basins of water, to protect them from ants. When the silkworms are ready to form their cocoons, they are transferred to cells formed of planted bamboo.

Formerly, it has been the practice in many parts of Europe, to inclose a couple of ounces of eggs, in a silk or cotton bag; which was worn in the bosom next the skin, and at night was placed beneath a warm pillow. After three days the eggs were carefully transferred to thin shallow boxes, these being placed between warm pillows. The heat of each was frequently renewed, as the silkworms were expected to appear toward the fourth day.

In Italy, Count Dandolo had recommended and adopted the plan of using stoves for warming and regulating the temperature of the apartments in which the eggs were hatched. The heat of these rooms being regulated by the thermometer, is raised during the first day to sixty-four degrees ; raising it gradually a degree or two a day, till it shall have reached eighty-two degrees on the tenth day, and this point is not to be exceeded. Count Dandolo has suggested that one room might answer for all the silkworms of a whole district. Fortunately, the necessity of rules like these is unknown in California, and in a great portion of America.

In some of the late establishments of France, they have altogether dispensed with the use of fireplaces and stoves, the apartments being now warmed when 
needful by currents of heated air, caused by a furnace placed beneath or without the main apartment.

Broussa, a city at the foot of the Mount Olympus, like many other cities of Turkey, says Commodore Porter, is surrounded with plantations of the mulberry trees; and asses laden with the limbs and leaves are continually going into the city.

Mrs. Rhind says, that in Turkey the production of silk is confined to the cities, or large towns, in the vicinity of which the mulberry trees are chiefly cultivated by the farmers and landed proprietors, who do not raise the silkworms themselves; at the suitable season, the leaves are daily collected by them, and sold in the market of the city as fruits or vegetables are sold. When the season commences, almost every family clear out all the rooms in the house, except the one in which they live. The worms being hatched, they purchase sufficient leaves, and strew them over the floor of each room, leaving only a small space round the four walls, for the convenience of feeding; they then place the worms on the leaves, who rapidly attack them. New quantities of leaves are daily added to supply the wants of the worms; the litter is never removed, but is suffered to accumulate frequently to the height of three feet. When the worms are ready for winding, branches and brushes are planted immediately over the collected mass, and on these the cocoons are formed; and these being collected, the rooms are then cleared out, and the reeling is commenced.

This is the rude and abominably negligent mode 
which is practiced in Broussa, the great silk district of Turkey, where the best silk is produced. Thus in Turkey, the silkworms are reared in cities, as well as in country villages, and the food is purchased in the market; these cities and villages being surrounded by the plantations of the mulberry.

I have been thus particular in describing the mode of rearing the silk in Turkey, but not by any means that I would propose it as an example for us to imitate in California, but as a striking proof of the great strength of constitution which the silkworms possess; and the only mystery appears to be, to comprehend with what power the silkworms are endued, which can enable them, thus situated, not only to live and survive, but also to produce valuable erops. It shows that in Turkey, their trees are constantly growing under the influence of a genial sun.

I have also tried here in San José, to raise the silkworms in open air. In 1861, knowing that the birds would eat them all, I covered with mosquito bars the two trees on which I put my worms. I put them in the morning at about 8 o'clock, and the next morning at about the same time, I visited them and found them almost all gone; and the few that were left were surrounded, each one, by a half dozen of ants, that were carrying them away. Finding that we have so many enemies outside, I concluded that it was of no use to think of raising them in the open air, in Cali fornia. 


\section{CHAPTER XIII.}

\section{AMOUNT OF FOOD.}

According to Count Dandolo, five ounces of eggs will furnish two hundred thousand silkworms, which will consume seven thousand pounds of leaves; and one hundred trees can furnish the food for all ; and twentyone pounds of leaves will furnish food for one pound of cocoons. Count De Hazzi, from the sources above named, calculates that two hundred thousand silkworms require ten thousand pounds of leaves in the different stages of their existence, in the following proportions: in the first age, fifty pounds; second age, one hundred and fifty pounds; third age, four hundred and sixty pounds; fourth age, one thousand three hundred and ninety pounds; but in the fifth and last age, which usually comprises near one-third of the brief existence of the silkworm, they will require seven thousand nine hundred and fifty pounds.

It is evident that the curious tables of the progress of the insect which some of the best authors have given us, can be no sure guide, even with a regulated atmosphere; the progress, space, and time, and proportion of food which will be required for the forty thousand silkworms, hatched from one ounce of eggs, from their birth, till the time they begin to spin, has been given by Mr. Bonafoux. I will here state in the abstract, that in the first age, seven pounds of leaves are con- 
sumed; in the second, twenty-one pounds ; in the third, sixty-nine pounds and twelve ounces; in the fourth, two hundred and ten pounds; and in the fifth, or after the fourth moulting, one thousand two hundred and eighty-one pounds. In the consumption of their food, their progress, though irregular in the detail, is uniform on the whole. On the third day from their birth, they consume three pounds of leaves; on the fourth, but one pound and six ounces; on the fifth day, they begin to cast off their skins, and being sick and torpid, they consume but six ounces; in their second age, and on the first day, they consume four pounds eight ounces, thus atoning for previous abstinence; on the third day, seven and one-half pounds; but on the fourth day, comes on the moulting sickness, and they eat no more than two and one-half pounds; in the third age, and first day, they consume six and three-fourths pounds; on the second day, twenty-one and one-half pounds; on the third day, twenty-two and one-half pounds; on the fourth, twelve and one-half pounds; and but six and one-half pounds on the fifth day; on the sixth day they become sick, and take no food, this being a critical period. They cast their skins for the third time. On the first day of the fourth age, twentythree and one-fourth pounds are consumed; but on the seventh day they eat absolutely nothing, and are again torpid, this being the critical period. They cast off their skins for the fourth time. In the fifth age and first day, they consume forty-two pounds; on the sixth day, they become most of all voracious and con- 
sume two hundred and twenty-three pounds; from this time, their appetites daily lessen, until the tenth day, when they consume only fifty-six pounds. The silkworms, which at their time of birth occupied but nine feet of the hurdles, now require two hundrea and thirtynine feet of space, and the whole quantity of food consumed is about sixteen hundred pounds.

According to another account of Mr. Bonafoux, two hundred thousand silkworms were sustained on seventytwo hundred pounds of leaves; but it is admitted that a certain quantity of leaves were given in the intermediate meals, which were not reckoned in the account; also, that in the first stages, the leaves were chopped, which enables the silkworms to consume them without waste.

Other and authentic accounts make the amount of food consumed even less than five thousand pounds. We will admit nine thousand pounds; but much must necessarily depend on care, and economy in feeding.

The quantity of food consumed, depends also in some rneasure on the season; if that be moist, the leaves will contain less nourishment, and consequently more weight of food will be required; but if, on the contrary, the season be dry, less quantitics will be required, as the leaves contain much more nourishment. Something also depends on the species or variety of mulberry which is used. The Morus multicaulis has no gross or coarse fibers. It is found that a less quantity of food of this species will suffice for the precious insects. The same may be said of the Morus moretti, which contains in proportion more nourishment. 


\section{CHAP'TER XIV.}

OBSERVATIONS ON THE FEEDING AND QUALITY OF FOOD.

The quantity of silk which the insect affords, is in proportion to the amount of food consumed; the duration of the silkworm is prolonged by a cool season; or by scanty, or irregular supplies of food; in this case, the amount of silk is greatly diminished. When a crop of silkworms lingers, either through cold or famine, for forty days, the amount of silk which they can afford is not considerable; while the bounteous harvest afforded by a crop of silkworms fully fed and well attended, which in a warm temperature finish their labors in twenty-four days, will produce more than double the amount of silk. The silkworm feeds night and day, and the more they are fed, the faster they grow, and the sooner they will come to maturity; and in proportion to the dimensions of the insect, will be the size of the cocoons, and the amount of silk produced.

A certain quantity of food being indispensable to sustain life, and the amount of silk which is afforded being of itself wholly the production of the excess of the food consumed, it follows as a consequence that to feed them profitably, they must be fed well. Feeding with branches I consider the most economical mode for a warm and dry climate like ours in California, as the 
leaves retain their freshness and flavor for a longer time, and in that case are devoured with less waste.

The Italians insist on cutting the leaves fine for young worms; I did so the last season, but have observed that under our dry atmosphere we should not do it, as they get dried up, immediately, and the little ones have hardly time to eat anything before they are too hard; on that subject I am just reading now, that Mr. Smith, and some others of America, have rejected this mode, after trial, as the silkworms tread down the cut leaves, passing over them and eausing waste.

The young worms prefer twigs, or small branches, as the leaves keep longer in this state, or until consumed, and are more consonant to the natural habits of the worms. It has also been noticed, that the worms avoid the cut edges, and attack the leaf in any other part in preference. A dozen leaves torn in pieces at each feeding will support a great many worms during the first, second, third and fourth days, and but a very few leaves will suffice during the first ten days. Constant attention will soon enable the intelligent attendant to discover the quantity of food neeessary, and to avoid, on one hand, stinting them in the needful quantity, or on the other hand, a needless waste by over supplies of food.

The young leaves being replete with moisture, and very tender, are the only suitable food for the young silkworms, beeause their bodies perspire largely; and as the mature leaves contain a greater proportion of 
solid and nutritive food, so they are the only suitable food for the silkworms of a more advanced age.

Leaves of a crude and watery consistence, like wet leaves, are sour, and occasion disease; leaves which contain more nourishment, grown in the sun, being alone the more suitable. The best quality of leaves are produced, (as it is generally admitted) in dry seasons, and on dry soils, and particularly on trees little advanced in growth.

In our State, the whole summer season is continually dry, and being entirely without rain, most all of our soils are dry; this is why our leaves are of the first quality for the worms.

In the early or first ages of the silkworms the amount of food consumed is very small; but the amount is very great in the last age, as their dimensions and bulk are wonderfully increased.

If the longitudinal dimensions of the insect be compared during the different ages, and their length at hatching being unit, or one, then at the end of the second age, six ; at the end of the third age, twelve ; at the end of the fourth age, twenty; at the end of the fifth age, forty.

I have shown before that the duration of the insect is prolonged by cold, or for want of proper feeding; while on the contrary, the vital functions of the worms are accelerated by warmth, and also by the degree of attention which is bestowed on them.

To show that their life is prolonged, when not properly fed, a very remarkable fact occurred here last 
summer. Early in the season, I gave to Col. Warren, of the "California Farmer," a lot of young silkworms; and for many reasons it was impossible for him to feed them properly, and indeed they have been very badly fed, being often several days without food at all; and often, having no other, he had to feed them with faded, hard, dry leaves, that was impossible for them to eat. Under such treatment they lived mostly all the time in a torpid state, but remained small for three months. At that time the Colonel sent them to me; I then fed them well, and in a few days they got fat, and of pretty good size, and made their cocoons, although not very good ones. I do not know, but think that anywhere else they would not have lived such a long time.

In a regulated temperature, or such a temperature as Count Dandolo has prescribed, and where the heat indicated by the thermometer is gradually reduced from seventy-five degrees on the first day, to sixtyeight degrees on the last, though the weather is constantly growing warmer; in a temperature thus regu. lated, their various changes, or moultings, usually occur on the fifth, ninth, fifteenth and twenty-second days; and they generally will quit feeding on the thirty-second day; but in warm climates, as I have shown, the various mutations or changes are hastened; but it seems agreed, that the amount of food consumed is the same; it is evident that the diary, which I shall omit, is only for the regulated temperature, and we have it naturally pretty well regulated here, during the feeding time. 


\section{CHAPTER XV.}

TREATMENT OF SILKWORMS, ACCORDING TO OUR CLIMATE.

What I have previously said in the different sections is in order to familiarize my readers with the nature and treatment of the silkworms, that they may be able to know what is best to do, and then be competent judges to appreciate the advantages of our California silk culture, which is so simplified that it gives us a great advantage over other silk countries.

Count Dandolo is considered the best writer on silkworms, and the best authority; this explains to you, how a book on the silk raising cannot be written without referring to him often; but to give you an idea of the immense work that the climate in Italy forces them to do, compared with the simple and economical mode of feeding, etc., that our fine silk climate allows us to use here, I only have to say to you that Dandolo's work on the treatment of the silkworm is a book of large size, containing three hundred and eighty-four pages, and a great number of plates; giving, first, a plan of the complicated and expensive cocoonery which must-be built there, with also the figures of a great number of different apparatus that are needed there, which are very costly, and of which we have no need here.

They have been obliged to feed there with leaves up to the present day, while here we feed our worms with branches. I have explained in my letters in the be- 
ginning of this book, how I came to that; it was in order to curtail the labor. With the exception of Dandolo's work, that I have in French, I never had in California, any other book on silk, till September last, when at Sacramento, my old friend Mr. A. P. Smith of that place, presented me two; one, the "American Silk Grower's Guide," by William Kenrick; with whom about the year 1838, I was acquainted. The second book is "Mulberry Tree and Silk Worm," by Mr. Samuel Whitemarsh. Both books were written in 1839.

In regard to the feeding with branches $I$ have just read in Mr. Whitemarsh's book an article that pleased me very much, as it coincides with my ideas, and so well with all I have said before about it, that I cannot help giving it to you here; it reads thus:

"When the mulberry branches cease to be worth six cents an inch, I propose to feed with branches as they come from the tree. I am persuaded that this practice will be generally adopted in this country, as it has. many advantages, some of which I will enumerate.

"In the first place, the foliage may be gathered in much less time; it will keep better till consumed; the same saving of time is gained in feeding, and much more in cleaning off the frames; the worms mount the twigs while feeding, and remain afterwards, having more advantage of the air, and more space than on a flat surface; the leaf will be entirely consumed, leaving nothing but dry branches to remove; the ordure of the worms will fall through to the shelf, themselves 
entirely free from it; on the branches they will have a better chance to be equally fed, and if this be not attended to, the ill fed ones will lag behind. But the greatest advantage of all is, that they need not to be removed from the frame, from the time they are put on it, till they mount to wind the cocoon; this will be a vast saving of labor, and prevent the handling of the worms, which is always to be avoided. As the branches are laid on, they should be laid first crosswise; and then lengthwise with the frame; making thus a sort of net-work which can be easily separated in layers when you clean them off; the worms will be more healthy, particularly in moulting time, as in the usual way of feeding with leaves; they retire under the litter, and remain there till they change, where they must breathe a bad air, and in many cases be smothered by the accumulation of matter.

"I may as well mention here the system of cutting the branches. Cut your trees within three or four feet of the ground, making clean work as you go, cutting the branches within two or three inches of the body. The trees thus trimmed will produce a head to be taken off at the feeding time; they will be thus kept within reach, and always handsomer and better than when stripped of their leaves. The branches when cut should be laid in the cellar, when if wet, they will soon dry; after being fed from, they may be planted in furrows, and will many of them grow."

Though I have never seen the above article before to-day, December $22 \mathrm{~d}, 1866$, it seems to me curious 
that Mr. Whitemarsh proposed in 1839 what I have been doing here in California for six years without knowing of the existence of - Mr. Whitemarsh's book; but I feel really happy to find that good article and to lay it before you, as it corresponds entirely with my views on that subject; it is also an approval and a proof that what I said about the feeding with branches is true, according to that authority.

Mr. Whitemarsh values very highly this mode of feeding when he says: "When the mulberry branches cease to be worth six cents an inch ;" but here we don't want to create any mulberry fever, and my principal object in publishing the Manual is to prevent it, by giving every farmer and planter the means of propagating his own mulberry trees; in that way, within a short time, we will have millions of them, and they will be the cheapest of all the trees produced, as it is my aim that we should be able to raise the best silk and produce it cheaper than in any other silk countries.

But I must go on with the treatment of silkworms in California. I will just take the eggs, go through the whole process, and leave them when they are eggs again.

First, Hatching. The eggs of the silkworms are of a pale slate or dark lilac color, and of the size of a pin's head; those of a yellow color are imperfect. The eggs are generally on paper or on cloth, and kept in a cool, dry place in the cellar, to prevent them from hatching; but to hatch them, they must be put to the heat. In Europe they have to use artificial heat for their hatch- 
ings, but here in California we have no need of it, as when I want to hatch mine, I simply take the papers on which my eggs are, from the cellar and carry them to my garret, and there the heat caused by the sun through the roof makes them hatch promptly, which they generally begin to do on the third day and continue for a few days, permitting them generally to hatch for four days; the balance not hatched, which are few, I throw away, considering that these late ones are not very good.

It is very important that those that hatch the first day and those that hateh the second day, etc., should be kept by themselves, and not mixed together. This is very easy by marking with your pencil the papers on which you put your young worms, with "No. 1"- " 2 ," etc. This is necessary, because when they are moulting, being of the same age, they are all moulting at the same time, and if they were the different days or ages mixed together, some would be moulting when others want to eat, and those eating would be very injurious to those in the critical function of easting off their skins : they need at that moment to remain undisturbed.

First Age. When the silkworms are hatched, they are of a black color, one-twelfth of an inch in length; those of a red color may be thrown away, if there are any. As soon as they are hatched they need to be fed; put on them then young and very tender leaves; they crawl on them, and then they are easily removed to the papers and placed on the shelves by taking the leaves on which they are. After, you feed them with 
very tender leaves for that first age, but they prefer young twigs, as I have said before, and with twigs they are easier to remove from one paper to the other; give them small quantities at the time, but often, at least six times or more during the twenty-four hours.

When the young brood are piled too closely, a part can be removed on the young twigs or branches. They eat well for about three days, after which they grow torpid, and must not then be disturbed till awakened. You need not remove the litter during this stage, but remove them afterwards by putting fresh twigs two or three times, so as to cover all the worms or nearly so, after which you throw the litter away.

After each and every successive change, their appetite increases daily more and more, but gradually diminishes as their change approaches.

Second Age. The silkworm now awakes hungry, but let those which awake too soon still hunger till all are awakened, that all may be equal; they have now become of a dark ash color. Feed them for two or three days with branches containing young and tender leaves, and afterwards with branches having young leaves and some older, but when they will grow torpid they must not be disturbed. The litter during this stage is to be often removed, and you may lure the silkworms to any corner of the shelf by a few twigs, when you choose, for the purpose of sweeping the litter, or you may remove them to other shelves on branches.

Third Age. Then you begin to place your branches as represented in the engraving, (see frontispiece) and 
from this time continue feeding the silkworms with fullgrown leaves; and their mouths, with which they saw their food, is changed in color, originally white and soft, but soon becoming hard and black, continually growing harder with every successive change.

Fourth Age. When they wake up in this age, the silkworms are of a whitish flesh color, except the spotted species, called tigres; their head and body has become enlarged, their appetite becomes voracious, and they can now devour all the coarse leaves.

Fifth Age. Their color has now become of a dark gray with a reddish hue ; they continue, however, growing whiter for about seven days, when they generally become of a yellow color, their backs becoming shining and their mouths of a red color.

A great quantity of food is now needed, and the branches must be brought by wagon loads and distributed to them. It is curious to see the incredible quantities of full-grown leaves that they devour at present; even the coarsest leaves are equally valuable, and night and day they must be fully fed. Their time now being short, must be improved continually and to the utmost, for now they hunger incessantly, and the more they eat and the faster they feed the more abundant will be the produce of silk. If you find that your heaps of branches are too high, like coming eight or ten inches from the shelf above, you take the whole top with all the worms on ; see that you hold it up carefully, so as not to hurt the worms, during which time another person takes off all the branches from beneath, and sweeps 
from the papers the ordures of the worms; after which you replace your top where it was ; this is easily done, and it would take but a short time to cleanse, in that way the whole room, if it was necessary. It is never needed more than once during the whole feeding.

When the warmth of the atmosphere will admit, as in the former ages, the numerous windows in the roof and on the sides must be opened to preserve a pure atmosphere. They delight, in all the latter days, in a cool, fresh, and pure atmosphere; then when the weather is parching, hot, and dry, sprinkle the floor with water occasionally, and keep shallow vessels filled with water to rectify the air.

During every age and until the silkworm has ceased taking food, it never inclines to wander-a circumstance which has rendered this insect wonderfully easy of control.

In the other chapters I have already expressed my views on frequent feedings, and also the advantage of feeding in the night, though I have not done this yet in California, as I always raised them in small quantities; but $I$ know that it is admitted everywhere, and that we must do it if we wish a complete success, and to obtain silk of superior quality. But before concluding the subject of feedings, I wish to say a few words more: feed the worms frequently and as regularly as possible, and as abundantly as circumstances permit; let them always have as much as they will eat with a good appetite, always observing that when the time of moultings arrives, they will cease to eat and retire among the branches; 
they must then be left quiet till they revive, which is generally in about twenty-four hours, and when well awakened, feed them again; and so on through every age; but for the last age make your arrangements for large supplies of branches, as more will be required than in the whole previous ages; and then for a week or ten days you must be active, because your own labor is nearly over and that of the worms is about to commence; and you will soon see them looking about for a place to retire into, as they do not like much to be seen making their cocoons in public. You will then provide for them when you see them raising their heads from their fresh food and moving about.

Formation of the Cocoons.-When the silkworms become transparent and of a pearly color, when they cease eating and are running to and fro, looking upwards or trying to ascend, when the skin about their necks becomes wrinkled and their bodies have a softness to the touch resembling soft dough, and their backs become unusually shining, when the green circles around the body contract and become of a bright gold color, these are sure indications that they are prepared for the last work of forming the cocoons; then, and not before, you must provide them with something to attach and place their cocoons in sometimes it is made with the twigs of the oak with the leaves on, which had been before provided; the leaf of the oak is strong, and the cocoons are separated from it without injury; they should be cut and dried some three weeks previous, preserved in readiness till required. They are placed 
in the center of the heap of branches on which your worms are, upright, with the top spread, forming harbors twenty inches or more in width, with circular heads. Some are using rye or wheat straw, after cutting the heads, tied in small bundles of the size of your arm, placing them also upright and spreading the top under the shelf above.

With our mode in California of feeding with branches, if you do not give them enough twigs to place their cocoons in, they make them in the branches of the heap on which they are.

The insect generally requires from three to five days to form the cocoon completely. During the first day, the insect forms a loose oval structure of thin, irregular, coarse threads, called floss. Within this structure, during the three following days, it forms the silken ball; not, however, in concentric circles, but by irregular movements, backwards and forwards in spots. The silken fiber is covered with a gum, which contributes to exclude the water.

Sometimes, even after its ascent among the branches or straw, the silkworm will look back, and descend once more, for the last time, to take some more food.

Ventilation is very important during the period while the insects are performing their last labor; yet, in no case is a due and comfortable degree of warmth more needed than while the insect is forming its cocoon, as this enables them to draw forth and to surrender the whole amount of silk which they had laid up in store.

Gathering of the Cocoons.- In about eight days after 
the cocoons are finished, they have to be gathered, and the floss silk taken off from around them, and saved, if clean; they can be reeled off at that time if you are prepared to do it; but if you are not, you must stifle the chrysalis, so as to reel them at any time after, or to sell your cocoons. In more temperate climates, as in some parts of Europe, ovens are used for destroying the insect. The cocoons are placed in oblong shallow baskets, covered with a paper, and over it a cloth, and these are placed in an oven, the heat of which should be very nearly that of the oven after the bread is drawn; thus wrapped up and exposed during half an hour or an hour, the chrysalides taken from the centre of the basket will be found dead; on removal from the basket, they are covered closely with blankets for a few hours, and then dried in the sun.

They can also be stifled by steam and other processes, but all of them require much work and expense for artificial heat; and besides that, nearly in every case it injures the luster of the silk, particularly that of the white variety.

Stifling the Chrysalide in California.-Here, in our blessed silk climate, we have no need of all this, and we are not likely, to injure the luster of our silk, as I found that the power of our solar rays is sufficient to destroy the chrysalide in the cocoon. This is the best and simplest mode. The cocoons need only to be exposed fully to the scorching rays of the sun, from ten o'clock in the morning till four in the afternoon; two or three days of such exposure are sufficient. But to make the work surer 
and better, I would recommend to have for that purpose long boxes four feet wide, sides six inches high, to be covered with glass frames; this will greatly increase the heat, and will have the effect of destroying the insect promptly and surely. In this way, your cocoons will also be protected against being destroyed by mice or rats, or otherwise, as your boxes must be made close, to afford no chance for these pests to get in, because they are immoderately fond of chrysalides.

Select your Cocoons for the eggs.-For seed, the very best cocoons should be selected, that is, those which are of the largest size and feel firm, and are of a bright color; and so far as possible, an equal number of males and females; the male cocoons are slender, depressed in the middle, and pointed at both ends; the female cocoons are of a larger size and of a rounder form, and resemble in shape a hen's egg.

If we keep selecting carefully our very best cocoons for seed, it is my opinion, and also that of other competent silk growers, that under our fine climate, so very favorable to silk culture, within a few years, we will obtain a California variety, that will surpass in size and quality all the varieties known and cultivated now.

After having stripped the floss, they may be strung together by threads, being careful not to pierce the cocoon, and hung up to the wainscot in festoons; or placed in a single layer in open paper boxes, on shelves or tables, in a darkened, retired, warm and airy place; and from ten to fifteen days from the time they complete spinning, according to the warmth of the season, 
the moth emerges from the cocoon, in the shape of a large butterfly, of a grayish white color, with four wings, two eyes, and two feathery plumes or horns. The male usually appears first, and is known by his smaller size, and a continual flutter of his wings. The female is of a larger size, of a whiter color, and seldom moves. These are to be paired, and then removed by their wings to sheets of paper spread on tables or boards, where they are to be left in darkness, as when complete, the silkworm is a night insect.

They generally come out of the cocoons in the morning, between seven and nine o'clock, when you have to be there, and see that they are all paired; otherwise, your eggs would not be good for anything. Those that are paired, you take by the wings, being careful not to hurt or separate them; you put them on the papers, and those that are not paired, you take them, males and females, and put them together on a separate sheet of paper, and they will soon get paired there; and when they are, you take them and put them with the others.

Sometimes, among the paired ones, a male or more gets loose; and as soon as you see it, you must take them off, because they would disturb the others, and cause many of them to get loose also ; and it is important that they should not be disturbed. You put these loose ones, male and female, back with the unpaired ones, so that they may all get paired again.

After they are all paired, you leave them in their dark place, till about four or five o'clock in the afternoon, when you have to separate them. For that, take 
the wings of the male with one hand, and the wings of the female with the other; draw them apart gently, so as not to hurt them; place the males in a box, and the females on the paper or cloth, on which you wish to have them lay their eggs.

Most of the females begin to lay as soon as separated from the males; but be careful to leave no male among the females, that are placed to lay their eggs, and if by mistake you have thrown a female among the males, carefully place it with the others.

After that operation is done, and the females commence laying, you have nothing more to do with them; cover the box which contains the males, and keep it so until the next morning: it is what is called the reserve. The next morning, proceed the same way as I have said above; but it happens sometimes that you have more females than males, in which case, after you have all your males of the morning employed, you take the quantity you need from your reserve, as you must remember that every female must be provided for producing good eggs.

After you have been using the males you want from your reserve, throw all the balance out, and the birds will soon eat them. Do the same thing every day, till all the moths have emerged from the cocoons.

One hundred pairs of cocoons, which weigh a pound, will produce an ounce of eggs; and an ounce of eggs is considered to produce forty thousand silkworms.

After your females have done laying their eggs, they will all die, and then you can roll together carefully 
the papers on which your eggs are, and place them in tin boxes. Two sides or more of these tin boxes should be of perforated tin. These boxes, to be preserved, should be placed in a cool room, or dry cellar, where they will not be liable to freeze : but freezing, though it may injure by retarding the period of their hatching, yet does not destroy them.

Now, we have been through the whole process, and you have your eggs again, ready for next year, which you will take care to hatch when your mulberry trees are growing finely, so you may be sure of having plenty of good food for them; and this is, in California, usually about the tenth or twentieth day of June.

\section{CHAPTER XVI.}

TALK WITH THE FARMERS AND PLANTERS.

Now, farmers and planters generally, in giving to you all my experience, and all I know about the raising of the mulberry trees and silk, I have proved that I am your friend-then I can have a talk with you on the subject; I will try to make it interesting and useful to you, as under that head I may say whatever comes to my memory about mulberry trees and silk raising in our silk State, etc. To farmers and planters we must look for the production of that rich article, and as 
they are only those who enrich a country, then it is to the farmers and planters throughout our silk climate that I particularly address myself, and urge them to give their immediate and earnest attention to this so important a subject; to look into the matter thoroughly, and not only look, but act. They must not be alarmed with the frequent croakings about the high price of labor in this country, and the impossibility of raising the silk in competition with other countries. It is too late now for such arguments; they vanish completely before the face of facts, which are better than all the theories. The silk culture has now gained too much headway in California to be checked in its speed by the fears and doubts of the timid and shortsighted-as any doubts of its full and complete success cannot be entertained any more by any reasoning person. Then I urge you all to plant mulberries, in the full assurance that they will be wanted; this will be a rich legacy to your children, for you may be assured that silk must and will be raised all over California, from one corner to the other, and also in several other of our States, that possess a similar climate to our own, and to which then our simplified culture can be applied :

1st. The difference in the price of labor here and in France does not hardly exist any more, as the price of labor there is double now of what it was thirty years ago ; but supposing that it is now as low as then, we could certainly obtain and raise the silk for half of the cost there, for the different reasons that $I$ have already stated in the first chapter, in my letter. 
$2 \mathrm{~d}$. There is no other culture so rich as the culture of silk, if the farmers and planters only give their attention to it; and with that culture only, we would soon be able to pay our national debt and our own. Nothing could be so profitable to the United States, and our Congress ought to take the matter into serious consideration. We have in a great measure to depend on our Congressmen to see that that rich culture is established generally. They only have simply to maintain a high tariff on the article for a few years, and the cultivation and the manufacture of silk will be established everywhere throughout the country. We trust that they will look to the general good of the country, and not to the benefit of only a few.

$3 \mathrm{~d}$. The culture of silk is in itself simple; and the farmers, their wives and their children, the old and the young-all will find pleasure and profit in that culture. It is principally for them that I write this little book, in giving them facts only, and the simple culture of our silk producing country.

4th. The farmers who are blessed with a large family of children, are those that are naturally better situated to cultivate and raise the silk more profitably than others, as they are not obliged to hire any extra help at feeding time.

5 th. The wife, or the eldest daughter, of the farmer can study this Manual, and then they will be able to superintend the work of feeding, etc., in showing and telling the younger ones what they have to do.

6 th. I wish that each farmer would take the trouble 
of counting his children, and plant one acre of mulberry trees for each one of them, in the best mulberry land of the farm ; in that way they will not cost them anything, and I think that, on the contrary, they will be a benefit to them; they will anyhow be able to support themselves, and be independent from the product of their acre. But some have told me that the children have to go to school. I admit that, and particularly recommend you to send them to school. But as the whole process of feeding and cleaning the cocoons, etc., etc., does not exceed two months, then they have ten months in the year to go to school - and I suppose this is about sufficient for them; besides that, the raising of silk is also a useful school to go to.

7th. The feeding and taking care of the worms and cocoons, the reeling of silk-all this work in silk countries is done by the ladies, of all ages: this will also be the case in California. Some say that our California ladies do not like to work. I do not believe it; if some of them do not work as they ought to do, the reason is that they have no profitable work to do that suits their delicate natures; but the moment they will have that work, I guarantee you that they will nearly all go into it, as in this kind of work a woman can do it better than a man; and they will then contribute to enrich the country. This will certainly be a great improvement and benefit to our young ladies, who will certainly be proud to wear fine dresses from silk raised by their own hands.

8th. In France, where silk is a national culture, it is 
a part of the education of young ladies. In their schools, convents, or academies, they are to receive a small lot of silkworms' eggs, and they have to hatch them and raise the worms. Those that know all about it show the others. Thus they are educated and familiarized with the treatment and the culture of silkworms, which may prove afterwards very useful to them.

9th. Aged persons, no more fit for hard labor, men and women, will find in the culture of silk an agreeable and profitable employment.

10th. I have many, questions asked me on the subject, by letters. Some ask how many trees are required to the acre. To those I would say, that in the way they have to be planted, as I have indicated for the plantation, an acre will take from six to eight hundred, according to the distance you plant them-to suit your soil.

11th. Others ask how long they will have to wait before the trees will give leaves in sufficient quantity to begin to feed the worms. We are in a country so extraordinary for being favorable to the growth of the mulberry trees, that we have not to wait, we can feed in the summer from trees, and even from cuttings planted in winter. This will hardly be believed in other silk countries; but is a fact here. If your trees or cuttings are planted in good mulberry soil, with some little care, of course, a small quantity of worms can be fed the first year.

12th. Others ask how many worms can be fed from one acre. This is very hard to tell, as it depends on a great many circumstances: First, on the quality of the 
soil. Second, on the amount of care given to the trees. Third, on the age of the trees, etc. So it is very difficult to make an exact estimate; we have to come to a general one, and make it as near as possible.

13th. That an acre will produce from forty to four hundred pounds of silk, at a cost of not exceeding two dollars per pound, ready for market. The value of the raw silk is from six to eight dollars per pound, according to quality. The quantity must be determined by the circumstances above mentioned.

14th. But for those that are not prepared to reel their own silk, they can sell their cocoons as they are, to the manufacturer, or sell them for exportation, lif they choose. As there is, and will be a great demand for them, one of our silk merchants, in our city of San Jose, has already asked me how many thousand pounds of cocoons I had to sell, as, he said, he would find me a purchaser, who would buy them immediately. In selling cocoons, in proportion to the work done, they will have pretty much the same profits.

15th. Each cultivator may make a calculation to suit his own soil and locality, by taking one hundred pounds of leaves for one pound of reeled silk. Forty thousand worms, well fed, will give fifteen pounds of silk ; an acre of trees, or stools, in good situations, and good soil, will certainly yield, here, at four years of age, from fifty to sixty thousand pounds of leaves, and probably more, which, at one lundred pounds per one pound of silk, will be five hundred pounds; but we must leave a few thousand pounds for wastage, and then 
the quantity will be still large enough. The leaves must be of the best quality to give a pound of silk to one hundred pounds of leaves ; it would require much more of watery leaves, or leaves grown in the shade.

16th. Supposing, as an average, fifty-five thousand pounds of leaves to the acre, on stools four years old, this would, consequently, at one hundred pounds for each pound of silk, give five hundred and fifty pounds of silk, which, at seven dollars per pound, would be only $\$ 3,850$ per acre. Now, the work to be done that year, to have the silk ready for market, according to our simplified culture, which is the only one to follow under our fine and dry climate-I have tried to calculate in different ways, and I find it always $\$ 840$ and $\$ 850$ this would leave, then, a net profit of three thousand dollars per acre; but supposing two hundred dollars more were needed, for things that I may have forgotten, (but I think not) it would still be two thousand and eight hundred dollars net profit per acre. This is about reasonable, and I would feel satisfied to have one hundred acres paying me in that proportion.

17th. The business is rather new in this country but I would recommend that all would try it. This can be done with a small expense, as we ought all to help each other to go into that enterprise, as it is the surest, the best, and the only one where competition need not be feared. Then I hope that a liberal spirit will pervade all classes throughout our silk State.

18th. Now, another thing: it is well known that poorhouses and orphan asylums are public burdens 
upon our towns and cities, which have to support them. These different places could be relieved from these burdens by planting with mulberry. trees all the farms that are connected with many of these establishments. The gathering of the branches, the feeding of the worms, the cleaning of the cocoons, etc., would be an agreeable pastime for the children and aged persons; and this will have the advantage of learning the young a useful business for the future; and also, in doing so, it will afford the institutions an opportunity of making them comfortable, and have them well edueated, in providing them with good teachers. They will be enabled also to give comfort to the poor and aged persons that have been driven there through adverse fortune, as a last resort, and have placed themselves under the public care, but are still possessed of the finer feelings of our nature.

19th. If any of the above-named benevolent establishments are still inside of the cities, and consequently not connected with any land to cultivate and work upon, it would be necessary that such establishments, for the benefit of all, should be removed to the country; and I would suggest, in that case, that good mulberry land should be selected in a healthy locality, in view of the good health and comfort of the inmates; such a locality will be ten times better for them, as they will have more of the pure air than they have in the eities, and the cities, at the same time, will be benefited thereby. These remarks I leave for consideration.

20th. In these benevolent institutions, besides the raising of silk, that would keep them busy for about two 
months only in the year, it would be easy for the young folks to learn the reeling of the silk, particularly the young ladies, who are generally more capable for that-work than the boys. Then, taking cocoons in from outside, would keep them busy a great portion of the year, by having them work only one part of the day, and the other part for their education.

21st. If anything is done in these benevolent institutions, as I have said above, and managed right, I can say that thus the poor will be enabled to support themselves, and enjoy the satisfaction of knowing that they are not entirely objects of charity, but earning their own living, under the direction of those that are more capable of guiding the helm than themselves. Friends of humanity, do try the experiment, and I truly and sincerely believe in its good results.

22nd. Besides the great profits that arise naturally from the raising of silk, those that will start in that business soon will receive the bounty from the State, which is three hundred dollars for each one hundred thousand of cocoons, and also a bounty on their plantations; but this will be only for three years more. Some may say, if the silk business is so profitable, why is it that the State gives bounties? The answer is simply this: we have to look to the great body of farmers to engage in this business, and the farmers generally in all countries are slow to adopt improvements. But I think that our farmers in California will differ from the general rule, as I show them how to do it, and have fully demonstrated the superiority of our climate over that of other prosper- 
ous silk countries; and that particularly, also, our soil is so superior for the growth of the mulberry trees, that they have not to wait for the results, and are assured of regular and abundant crops, they will find that it is to their interests to go at it immediately.

23rd. My object in publishing this Manual is, to be useful to all of you, in indicating how to go into the business, with or without eapital, or hardly any; as the one who has no capital can put his work, (which I know is equal to capital) he then can buy the seeds, sow, and take care of them, the following year he will have young trees to plant; while those that have capital will not have to wait, as they can buy the trees, and they will have a crop immediately. Those that have a small capital can buy the cuttings, and will then have a small crop the first year, as the cuttings are more certain than the seeds, and also grow more rapidly; and, by having shown the different modes of propagating the mulberry, I expect by that to prevent its selling at high price, thus allowing every. one to go into the business, according to their means. I wish also to prevent any mulberry fever, that benefits only few; I wish to see the culture of silk, all over our silk State-that will benefit all.

24 th. The culture of silk is so important for a nation, that in Germany they came to be a silk country by compulsion; laws have been enacted, compelling every owner of land to plant mulberry trees and raise silkworms : the result is known, they have become silk-producing countries. But here in California, I wish to compel our farmers in quite another way, and that is by 
persuasion, in fully demonstrating to them that we are in the best silk country, so that before going into it, they may be fully convinced that they are going into the best and most profitable business for them and the country at large.

25 th. We are sending out about seven millions of dollars annually to import silk for our ladies; and it is immense, the quantity of millions sent out for that article, if we take all the United States together. Every one of you understand the importance of retaining such a large amount in the country. But not only must we do all we can to raise enough for our own consumption, but also for exportation.

26th. Why I address the farmers, and tell them the importance of the silk culture for them, is because they are the men qualified for it; as, besides what I have said, there is another important point for them, and that is, that it does not interfere with their other crops; it just comes at the moment they have least to do, and then, instead of interfering with the other crops, I find that they help each other, as the building needed for the worms, is also of great importance for the other products of the farm.

27 th. The reeling of the silk will also, in future, be done by the farmers' wives and daughters. But, being in a hurry, as it is late in the season, I will prepare that article, and will have it in my second edition, with many other additions.

28th. Count Hazzi states that seven to ten pounds of cocoons will make a pound of raw silk. In some silk 
countries, sometimes twelve pounds are necessary, while in California, when the culture shall be well understood, I think that no more than seven or eight pounds will be required.

29th. One pound of silk, when well reeled, is capable of being converted into sixteen yards of the ordinary quality of Gros de Naples, or into fourteen yards of the first quality, and worth twice its weight in silver.

30th. The reeling of silk in France and Italy is performed almost exclusively by females. In these countries there are innumerable domestic filatures, where the cocoons, raised by one or more families, are reeled by the wives and the daughters of the farmers. These $\mathrm{cm}-$ ploy from one to five or six reels, and the art of reeling is preserved in families from generation to generation. There are also, in these countries, large establishments, or filatures, which employ from fifty to five hundred reels. These establishments have a superintendent who is thoroughly and practically a perfect master in the business in every department ; women there work at the reeling all their days as an exclusive occupation. At these large establishments the most perfect silk is reeled, which commands the highest price.

31st. I wish to give you here a few facts that will certainly be more than sufficient to prove to you how easy the silk can be raised in California ; as, besides my cocoons, we had on exhibition at our agricultural fairs, specimens of good cocoons raised by the following persons : Mr. J. N. Hoag, Secretary of our State Agricultural Society ; Capt. Haynie, of Sacramento ; Mr. Tif- 
foinet, of Columbia, Tuolumne County; Miss Hattie Isaacs, of Sacramento; Mrs. Sauffrignon, of San José; Miss Mary Johnson, of Sacramento; Mrs. George A. Jones, Brannan Ranch, on the Feather River; Hon. Teegarden, of Marysville ; Mrs. Catharine Corbusier, of Sacramento; Mrs. Stephen Davis, of Angel's Camp; Mr. John Smith, of Sacramento ; Mr. Oliva, of Hornitos, Mariposa County ; and among others that have been successful in raising the silk, and have not exhibited, are Mr. Charles F. Reed, President of our State Agricultural Society, at his residence in Yolo County; Mr. Wilson Flint, on the Sacramento River, near the city; Mr. A. Packard, Santa Barbara ; Mr. G. Gluesing, San Joaquin Valley; Mr. E. Goux, Santa Barbara, and many others that $I$ have neglected to record their names. 'To all these persons I sent silkworms' eggs, or gave, to some, young worms, and all these persons succeed in having the worms to perfection. This tells volumes about our fine climate, and shows how easy we can raise silk in California, as nearly all of them never saw a silkworm before. Mr. J. Q. A. Warren exhibited very fine and good cocoons raised by him, at Honolulu, (Sandwich Islands) from eggs that I sent him there.

$32 n d$. It was last year, 1865 , that I made the first large exhibition that began to be appreciated. If we consider a moment the progress made in such a short time, we can hardly believe it; as, besides the plantations of mulberry trees made, we have our pioneer silk manufactory. Mr. Joseph Newmann has exhibited at our fairs the first California manufactured silk, made by 
himself and his brother, as both are practical silk weavers ; that silk has been generally admired, and considered by all of the best quality. He is now making a fine show of a large quantity of that silk in Montgomery street, San Francisco. There is at that exhibition samples of cocoons, as mentioned above, a lot of weavers' tools, a miniature silk winder, to show the process of reeling; there is raw silk, floss silk, and silk in skein as taken from the cocoons, etc. This exhibition attracts the crowd constantly, as every one foresees in that the foundation of a great enterprise which is bound to save millions to our State.

33rd. As at San Jose the first silk of the State has been raised, it was due to the place to have the pioneer silk manufactory, and land has been given for the erection of it near the city. Besides that, it is the natural place for such a manufactory for many reasons : the principal is, that San Jose is the healthiest place in California, and probably in the world, and is near San Francisco by railroad, and also that our water is so fine and soft, that it has been tried and found of first quality for the dyeing; this is very important, as one of the reasons that makes the silk of Lyons (France) renowned all over the world, is its water; and thus, we may expect, that San Jose will eventually be the Lyons of California. They have a large quantity of machinery already on the place, and some more on the way from the States, everything complete, from taking the silk from the cocoon up to manufacturing it in every style. 34 th. I am receiving three different silk papers from 
Europe, that give me information about everything pertaining to silk-transactions in silk and prices - all over the different silk countries; and as we are becoming a silk country also, I will translate, from time to time, for the benefit of our California silk growers, the articles that I may find of some interest for them, and publish them in our leading papers.

35th. America, by the skill and ingenuity of her people, has been enabled to compete with India and China, and even with the world, in the culture and manufacture of cotton; is there an American who can doubt now that we shall do the same ere long with the silk?

36 th. In all other works on silk raising, they have chapters on the diseases of the worms. We have no need in our California Silk Manual of such chapter, because, as long as we shall be able to give our worms fresh food from mulberry trees that are growing under the genial rays of our sun, no disease can be expected, as the disease is in the food. It is my positive opinion, that these watery leaves, taken from trees, growing most the time in the shade, in a wet, damp atmosphere, are what create the disease; I say, from trees growing in the shade, because, as long as the sun's rays do not strike on them, they are in the shade, no matter if it is caused by the clouds or anything else.

37th. As I have many visitors coming for information about silk, and other things to attend, I have but little time left to me: thus $I$ have been obliged to write this Manual in a hurry, and may have omitted some points ; but of anything that shall come to my knowledge of 
any interest I will keep a memorandum, so as to make a more complete work of my second edition. However, I hope that I have said enough in this, my first essay, to put you on the track, and enable you to carry on the business profitably all over our silk State. But remember, that I am at your service, always ready to tell you all I know, to enable you to go into this business immediately, because the sooner you will do it the better.

L. P.

San Jose, December, 1866.

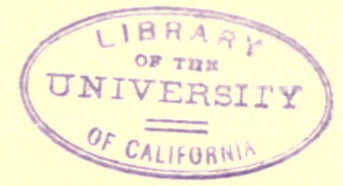




RETURN TO the circulation desk of any University of California Library or to the

NORTHERN REGIONAL LIBRARY FACILITY Bldg. 400, Richmond Field Station University of California Richmond, CA 94804-4698

\section{ALL BOOKS MAY BE RECALLED AFTER 7 DAYS}

- 2-month loans may be renewed by calling (510) 642-6753

- 1-year loans may be recharged by bringing books to NRLF

- Renewals and recharges may be made 4 days prior to due date.

DUE AS STAMPED BELOW

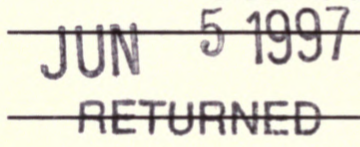

MAY 281997 


\section{3}

10.6.

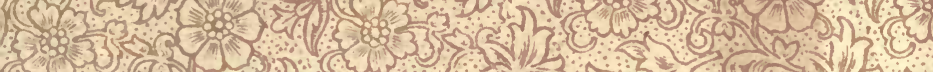
(6) (5)

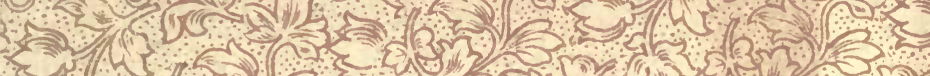

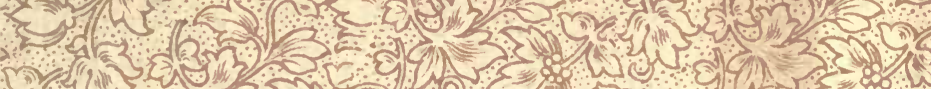

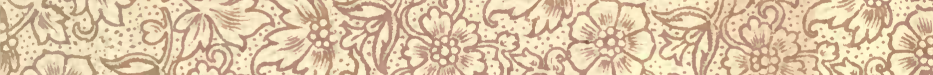
(n)

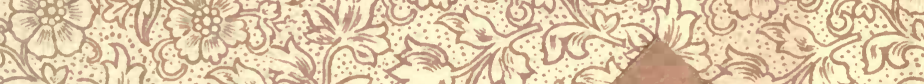
urm, (3) 2. C? G w w. in 3. int $x \rightarrow$ ares 3 (1)

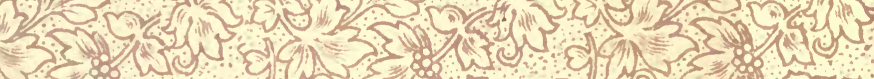

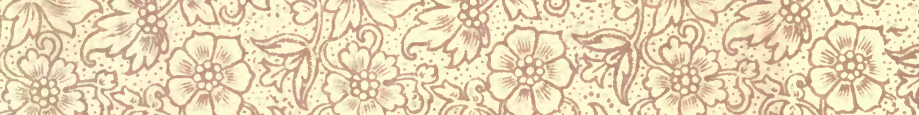
(1)

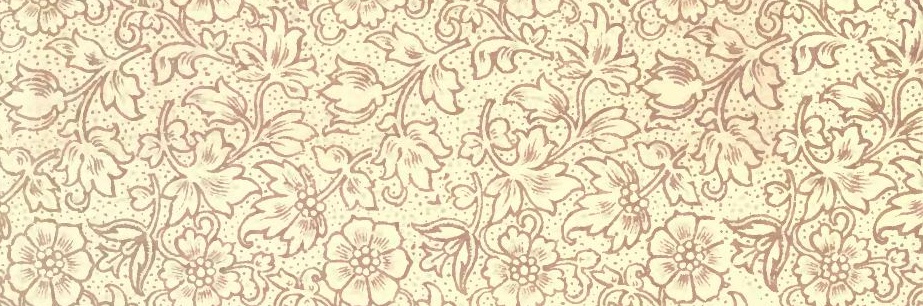

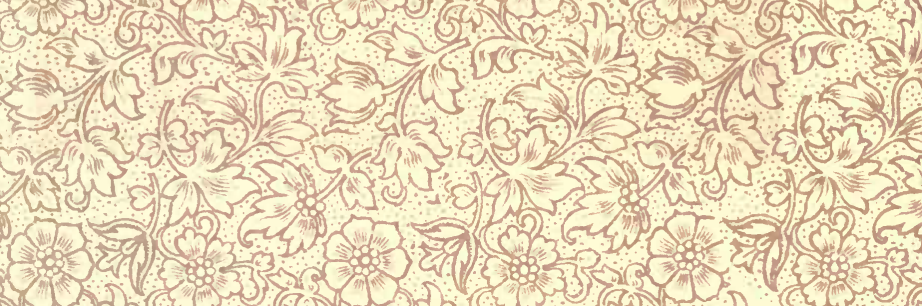
(1) (1)

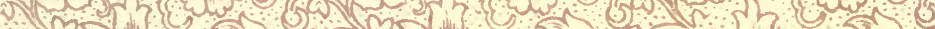


